CALIFORNIA AGRICULTURAL EXPERIMENT STATION BULLETIN 703

JANUARY, 1948

\title{
THE COMMERCIAL FREEZING OF FRUIT PRODUCTS
}

M. A. Joslyn and Leonora A. Hohl

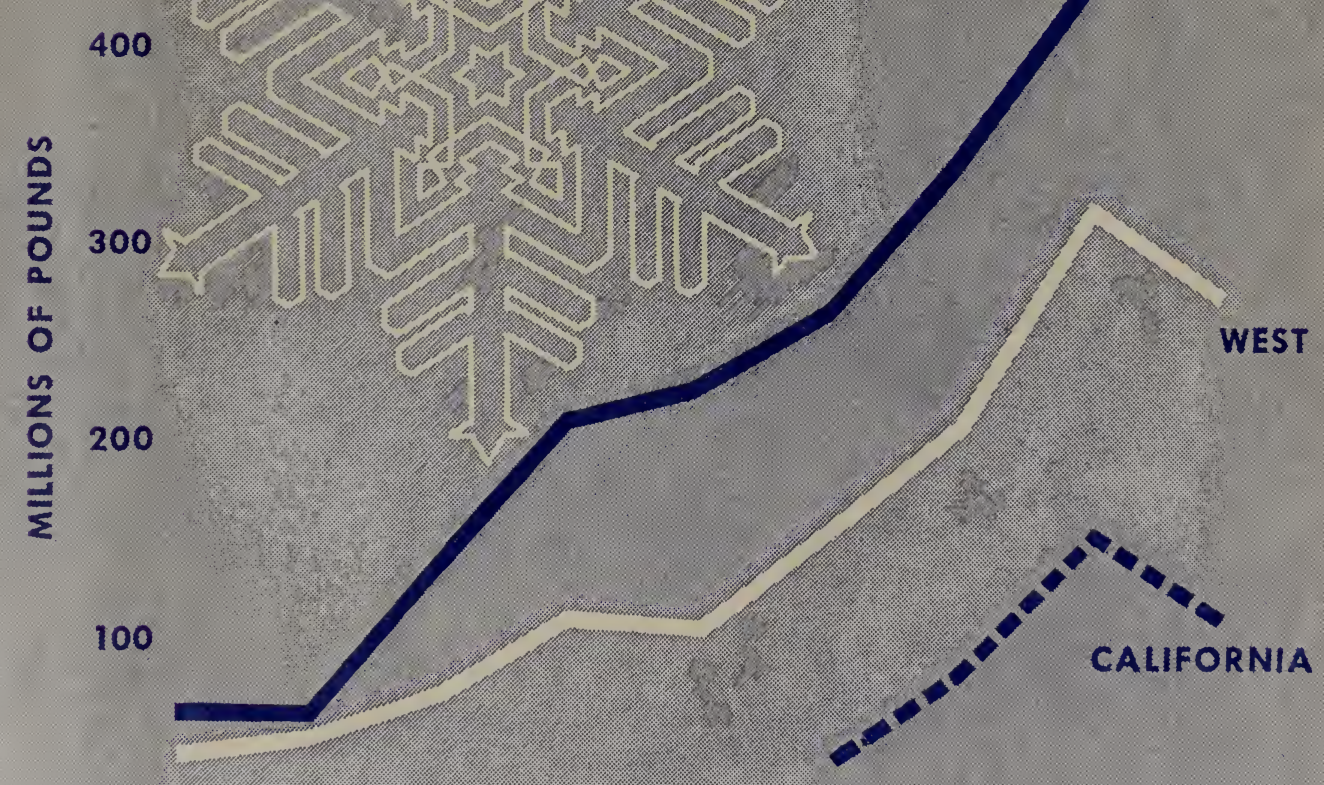

0

1926- 1931- 1936-

$\begin{array}{lllllllll}1930 & 1935 & 1940 & 1941 & 1942 & 1943 & 1944 & 1945 & 1946\end{array}$

THE C O L LE G E O F A G R I C U L T U R E UNIVERSITY OF CALIFORNIA BERKELEY 


\section{THIS BULLETIN}

is intended primarily for the commercial processor of frozen fruits. It is based on observations in the field, on available scientific and technological information, and on results of investigations carried on by the Division of Food Technology over the past twenty years. Part of the bulletin contains material which has already been presented elsewhere. This has been reviewed and brought up to date in the light of more recent knowledge. Much of the material is new, presented here for the first time.

GROWERS may also profit from this publication, which should be a guide in cultural and harvesting practices, and in selection of varieties suitable for freezing processes.

With processor and grower in mind, the bulletin discusses the principles involved in preservation freezing with considerable technical and scientific detail. A thorough understanding of these principles is important to the processor who wishes to improve present methods of freezing standard items or to develop specialty items. The processor must also know the nature of the physical, chemical, enzymatic, and bacteriological changes which occur during freezing and thawing of fruits. He must know this in order to determine what fruits and fruit products can be successfully preserved by freezing, and how those fruits should be prepared, packed, frozen, and stored. Such changes also determine how the products may best serve the needs of the manufacturer of preserves, the baker, the ice cream maker, or the housewife.

Continued improvements in the freezing process have made it possible to retain, to a fairly high degree, the original appearance, flavor, and nutritive values of various products, such as fresh fruit, vegetables, meat, and fish. As a result, commercial freezing has been profitable, through a variety of outlets, to the grower, the manufacturer, and the consumer.

Future possibilities for this method of food preservation are great, as evidenced by the continued growth of the industry. In fact, its potentialities are still largely untapped. But if the industry is to continue to show a profit, and to realize its fullest development, it must improve its methods still further, and correct past mistakes. Many of those mistakes were the result of increased wartime production, when quality was sometimes sacrificed to quantity. Now that production is returning to a more normal basis, this bulletin suggests ways in which the industry may learn from past experience, raise its standards, and in general give the manufacturer and consumer a better grade of frozen food product.

Those who are interested only in practical directions for freezing may turn to the section beginning on page 55 .

For those seeking more detailed information on principles and practices, a list of references is included at the end of the bulletin.

The bulletin is not intended as a guide to users of frozen-food lockers or home freezers. 


\section{CONTENTS}

Regulations for frozen-pack fruits . . . . . . . . . . . . . . . . . . 6

Food and drug standards . . . . . . . . . . . . . . . . . . . . 6

Grades . . . . . . . . . . . . . . . . . . . . . . . . 6

DEVELOPMENT AND EXTENT OF THE INDUSTRY • •. . . . . . . . 7

Early history . . . . . . . . . . . . . . . . . . . . . . . . . 7

Development . . . . . . . . . . . . . . . . . . . . . . . . 8

California production history . . . . . . . . . . . . . . . . . . . .10

Container trends . . . . . . . . . . . . . . . . . . . . . . . 12

PRINCIPLES OF PRESERVATION FREEZING . . . . . . . . . . . . . 15

Microbial spoilage and its control . . . . . . . . . . . . . . . . . . . 16

Enzyme activity and its control . . . . . . . . . . . . . . . . . . . 17

Selection of varieties . . . . . . . . . . . . . . . . . . . . . . . 19

Maturity . . . . . . . . . . . . . . . . . . . . . . . . . . . 20

Exclusion of oxygen . . . . . . . . . . . . . . . . . . . . . . . 20

Addition of sugar or sirup . . . . . . . . . . . . . . . . . . . . . . . 21

Addition of acids . . . . . . . . . . . . . . . . . . . . . . . . 24

Antioxidants or reducing substances . . . . . . . . . . . . . . . . . 25

Heat inactivation . . . . . . . . . . . . . . . . . . . . . . . 28

Nonenzymatic chemical changes . . . . . . . . . . . . . . . . . . 30

Crystallization of sugar . . . . . . . . . . . . . . . . . . . . . 31

Physical changes during freezing and thawing . . . . . . . . . . . . . . . 31

Texture . . . . . . . . . . . . . . . . . . . . . . . . . . . 31

Volume . . . . . . . . . . . . . . . . . . . . . . . . . . . 34

Weight . . . . . . . . . . . . . . . . . . . . . . . . . . . 35

Relations of loss in weight to texture . . . . . . . . . . . . . . . . . . $\quad$. 37

HEAT-TRANSFER DETERMINANTS . . . . . . . . . . . . . . . . . 37

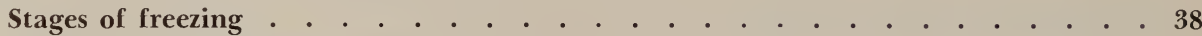

Temperature changes in various products . . . . . . . . . . . . . . . . . 41

Effect of type, size, and shape of container . . . . . . . . . . . . . . . . . . 42

Effect of initial temperature . . . . . . . . . . . . . . . . . . . . . 43

Effect of freezing medium . . . . . . . . . . . . . . . . . . . . . . 45

FREEZING STORAGE CONDITIONS . . . . . . . . . . . . . . . . . 47

CONTAINERS AND PACKAGING MATERIALS AND PRACTICES . . . . . . 50

THE FREEZING OF FRUITS . . . . . . . . . . . . . . . . . . . . 55

Apples . . . . . . . . . . . . . . . . . . . . . . . . . . . 55

Varieties . . . . . . . . . . . . . . . . . . . . . . . . . 55

Apples for bakers . . . . . . . . . . . . . . . . . . . . . . . . 59

Applesauce . . . . . . . . . . . . . . . . . . . . . . . . . . 60

Baked apples . . . . . . . . . . . . . . . . . . . . . . . . . 62

Apricots . . . . . . . . . . . . . . . . . . . . . . . . . . . . 62

Varieties . . . . . . . . . . . . . . . . . . . . . . . . . 62

Apricots for bakers' or processors' use . . . . . . . . . . . . . . . . . 62

Apricots for dessert use . . . . . . . . . . . . . . . . . . . . . . 63

Berries . . . . . . . . . . . . . . . . . . . . . . . . 64

Varieties . . . . . . . . . . . . . . . . . . . . . . . . . 64

Barreling of strawberries . . . . . . . . . . . . . . . . . . . 65

Sliced strawberries . . . . . . . . . . . . . . . . . . . . . . . . . . 68

Other berries . . . . . . . . . . . . . . . . . . . . . . . . . 68 
THE FREEZING OF FRUITS (Continued)

Cherries

General discussion and varieties .

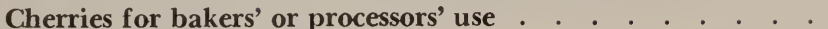

Cherries for dessert use . . . . . . . . . . . . . . . . . . . . . . . 70

Citrus fruits

Varietal adaptability . . . . . . . . . . . . . . . . . . 70

Maturity, harvesting, and storage . . . . . . . . . . . . . . . . . . 71

Grapefruit hearts . . . . . . . . . . . . . . . . . . . 71

Figs . . . . . . . . . . . . . . . 72

Varieties and maturity . . . . . . . . . . . . . . . . . . 72

Preparation for freezing . . . . . . . . . . . . . . . . . 72

Grapes . . . . . . . . . . . . . . . . . . 73

Melons . . . . . . . . . . . . . . . . . . . . . . . . 74

Nectarines . . . . . . . . . . . . . . . . . 74

Varietal adaptability . . . . . . . . . . . . . . . . . . . 75

Harvesting and handling . . . . . . . . . . . . . . . . . 75

Packing procedures . . . . . . . . . . . . . . . . . . . . . 76

Olives . . . . . . . . . . . . . . . . 76

Peaches . . . . . . . . . . . . . . . . . . . . . . . 76

Varietal adaptability . . . . . . . . . . . . . . . . . . 76

Maturity, harvesting, and storage . . . . . . . . . . . . . . . . . 78

Preparation for freezing . . . . . . . . . . . . . . . . . . . . . . . . . . $\quad 79$

Special products and treatments . . . . . . . . . . . . . . . . . . 81

Pears . . . . . . . . . . . . . . . . . . . . . . . . . . 82

Persimmons . . . . . . . . . . . . . . . . . . . . . 82

Plums and prunes . . . . . . . . . . . . . . . . . . . . . . . . 82

Rhubarb . . . . . . . . . . . . . . . . . . . . . . 83

TROPICAL AND SUBTROPICAL FRUITS . . . . . . . . . . . . . . . 83

Avocados . . . . . . . . . . . . . . . . . . . . . . . . . . . . 83

Coconuts . . . . . . . . . . . . . . . . . . . . . . . . . . 84

Dates . . . . . . . . . . . . . . . . . . . . . . . 84

Guavas . . . . . . . . . . . . . . . . . . . . . . . . . 84

Mango, papaya, and passion fruit . . . . . . . . . . . . . . . . . . . 85

Pineapple . . . . . . . . . . . . . . . . . . . . . . . . . . . 85

CRUSHED, SIEVED, OR PURÉED FRUITS . . . . . . . . . . . . . . . 86

Velva fruit . . . . . . . . . . . . . . . . . . . . . . 87

JELLY AND JAM BASES . . . . . . . . . . . . . . . . . . . . . . 88

FROZEN FRESH FRUIT SPREADS . . . . . . . . . . . . . . . . . . 90

FREEZING FRUIT JUICES . . . . . . . . . . . . . . . . . . . . . 91

Orange juice . . . . . . . . . . . . . . . . . . . . . . . . . . 92

Lemon juice . . . . . . . . . . . . . . . . . . . . . .994 94

Grapefruit juice . . . . . . . . . . . . . . . . . . . . . . . . . 94

Other fruit juices . . . . . . . . . . . . . . . . . . . . . . . . . 94

FREEZING SWEETENED FRUIT JUICES, SIRUPS, NECTARS, PUNCHES, AND CONCENTRATES

FROZEN CITRUS JUICE CONCENTRATES . . . . . . . . . . . . . . . 98

LITERATURE CITED . . . . . . . . . . . . . . . . . . . . . . 100

GENERAL REFERENCE SOURCES . . . . . . . . . . . . . . . . . . 106

Bibliographies . . . . . . . . . . . . . . . . . . . . . . 106

Preservation freezing . . . . . . . . . . . . . . . . . . . . . . . . . 106

Refrigeration . . . . . . . . . . . . . . . . . . . . . . 106

Fruit production . . . . . . . . . . . . . . . . . . . . . . . . . . 107

California Experiment Station publications on fruit production . . . . . . . . . 107

Journals . . . . . . . . . . . . . . . . . . . . . . . . 107 


\title{
COMMERCIAL FREEZING OF FRUIT PRODUCTS ${ }^{1,2,3}$
}

\author{
M. A. JOSLYN ${ }^{4}$ AND LEONORA A. HOHL ${ }^{5}$
}

\section{DEFINITIONS AND REGULATIONS}

\section{The frozen-fruit industry has undergone various changes during its} expansion, both in the terminology employed by the industry and in the regulations governing it. This section defines some of the terms used and indicates the extent of the regulations.

Originally, the process of preserving fruit by storage in bulk containers, at freezing temperatures, was termed the "cold pack process" and the product, "cold packed fruit." Diehl et al. (1930) ${ }^{8}$ have suggested "frozen pack" as a more acceptable term, and this is now widely used for fruit and fruit products preserved by freezing in bulk containers, for use in bakery products, frozen dairy products, preserves and jams, and similar foods.

"Sharp-freezing" is still used industrially for products frozen at low temperatures $\left(+5^{\circ} \mathrm{F}\right.$ to $\left.-20^{\circ} \mathrm{F}\right)$ in a room where there is no provision for forced air, or where only a minimum of air circulation is provided by portable fans. Since the relatively still air is a poor heat-transfer medium, fruits placed in sharpfreezer rooms freeze so slowly that many hours or sometimes days are required for complete freezing. In that time, the product may spoil by fermentation or excessive oxidation.

Fruits and fruit products rapidly frozen in blast, immersion, or contact freezers are referred to as "quick-frozen" fruits. There is no entirely satisfactory definition of "quick-freezing." The one most commonly used is: Quick-freezing is the process in which, by rapid heat transfer, the temperature of the product is lowered from that at which initial ice formation occurs (usually $28^{\circ} \mathrm{F}$ ) to that at which most ice formation is complete (about $15^{\circ} \mathrm{F}$ ) within thirty min-

\footnotetext{
${ }^{1}$ Received for publication May 16, 1947 .

${ }^{2}$ This bulletin supersedes Circular 320, Preservation of Fruits and Vegetables by Freezing Storage, by M. A. Joslyn, published in 1930, and Bulletin 551, Changes Occurring during Freezing Storage and Thawing of Fruits and Vegetables, by M. A. Joslyn and G. L. Marsh, published in 1933 .

${ }^{3}$ The preparation of fruits and vegetables for freezing in locker plants is described in Freezing Storage. Preparation, Freezing and Storage of Fresh Food for Home Use, by Vera Greaves Mrak. Cal. Agr. Exp. Sta. Ext. Leaflet H.D. 473:1-6. Revised, 1947.

${ }^{4}$ Associate Professor of Food Technology and Associate Biochemist in the Experiment Station.

${ }^{5}$ Instructor in Food Technology and Assistant Mycologist in the Experiment Station.

"See "Literature Cited" for complete data on citations, referred to in the text by author and date of publication.
} 
utes. (The desirability of rapid freezing in the zone of maximum ice formation will be discussed elsewhere.)

Dry sugar is used as a color and flavor preservative in the freezing of fruit in 3o-pound, or larger, containers for use in bakery and dairy products, and in preserves. The ratio of fruit to sugar is commonly expressed as weight in pounds of fruit per pound of sugar. Thus, $4+1$ or $4: 1$ pack contains four pounds of fruit to one of sugar. Sirup is now used in place of dry sugar for consumer packages or for fruit packed in institution-sized units for dessert uses, with the exception of sliced strawberries. But the use of sirup has introduced problems of definition. The Food and Drug Administration has accepted the dictionary definition of sirup as "any concentrated aqueous solution of sugar." It requires any sucrose solution to have a concentration of at least $65^{\circ}$ Balling or Brix (per cent sugar by weight in water solution) to be termed "sirup" when applied to frozen fruit and fruit products. Exception was made for canned fruits which may be marketed as packed in light, medium, or heavy sirup. Since the use of sufficient $65^{\circ} \mathrm{Bal}$. sirup to completely cover the fruit in small containers would result in an excessively sweet pack, and since frozen fruit packers rarely use sirup of over $50^{\circ} \mathrm{Bal}$., this ruling works a hardship upon them. At present, if the ruling were enforced, packers would have to declare that fruit frozen with a light sirup is "frozen with sugar and water."

Regulations for Frozen-Pack Fruits.-Since 1928, frozen-pack fruits have been included within the scope of the U. S. Warehouse Act. Every packer should be familiar with the regulations, which may be found under U. S. Department of Agriculture, Agr. Marketing Service, Service and Regulatory Announcements, No. 159 , October, 1940.

Food and Drug Standards.-The U. S. Food and Drug Administration has not yet promulgated standards of identity, quality, and fill of container for frozen food products, under the Food, Drug, and Cosmetic Act of June 25, 1938. Basically, however, any frozen-pack food should be "the clean, sound product obtained by packing in a suitable container, properly prepared fresh fruit, vegetable, meat, or other food, with or without the addition of sugar or salt, and maintaining it at a temperature sufficiently low to insure its preservation."

Grades.-Standards of fill, identity, and quality for the various fruit products now frozen commercially are being developed by the industry. At present, the only standards of quality available are the "Tentative U. S. Standards for Grades of Frozen Fruits" proposed by the Processed Products Section, Fruits and Vegetable Branch, Production and Marketing Administration of the U.S. Department of Agriculture. These standards may be obtained through the Washington Office or from the San Francisco Office, 821 Market Street. Tentative standards have been formulated for apples, apricots, berries, cherriessour pitted and sweet-peaches, raspberrics, rhubarb, and strawberries. 
These tentative grades are based on the following factors: appearance; texture; flavor; odor; color; absence of defects; development; and degree of disintegration. Critical evaluation of grade by these standards requires considerable practice and familiarity with the product, and the tolerances allowed are based largely on subjective methods. Evers (1947) has suggested quality control procedures for frozen peaches based upon these grades. There is need for development of more satisfactory grades, based on critical evaluation of consumer acceptance of the product. More exact methods for such evaluation have been developed by Dove (1946) and by the Committee on Food Research (1946). There is also need for the development of objective standards of quality.

\section{DEVELOPMENT AND EXTENT OF THE INDUSTRY}

Although experiments with commercial freezing of fruits were made as early as 1908, the years 1925-1936 marked the main period of experimentation. After 1936, the industry underwent a period of rapid growth, and reached a high level of development in 1941. Production and sales rose sharply during World War II, but in some instances quality was lowered. If wartime mistakes are rectified, however, continued high production may be expected.

If packers are to profit from the mistakes of the past, they should be familiar with some of the history of the frozen fruit industry. Its development has been rapid, especially during the war years, and because of this quick expansion, quality was sometimes sacrificed to quantity. Proper plant supervision was lacking, as was good market exploitation. As a result, some packers were left with large amounts of surplus products as soon as food supplies for civilians became more plentiful and military demands dropped.

Early History.-The historical record of the frozen fruit industry has been summarized in a survey of food processing in the West (Anon., 1934). The first experimental packs were made in Denver in 1908, and the first commercial output was in Salem, Oregon (1909) and Puyallup, Washington (1911). Early development of the frozen fruit industry was most rapid in the Pacfic Northwest, where chiefly strawberries, raspberries, and smaller quantities of other berries were frozen. Conditions favorable to berry production and location far from the main consuming center (eastern markets) forced the growers in that area to utilize all possible outlets. Second in production to frozen berries were red sour cherries, which in the early 1930's were packed chiefly in the tristate district of Delaware, Maryland, and Virginia. As shown in table 1, frozen berries predominated until the war years of 1941 to 1945 . During these years, the production of strawberries and cherries decreased, and the production of frozen apples, apricots, peaches, prunes, and rhubarb sharply increased as did also that of figs, nectarines, and pears. During 1941-1945, berry production was only 34 per cent of the entire fruit pack. 
Development.-Diehl and Havighorst (1945), in their recent survey of the progress and prospects of the frozen food industry, have divided its history into two periods: the first, of experimentation, $1925^{-1936}$ inclusive, and the second, of rapid growth since 1936 . In the first phase, preservation was limited largely to fruit intended for subsequent industrial use. This included fruits to be used in frozen dairy products, pies and other bakery goods, preserves, jams, and, to a limited extent, for fruits to be canned for salad, and as juice. During these years, the early investigators laid the foundation for future expansion of the industry by testing the behavior of different kinds of fruits to freezing and to freezing storage and subsequent thawing. They selected the more suitable

\section{Table 1}

UNITED STATES FROZEN-FRUIT PACKS, FIVE-YEAR AVERAGES 1908 TO 1945* (Weights given include sugar or sirup when used)

\begin{tabular}{|c|c|c|c|c|}
\hline ' & Years averaged & Berries & Other fruits & Total \\
\hline & & $\begin{array}{l}\text { thousands } \\
\text { of pounds }\end{array}$ & $\begin{array}{l}\text { thousands } \\
\text { of pounds }\end{array}$ & $\begin{array}{l}\text { thousands } \\
\text { of pounds }\end{array}$ \\
\hline $1908-1910 \dagger$. & . & 10 & $\ldots$ & $\cdots$ \\
\hline $1911-1915$. & & 500 & $\ldots$ & 500 \\
\hline $1916-1920$. & & 1,700 & 200 & 1,900 \\
\hline 1921-1925. & & 6,664 & 5,000 & 11,664 \\
\hline $1926-1930$. & 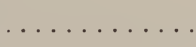 & 43,774 & 18,717 & 62,491 \\
\hline 1931-1935. & & 45,046 & 14,710 & 59,756 \\
\hline $1936-1940$. & & 78,889 & 59,509 & 138,398 \\
\hline 1941-1945. & & 100,924 & 194,490 & 295,414 \\
\hline
\end{tabular}

* Source of data:

Statistical Review and Yearbook Number. Western Canner and Packer 38 (6) : 257-93. April 25, 1946. $\dagger$ Three years only; no pack reported before 1908.

varieties, and developed processing methods. Packaging, freezing, storage, distribution, and marketing problems were solved by the pioneer frozen food packers. Mechanization of processing, and handling methods were developed by the industry and by machinery manufacturers. Gradually, the institution channels (hotels, restaurants, hospitals, clubs) and, finally, the retail outlets were exploited. Economical methods of refrigerated storage and of distribution to retailers were developed, as were refrigerated cases for distribution by retailers. Both retailers and consumers were instructed in the proper use of the frozen product. Then followed a rapid increase in production and distribution, and a continued improvement in processing and packaging techniques. During the war years, sales of frozen foods increased rapidly because they were not rationed, and canned foods were scarce.

The wartime conditions, however, were not without disadvantages, chief among them being the lowering of quality. The pioneers of the industry recognized that the chief justification of freezing as a means of preservation lay in its better retention of color, flavor, and nutritive value. This advantage in 
many cases amply justified the increased costs of packing, storage, and distribution. The provision of adequate low-temperature refrigeration to keep the product frozen at the processing plant, during transit to central warehouses, during transit and distribution to the retailer, and at the retail outlet is chiefly responsible for these increased handling charges.

During and immediately following the war, the quality of much of the frozen fruit and vegetable pack, which had reached high levels of development by 1941 , was poor.

The factors which contributed most toward this relaxation of quality control from field to plant, within the plant, and from plant to consumer were:

\section{Shortages of experienced labor.}

Lack of machinery for orchard cultivation and for preparation, processing, and packaging.

Shortage of packaging materials.

Limitations in availability of refrigeration facilities for storage and distribution.

\section{A large, unfilled consumer demand.}

Pressure on every packer to process as much tonnage as could be handled by his plant.

The entry of new packers into the field. Not all these were inexperienced. Some were skilled food processors from other fields. But some had little or no knowledge of the fundamentals by which high-quality and low-cost production of frozen foods could be achieved.

Keen competition for the limited quantity of available raw produce further influenced the trend toward lowering of quality (Joslyn, 1946a; Diehl, 1945, 1946; Cruess, 1946).

According to a recent analysis (Anon., 1947), two decided changes occurred in fruit-freezing operations during the war years, 1941-1945. First, the quantity of fruit frozen increased from an average of 140 million pounds during the five-year prewar period of 1936-1940, to about 300 million pounds. Secondly, the market changed. Before the war, the biggest part of the pack (about 57 per cent) was in barrels and other containers of over 30 -pound size, and was sold almost entirely to large manufacturers. Another $3^{6}$ per cent was in the 11- to 3o-pound class, and went mainly to smaller manufacturers, especially pie bakers. The institution trade took only about 3.5 per cent, in $11 / 2$ - to 10 -pound containers, and the remaining 3.5 per cent was packed in 1-pound units for retail sale. During 1941-1945, large manufacturers took only 34 per cent of the tonnage, the pack in institution sizes went up only moderately (to 4 per cent), but the production in retail sizes averaged 8 per cent, and the output in the 
smaller manufacturing sizes reached 54 per cent. Thus, during the war period, the industry had come to rely upon small manufacturers and large institutional buyers instead of the large manufacturer for whom the business was originally established.

The halting of large-scale government purchases, high production costs, poor quality of some of the packs, continued limitations upon sugar use, which kept bakers and preservers from buying the quantities they might otherwise have used, led to unbalanced inventories early in 1947 and distressed selling of both good and bad merchandise at prices below cost. Shortage of refrigerated cars for transporting the frozen food from production centers to the metropolitan marketing centers, saturation of the existing freezer storage space, and shortages in refrigerated sales cabinets in retail outlets have contributed to the difficulties encountered in distribution (Havighorst and Diehl, 1947). Whether the rapid development in frozen fruit production during the war years will continue or a recession occur, will depend upon whether the industry again packs only fruit of high quality and whether distributors can dispose of present stores of frozen produce. If the industry can weather the existing condition, it is likely that the forecast of Diehl and Havighorst for a continued increase in production will come to pass. In the meantime, development of new types of pack, introduction of new products, and development of new uses for existing products will do much to overcome the threatened recession.

Where advertising and market exploitation are concerned, the frozen food processors have lagged far behind the producers of other food items, in bidding for public acceptance of their product.

California Production History.-In California the freezing preservation of fruit products was limited at first to small quantities of barreled strawberries and, on occasion, a limited pack of apricots and peaches. The freezing of orange juice began in a limited way in $193^{\circ}$, but was not commercially important until 1937. The production of frozen citrus juices (largely orange) for the years for which data ${ }^{7}$ are available was:

\begin{tabular}{|c|c|}
\hline YEAR & POUNDS \\
\hline 1937 & 691,000 \\
\hline 1938 & $3,285,000$ \\
\hline 1939 & $1,345,000$ \\
\hline 1940 & $2,297,000$ \\
\hline 1941 & 733,000 \\
\hline
\end{tabular}

The small production of frozen citrus juices during the war years was due primarily to heavy demands upon the citrus processing industry for concentrate for government use, and to restrictions on containers.

\footnotetext{
${ }^{7}$ Source of data: Yearbook and Statistical Number. Western Canner and Packer 36(5):239, April 25,1944 . In subsequent production statistics, production of citrus juices is included with that of figs, grapes, and miscellaneous fruits.
} 
Table 2

FROZEN-FRUIT PACKS BY DISTRICT, 1943 TO 1945*

(Total pack, all fruits, including sugur or sirup when used)

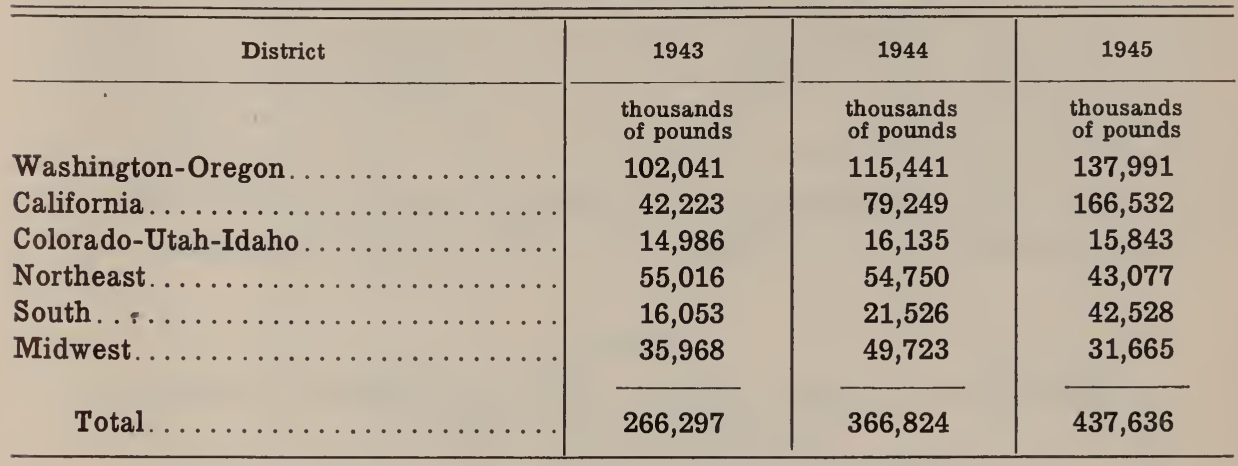

* Source of data:

Statistical Review and Yearbook Number. Western Canner and Packer 38(6) : 257-93. April 25, 1946.

Table 3

CALIFORNIA FROZEN-FRUIT PACK, 1943 TO $1946 *$

(Total weight, including sugar or sirup when used)

\begin{tabular}{|c|c|c|c|c|}
\hline Fruit & 1943 & 1944 & 1945 & 1946 \\
\hline & pounds & pounds & pounds & pounds \\
\hline Apples and apple sauce. & $9,038,309$ & $12,160,824$ & $44,768,160$ & $26,817,991$ \\
\hline Apricots............ & $11,709,793$ & $34,809,185$ & $50,619,008$ & $33,882,158$ \\
\hline $\begin{array}{l}\text { Bush berries (un- } \\
\text { classified) } \ldots \ldots \ldots\end{array}$ & & $2,132,155$ & 392,459 & 84,886 \\
\hline Blackberries........ & $\ldots \ldots \ldots$ & 128,560 & 232,905 & 190,551 \\
\hline Boysenberries....... & $1,543,639$ & 316,981 & $2,182,730$ & $4,133,965$ \\
\hline Loganberries......... & $\ldots \ldots \ldots$ & 136,000 & 488,375 & 656,223 \\
\hline Raspberries......... & $\ldots \ldots \ldots \ldots$ & & $\ldots \ldots \ldots$ & 67,906 \\
\hline Youngberries...... & $1,200,247$ & 106,775 & $1,222,667$ & $1,522,020$ \\
\hline Strawberries..... & 727,761 & $1,005,195$ & 969,741 & $3,916,119$ \\
\hline Cherries (sweet)..... & $\ldots \ldots \ldots$ & 693,280 & $5,832,659$ & $5,227,190$ \\
\hline Nectarines.......... & 877,718 & 580,102 & $1,737,476$ & 885,151 \\
\hline Peaches (cling)....... & $\ldots \ldots \ldots$ & $15,119,361$ & $26,955,833$ & $5,383,898$ \\
\hline Peaches (free) ....... & $11,816,734$ & $7,851,401$ & $23,004,394$ & $21,130,000$ \\
\hline Peaches (unclassified). & $\ldots \ldots \ldots \ldots$ & $1,275,963$ & $\ldots \ldots \ldots$ & $\ldots \ldots \ldots$ \\
\hline Pears.............. & 564,473 & 28,350 & 271,620 & 817,845 \\
\hline Plums and prunes.... & $1,550,097$ & $1,518,347$ & $1,642,936$ & $2,680,966$ \\
\hline Rhubarb............ & $\ldots \ldots \ldots$ & $\ldots \ldots \ldots$ & $1,631,988$ & $1,496,495$ \\
\hline Miscellaneous $\nmid \ldots . .$. & $1,634,837$ & $1,656,212$ & $4,587,810$ & 683,807 \\
\hline Total. & $40,663,608$ & $79,248,691$ & $166,531,761$ & $111,483,816$ \\
\hline
\end{tabular}

* Sources of data:

1943 to 1946, compiled by Western Frozen Foods Processors Association in March, 1946, and March, 1947.

1946: Western Canner and Packer 38(13): 91. Dec., 1946

$\dagger$ Includes figs, grapes, and citrus juices. Fruit purée included in fruits. 
Considerable quantities of Youngberries (subsequently displaced by Boysenberries) were frozen in Los Angeles and vicinity for local use out of season, and this berry pack has increased.

California, at present, is an important producer of frozen fruits. In fact, in 1945, it led even the Pacific Northwest, as shown in table 2. This was due to the large production of frozen apples, apricots, peaches, and nectarines and to the phenomenal increase in production of strawberries and other berries. Ordinarily, California cannot compete with other districts, particularly the Pacific Northwest, in strawberry production because of the higher costs (land, labor, etc.) and because of the difficulty of raising strawberries resistant to plant

\section{Table 4}

CALIFORNIA FROZEN APRICOT AND PEACH PACK FOR 1946, BY SIZE OF CONTAINER*

(Weights given include sugar or sirup when used)

\begin{tabular}{|c|c|c|c|}
\hline Size of container & Apricots & Freestone peaches & Clingstone peaches \\
\hline & pounds & pounds & pounds \\
\hline 1 pound or under. . . . & $5,841,811$ & $12,095,596$ & 70,848 \\
\hline Others under 10 pounds & 29,284 & 326,365 & $\ldots \ldots \ldots$ \\
\hline 10 pounds. . . . . . . & $2,779,550$ & $1,345,330$ & $1,558,960$ \\
\hline 30 pounds ... & $21,956,456$ & $6,678,936$ & $2,992,830$ \\
\hline Barrels ............. & 276,225 & $\ldots \ldots \ldots$ & 258,400 \\
\hline Others over 10 pounds. & $3,098,920$ & 735,335 & $\ldots \ldots \ldots$ \\
\hline Total. & $33,982,246$ & $21,181,562$ & $4,881,038$ \\
\hline
\end{tabular}

* Source of data: Western Canner and Packer 38(13):91, Dec., 1946.

pests and diseases but still of suitable quality for freezing (Joslyn, 1930a). The large demand for frozen berries, and the limited production in the Pacific Northwest, particularly in 1945, stimulated the freezing of strawberries in California.

The production of frozen fruit by variety in California during 1943-1946 is shown in table 3 .

A general decline in the pack of California apricots and peaches occurred in 1946 when there was also a decided shift from institutional- to consumer-size packaging (see table 4). The pack of cling peaches dropped 81.9 per cent from 1945 to 1946 , while apricots dropped 32.9 per cent during the same period. The pack of freestone peaches decreased only 7.8 per cent, but in 1946 over 11 million pounds more were in 1-pound, or smaller, containers than in 1945 .

Container Trends.-Early in the industry, most of the frozen fruits were packed in 5o-gallon wooden barrels, with smaller quantities in 30-gallon barrels, and in 5-and 10-gallon kegs. The 5-gallon can was introduced and used to a limited extent in the Pacific Northwest in 1926, and commercial packs of berries in the 


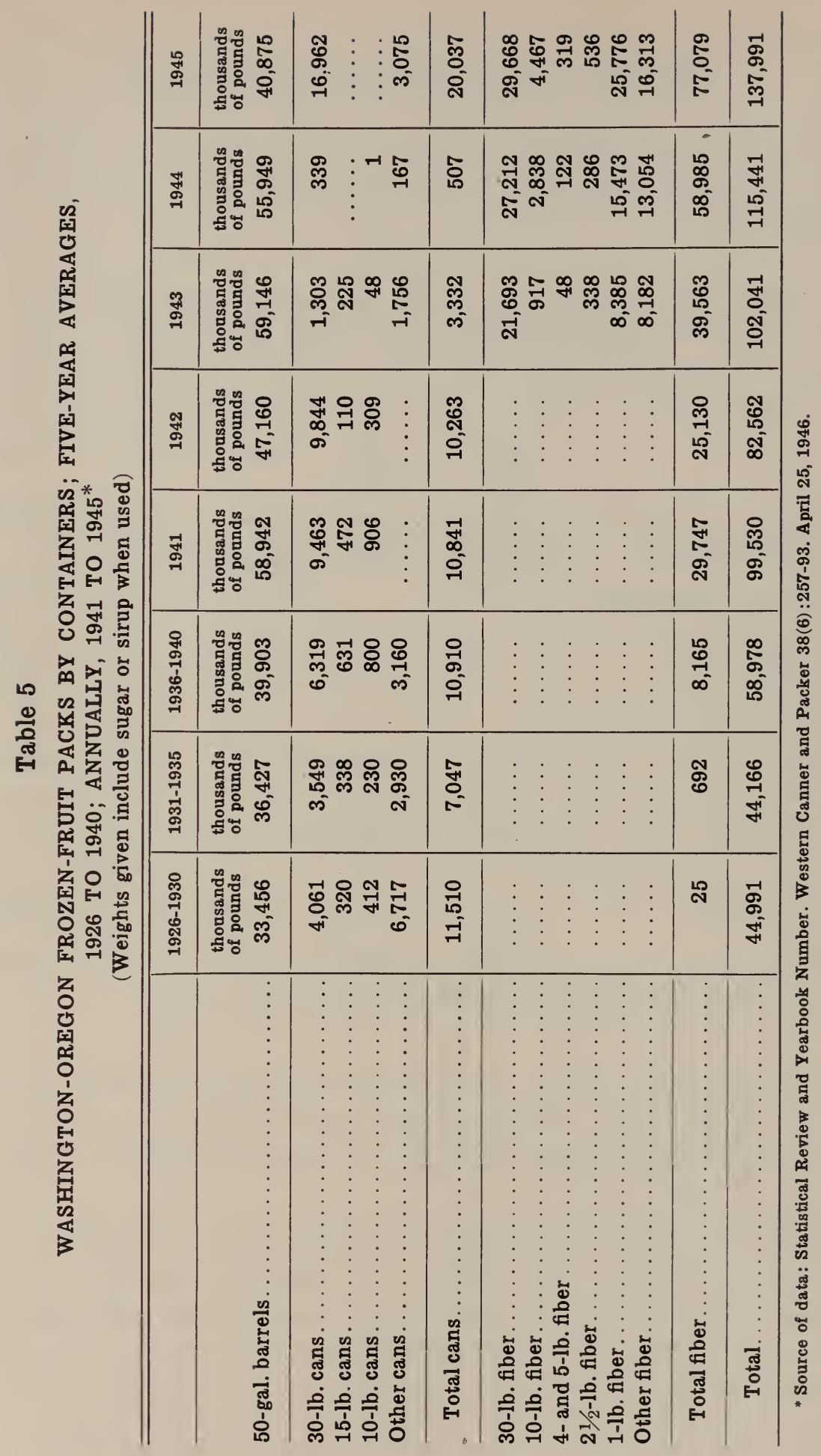


slip-over-top 30-pound can were first made in 1927. Smaller sized cans were used first in 1928 when the first pack of fruit in 1-pound cartons for consumer use was also made. One-pound cans were used commercially to an appreciable extent in 1929 (Joslyn, 1929a). Barrels and larger containers are still used (see table 5) for fruit packed for the preserve and bakery trade. But the smaller sized, fiber carton packs for retail distribution of dessert fruits have become more popular.

\section{Table 6}

CALIFORNIA FROZEN-FRUIT PACK BY SIZE OF CONTAINER, 1945* (Weights given include sugar or sirup when used)

\begin{tabular}{|c|c|c|c|c|c|}
\hline \multirow{2}{*}{ Fruit } & \multicolumn{5}{|c|}{ Size of container } \\
\hline & $\begin{array}{l}1 \text { pound } \\
\text { and } \\
\text { under }\end{array}$ & $\begin{array}{c}\text { Other } \\
\text { small sizes } \\
\text { (1-10 lbs.) }\end{array}$ & 10-30 lbs. & $30 \mathrm{lbs}$. & Barrels \\
\hline & pounds & pounds & pounds & pounds & pounds \\
\hline Apples and apple sauce. . . . . . & $6,427,864$ & 445,408 & $23,269,378$ & $14,625,510$ & $\ldots \ldots \ldots$ \\
\hline Apricots $\ldots \ldots \ldots \ldots \ldots \ldots$ & $3,073,965$ & $\ldots \ldots \ldots$ & $10,865,291$ & $36,132,031$ & 546,721 \\
\hline Bush berries (unclassified)... & $\ldots \ldots \ldots$ & & 73,803 & 318,656 & $\ldots \ldots \ldots$ \\
\hline Blackberries ............. & $\ldots \ldots \ldots$ & & 112,368 & 40,000 & 80,537 \\
\hline Boysenberries . . . . . . . . . . & 1,260 & & 769,663 & $1,292,560$ & 119,247 \\
\hline Loganberries . . . . . . . . . . & & & 4,375 & 460,000 & 24,000 \\
\hline Youngberries ............ & & & 780,987 & 390,000 & 51,680 \\
\hline Strawberries ............. & $\ldots \ldots \ldots$ & $\ldots \ldots \ldots$ & 16,000 & 333,170 & 620,571 \\
\hline Cherries................ & 570,631 & 75,648 & $3,477,982$ & $1,230,445$ & 464,944 \\
\hline Nectarines...... & 45,576 & $\ldots \ldots \ldots$ & 746,180 & 945,720 & $\ldots \ldots \ldots$ \\
\hline Peaches (cling) ..... & 393,340 & 37,092 & $4,811,122$ & $21,590,199$ & 124,080 \\
\hline Peaches (free)...... & $1,306,628$ & 284,578 & $2,972,279$ & $18,441,109$ & $\ldots \ldots \ldots$ \\
\hline Pears ................. & $\ldots \ldots \ldots$ & $\ldots \ldots \ldots$ & $\ldots \ldots \ldots$ & 271,620 & $\ldots \ldots \ldots$ \\
\hline Plums and prunes .......... & $\ldots \ldots \ldots$ & $\ldots \ldots \ldots$ & 102,316 & $1,371,090$ & 169,530 \\
\hline Rhubarb......... & $1,246,374$ & 364,704 & 13,500 & 7,410 & $\ldots \ldots \ldots$ \\
\hline Miscellaneous . . . . . . . & $1,697,474$ & $1,980,436$ & 284,814 & 290,670 & 334,416 \\
\hline
\end{tabular}

* Source of data: Western Frozen Food Processors Association, March 1, 1946.

In California (see table 6), an appreciable quantity of apricots, berries, peaches, plums, prunes, and other fruits was barreled for the preserve and bakery trade in 1944 and 1945 . Most of the fruit pack, however, was in smaller packages, of 5 pounds and over, and in 3o-pound cans for the bakery and institution trade. Considerable quantities of apples, apricots, and peaches were packed in $\mathrm{s}$-pound and smaller fiberboard containers for retail distribution for dessert use in the home. The development of locker plants as distributors for the 3o-pound packs of frozen fruit for home use in canning and making preserves out of season, has been an important recent development. While this market was stimulated by the wartime shortage of sugar, it could probably be continued as an important outlet for frozen fruit in normal times. The distribution of the 1945 pack of fruit by sizes of container is given in table 6 . 


\section{PRINCIPLES OF PRESERVATION FREEZING}

The physical, chemical, enzymatic, and bacteriological changes occurring during the freezing and subsequent thawing of fruits, and the present status of our knowledge of the means of controlling or eliminating these changes are discussed in this section. Microbial spoilage and its control, enzyme activity and its control, nonenzymatic chemical deterioration, and changes in texture, volume, and weight are described in some detail. It is necessary to know the nature of these changes in order to determine what fruit and fruit products can be preserved satisfactorily by freezing and how they should be prepared, packed, frozen, and stored.

The spoiling of foods, in general, is caused largely by the growth and activity of microörganisms, by enzyme activity, and by decomposition of certain of the constituents through reactions with each other, or with the environment (for example, oxygen of the air), container walls, etc. (see Joslyn, 1938, for detailed discussion of these factors). In the living tissue, these constituents do not react, and therefore do not decompose. But when the tissues are killed, whether in preparation or by freezing, the constituents are allowed to mix with each other and to react. Such reaction may result in decomposition. The living plant tissues also exhibit a certain resistance to the attack of microörganisms. In the living tissue the activity of the enzymes, which promote chemical action, is organized for the purpose of carrying on the ripening, respiratory, and other processes necessary for the life of the plant. The killing of the plant tissues by freezing places a definite limitation on the extent to which the natural qualities of the product may be retained.

In the preservation of food by freezing storage, we depend upon the preservative effect of low temperatures and the direct and indirect effects of the formation of ice in the tissues of the product. To properly preserve most food products, temperatures below those at which ice formation occurs are required. The undesirable effects that are produced by freezing, particularly on texture, are due largely to this separation of water from the tissues in the form of ice. Once separated in this way, most of the water cannot return to the tissue.

If it were possible to reach a temperature low enough to preserve the product for the desired period without actually freezing it, preservation by cold would be greatly improved. At present we are limited to the selection of varieties of fruits which are more tolerant of freezing and to the development of processing methods which minimize its undesirable effects. Even with fruit juices, the separation of ice often leads to undesirable changes in appearance (clearing and sedimentation). With fruit pulps and purces, the problem is not so acute. The presence of ice crystals necessitates constant temperature storage. 


\section{Microbial Spoilage and Its Control}

Little delay should occur between the harvesting and processing of fruit, and even less between processing and initial chilling or freezing. Speed of handling is necessary to reduce the danger of fermentation and microbial spoilage during freezing. This is especially important when freezing fruit in large containers.

The growth of all microörganisms decreases as temperature is lowered until a temperature is reached at which growth ceases. This minimum growth temperature varies with the environmental conditions, such as composition of medium, availability of oxygen, and type of organisms. It is lower for the coldloving (psychrophilic) organisms and increases as the optimum temperature for growth increases until the relatively high minimum of the heat-loving (thermophilic) organisms is reached.

The biological zero for growth was often considered to be $0^{\circ} \mathrm{C}$ or $32^{\circ} \mathrm{F}$, but since 1887 , numerous species of microörganisms have been observed to grow at $32^{\circ} \mathrm{F}$ and even considerably below that temperature (Berry and Magoon, 1934). In general, the extreme psychrophilic organisms are fungal rather than bacterial. The lower limit for microbial growth is now believed to be somewhere between $15^{\circ}$ and $20^{\circ} \mathrm{F}$.

Ice formation, which results in increased concentration of solutes, has a marked effect on microbial growth. In frozen foods, only those psychrophilic organisms will develop which are also osmophilic (tolerant to high concentrations). Bacterial activity usually will occur at lower temperatures in nonacid vegetables than in acid fruits, and for this reason the latter may be stored at somewhat higher temperatures.

At low temperatures; microörganisms will not only be retarded in growth and activity, but they may also be destroyed. The destructive action of cold is particularly great during the early stages of the refrigeration process and continues, though at a diminished rate, for many months. Complete destruction, however, has rarely been attained even at extremely low temperatures (Berry, 1933).

The killing of bacterial cells in frozen products results not only from temperature, but also from mechanical, and dehydrating effect of ice formation and from other conditions (Weiser and Osternd, 1945). Although a large percentage of the microörganisms present-often over go per cent-is destroyed by cold, the surviving organisms remain alive for a number of years, and will develop at favorable temperatures. The destruction of the plant tissues by freezing usually allows a more rapid development of those microörganisms present, so that the spoilage of frozen food after defrosting is often more rapid than that of the original fresh product even though the frozen contains a much smaller initial number of microörganisms.

In sound fruits and vegetables, microörganisms are present only on the 
surface tissues; the interior tissues are sterile. Thus the number of microorganisms remaining on the fruit or vegetable products after they are prepared for freezing is an excellent indication of the sanitary conditions prevailing in the plant. Although some attention is given to this point in the freezing industry, the high bacterial counts often reported in the literature indicate the possibility of further improvement in the sanitation of the harvesting and preparing units. Not all the types of microörganisms will develop in a given product because some of them require food elements that are either not present or not available, and because the acidity or the sugar content serve as natural checks. Thus each food product permits the growth of only certain types of microörganisms, and, in a sense, has a selective effect on them. Only those microörganisms which are capable of growing in the food need be destroyed. The others will cause no deterioration and need be killed only if they are pathogenic (cause disease).

Although freezing temperatures are required actually to stop the development of microörganisms in fruits, reducing the temperature of the fruit to $40^{\circ} \mathrm{F}$ as quickly as possible will very markedly retard the growth and activity and reduce the danger of fermentation and spoilage during freezing. There should be little or no delay between harvesting and processing and even less delay between processing and initial chilling or freezing. The conditions of freezing must be such that all the mass of the product is quickly brought below the temperature at which rapid spoilage will occur $\left(32^{\circ}-40^{\circ} \mathrm{F}\right)$. This is particularly important in the freezing of fruit in large containers where the rate of temperature change in the center of the mass is slow, occasionally permitting serious spoilage by fermentation. Precooling the fruit before packing in barrels, and frequent rolling of the barrels after they have been placed in the freezer is important. Rolling is particularly helpful in obtaining a uniform mixture of fruit and sugar and in hastening the freezing of berries packed with sugar (Ireland, 1941). The subsequent rate of freezing, and freezing storage conditions are governed by the character of the product and the length of time it is to be stored. However, because of the extremely slow rate of freezing and other disadvantages of barrels, the authors recommend 3o-pound tins or large cartons for bulk freezing of fruits.

\section{Enzyme Activity and Its Control}

Changes in color and flavor of fruits during freezing and thawing are caused mainly by oxidative enzymes. Such enzyme activity may be controlled by selection of varieties less susceptible to these changes, at the proper stage of maturity, by removal or exclusion of oxygen, by addition of sugars or sirups, by addition of antioxidants, or by heat.

Changes in color and flavor as a result of tissue damage during freezing and during slow defrosting are particularly profound in fresh fruit frozen for dessert use. Most varieties of apples, apricots, cherries, nectarines, grapes, 
peaches, pears, plums, and, to a lesser degree, berries, darken quickly after peeling or other mechanical injury. This discoloration, its resultant loss in characteristic flavor, and production of undesirable off-flavors are caused largely by oxidative enzymes. The chemistry of the enzyme-catalyzed oxidative discoloration of fruits has been summarized by Joslyn (1941). The browning of fruit is due largely to interaction of the enzyme, polyphenol oxidase, with molecular oxygen and a suitable phenolic substrate or color base. In the living tissue, oxygen tension is low and the phenolase is maintained in a reduced state through the activity of a dehydrogenase and suitable hydrogen donors such as ascorbic acid. On injury, the dehydrogenase is destroyed and the residual ascorbic acid is rapidly oxidized, thus permitting the formation and accumulation of quinones and higher products of oxidation of the mono- or polyhydroxy-benzene derivatives. These may be either free (for example, catechol, tyrosine, etc.) or combined (catechol-tannins, caffeic acid, etc.). The phenolic substrates themselves will form brown or red pigments, or their primary products of oxidation (the quinones) may induce oxidative discoloration in tannins and similar substances. It has been well established that no browning will occur in fruit tissues until practically all ascorbic acid (vitamin $\mathrm{C}$ ) has been converted by oxidation into dehydro-ascorbic acid. And the evidence available at present indicates that most of the loss in ascorbic-acid content in injured fruit tissue is brought about by induced oxidation by the phenolases in the presence of suitable phenolic substrates (Ponting, 1944a).

In addition to the phenolases, certain respiratory enzymes may be involved in the formation of off-flavors similar to those observed in unblanched frozen vegetables. Apricots, peaches, and plums occasionally develop haylike flavors; pineapple may develop musty or fishy flavors; and certain varieties of strawberries develop a strong manurial odor and flavor. These off-flavors probably are caused by the accumulation of intermediate products resulting from damage by freezing or mechanical injury to the cells. This leads to an imbalance in the chain of step-wise enzyme reactions occurring in normal respiration and metabolism, and the activation of enzymes such as catalase and peroxidase.

Hydrolytic as well as oxidative enzymes may produce changes in composition and flavor. The inversion of sucrose into dextrose and fructose in frozenfruit products is well recognized, and the activity of invertase even at low temperatures has been established (Joslyn and Sherrill, 1933; Kertesz, 1942). Losses in pectin content in frozen blackberries, raspberries, and strawberries have been reported, and since, at least in the case of blackberries, such loss was prevented by heating, it is likely that pectic enzymes were involved (Joslyn and Marsh, 1933, particularly p. 27).

Proteolytic enzymes may be active, also. Eckart and Cruess (1931) found bromelin to be present in undiminished activity in stored pineapple juice frozen for over three months.

It has long been recognized that low temperatures and ice formation do not prevent, although they do retard, enzyme activity (see review by Joslyn, 1946b). 
Although retarded by decreasing the temperature, so active are enzymes in promoting chemical changes and so resistant are they to the destructive effect of cold, that appreciable deterioration occurs in but a few months in tissues stored at commercially available freezing storage temperatures. Enzymes have been found to be unaffected by exposure to the lowest temperatures investigated $\left(400^{\circ} \mathrm{F}\right.$ below $\left.\mathrm{o}^{\circ}\right)$ and many of them are surprisingly active even in relatively concentrated solutions. Consequently they cannot be inactivated by cold alone. The undesirable changes brought about through the unchecked activity of the enzymes, however, may be minimized by storage at low temperatures, the lower the temperature, the longer the storage life of the product. The storage life generally is somewhat more than doubled for each decrease of $18^{\circ} \mathrm{F}$ in temperature, but the nature of the storage life temperature relationship is not definitely known.

In addition to being retarded by low temperatures, the activity of the enzyme concerned in the change of flavor or color must be prevented by some suitable method of inhibition or destruction. The discoloration of fruit can be prevented or minimized by the selection of varieties of fruit low in either the polyphenol oxidase or phenolic substrate content.

Oxidation may be minimized by:

1. Removal of oxygen from the tissues (either by forced respiration while immersed in dilute salt or sugar solution or by mechanical deaeration).

2. Exclusion of oxygen from the surrounding atmosphere (as by freezing and storage in vacuumized, hermetically sealed containers or immersed in sirup).

3. By the addition of substances which either inhibit the enzyme or maintain a reducing condition in the fruit tissues and surrounding atmosphere, such as edible acids, salt, sugar, sulfurous acid or its salts, and ascorbic acid.

4. By the destruction of the enzyme by heat (Joslyn, 1934; Hohl, $1946 a$ ).

Selection of Varieties.-Not all types of fruits can be frozen. The following are best adapted to freezing: Youngberries, Boysenberries, raspberries, strawberries, peaches, nectarines, and red sour cherries. Many tropical fruits, particularly pineapple, papaya, guavas, and passion fruit, can be preserved well by freezing. Some fruits, such as apples and apricots, which cannot be frozen successfully for serving without further preparation, can be prepared for use in bakery products. Most fruits can be well preserved as purées, juices, and sirups. Owing to loss in turgidity on freezing, the tomato cannot be preserved by freezing without such severe loss in crispness as to make it unacceptable.

Not all fruits are equally susceptible to discoloration, flavor changes, and 
texture changes. Even varieties or hybrids of a particular fruit vary in their responses to freezing. By selecting varieties of initial high color and flavor, changes in these characteristics may be minimized. One of the most striking examples of a variety which does not undergo oxidative browning is the Sunbeam peach. Kertesz (1933) made a study of this variety and found that it contains the necessary enzyme system, but lacks the phenolic substrate and therefore always retains its natural color. Unfortunately, there are very few of the well-known commerically grown varieties which have this nonoxidizing character. The Sunbeam peach is deficient in flavor, and very few plantings of it have been made. Crosses of the Sunbeam with more flavorful peaches should be available in the future. Variety, however, affects the magnitude of the darkening reaction, and those fruits less susceptible to browning should be selected.

Maturity.-Maturity is another important factor. The immature fruit is not only higher in tannin content but also contains a more active phenolase. The content of tannin or other color base as well as that of active phenolase decreases with maturity.

It has been reported (Caldwell, Lutz, and Moon, 1932; Lutz, Caldwell, and Moon, 1932) that the discoloration of peaches of all varieties was most rapid and pronounced in immature fruits and decreased in intensity with advancing ripeness. The best stage of maturity for freezing purposes was found to be one day before full eating ripeness.

Exclusion of Oxygen.-The removal of oxygen from the fruit tissues as well as from the atmosphere surrounding the fruit is necessary for the complete inhibition of browning. For small fruits, such as berries, packing in hermetically sealed containers closed under vacuum is sufficient. This procedure was introduced by J. E. McConkie in Oregon in 1929 and is again being used commercially. The removal of oxygen (present as such in the tissues or as organic peroxides) by forced respiration under water or brine, which is successfully used as a pretreatment in the canning of apples and rhubarb, was not successful in early experiments with fruit for freezing (Joslyn, 1934). It was found, however, that the gases present in fruit tissues could be almost completely removed by subjecting the sliced fruit in sirup (apples, apricots, and peaches) to a vacuum of about $29^{\prime \prime}$ until gas evolution ceased. During the course of the evacuation, the vacuum was released several times, care being taken to have the fruit covered with sirup. The fruit was found to absorb sirup which replaced the gases in the intercellular spaces, and the fruit became translucent rather than opaque. Fruit deaerated and impregnated with sirup in this manner did not brown so rapidly as ordinary sirup-packed fruit. More recent tests have confirmed the above results, and the development of the deaeration-impregnation treatment appears possible. To achieve satisfactory results, it is necessary to exclude air during defrosting as well as during freezing and freezing storage. 
Loss in flavor, browning, and production of off-flavors in crushed, sieved, or puréed fruits in the presence of oxygen are also catalyzed by phenolases. To avoid oxidative deterioration it is necessary to remove the oxygen from the pulp by subjecting it to a vacuum. Since the advantages of deaeration may be preserved by relieving the vacuum in the evacuation chamber with an inert gas, such as nitrogen, it is possible to fill, package, and freeze the product under a slight pressure of such gas. Such a treatment markedly improves the retention of flavor and prevents loss of vitamin $\mathrm{C}$ and discoloration. While deaeration is not as yet practiced commercially in the preparation of fruit purées, it is used in the production of frozen orange juice and other citrus juices.

Prompt handling of fruit and fruit products during preparation for freezing and packaging is necessary to minimize exposure to air. Fruits such as peaches, which are peeled, are particularly susceptible to surface discoloration during packaging. For best color retention, all fruit should be filled promptly into the package, covered with sirup without delay, and quickly sealed and frozen.

Addition of Sugar or Sirup.-Since the beginning of the industry, fruit has been frozen with added sugar. It was used to retard the development of yeast and mold and thus reduce the danger of fermentation during freezing, storage, and distribution, and to preserve color, flavor, and aroma. Sugar has long been known to retard the activity of phenolases. In 1929, P. J. Quin found that at the same concentrations, the retarding effect of sucrose was greater than that of glycerin or dextrose. The activity of peach oxidase was found to be completely inhibited in solutions containing 70 per cent sucrose or 6o per cent glycerin, although use of the latter is impracticable.

Sugar acts not only as an enzyme inhibitor, but also, particularly when present as a solution, as a means of excluding air. The solubility of oxygen in sugar solutions is low, and when the solutions fully cover the fruit, the rate of diffusion of oxygen from the head space in the container to the fruit is retarded. To exert its full effect, however, the sugar must be completely dissolved, and also absorbed by the fruit tissues.

Sugar added dry is most effective when uniformly incorporated with crushed or puréed fruit, dissolved in fruit juices, or mixed with sliced strawberries. It is not satisfactory for use with whole berries, or halved or sliced fruit, such as apricots, apples, and peaches. The sugar solution formed on contact with the surface of the fruit usually settles to the bottom of the container, carrying with it the unabsorbed sugar and leaving the upper fruit exposed. When the mixture is frozen quickly the sugar remains largely unabsorbed at the point of application and exerts only a limited preservative effect.

The use of sugar solutions instead of addition of dry sugar was introduced by Cruess, Overholser, and Bjarnason (1920). They suggested the use of a $60^{\circ}$ Bal. sirup for strawberries, $30^{\circ}$ for raspberries and apricots, and lighter sirup for cherries. They pointed out that there was a slight difference between the concentration of sirup (sugar solution) at which the flavor was best preserved 
and that at which the texture was best. Subsequent observations in this laboratory and elsewhere have confirmed these results and extended the observations to lay the basis for the industrial use of sirup in freezing fruit (Joslyn, $1930 b)$.

The use of sirup has the following advantages over the sugar-pack method:

1. Air discoloration is reduced to a minimum.

2. The sirup is more convenient than the sugar, especially if the latter is to be distributed uniformly throughout the mass of fruit.

3. There is less damage to the fruit during the addition of sirup than during the addition of sugar.

4. A more uniform and attractive pack is obtained as there is little or no change in fruit volume by loss of water from the fruit, and there is no settling of the fruit in the container as occurs in the sugar pack.

5. The sirup is a better aid to preservation during freezing than the sugar. It can be chilled before use and acts as a precooling agent.

6. The texture of the thawed fruit is better.

7. The sirup pack is applicable to all fruits.

There is some difference of opinion among investigators as to the concentration of sirup that is best. Joslyn has favored the use of medium sirups of about $40^{\circ} \mathrm{Bal}$. for most fruits, except strawberries and very tart fruit, which are better with $50^{\circ}$ sirup. Diehl, et al. (1939) recommended the following strengths of sirup.

FRUIT

PER CENT

DENSITY OF SIRUP

Blackberries

40 to 50

Blueberries .

40 to 45

Cranberries .

50

Raspberries, black

40 to 50

Raspberries, red

50

Strawberries 45 to 50

Apples 50

Apricots 60 to 65

Cherries, sour . 60 to 65

Cherries, sweet 40 to 50

Peaches 50

Prunes 50

The limit of the concentration of sirup to be used is set by the plasmolytic effects of sirups of high concentration-shrinkage and toughening of the tissue 
and extraction of much color and flavor-and by the degree of sweetness desired in the final product. Fruit also has a greater tendency to float in the heavy sirups, and requires additional precautions in packing. The volume of sirup added should be sufficient to cover the fruit in the container, and the package must be so designed as to keep the fruit submerged during freezing. In small containers, this is achieved by covering the top layer of the fruit with a parchment or cellophane liner; in larger containers, by the use of a perforated, paraffined paperboard cover or by insertion of a shallow, cone-shaped disk retained against the top rim by tabs or friction.

Dry sugar is still preferred by packers of fruit for bakers' or preservers' use, to avoid the larger volumes of liquid that would have to be handled. Color retention in fruit for bakers' use, however, is obtained by pretreatments other than those that rely upon exclusion of air. With the exception of sliced strawberries, which are frozen with added dry sugar, fruits for dessert use are now widely frozen with sirup.

The absorption of sugar by the fruit during freezing and subsequent defrosting is not large, amounting to about 5 per cent in berries frozen in sirup. In berries frozen with dry sugar, it becomes larger with the increase in ratio of sugar to fruit. Absorption varies from about 2 per cent in 1:6 pack to over 10 per cent in the 1:1 pack. Small quantities of sugar are absorbed by sliced apricots and peaches, but in general, the absorption is not large in fruit frozen slowly, and is even smaller in that frozen rapidly. Wiegand (1931) reported that Oregon (Marshall) strawberries held in sirup or with sugar at $30^{\circ}-31^{\circ} \mathrm{F}$ for 24 to 72 hours before freezing were superior in color, flavor, and texture to those frozen without such treatment. Joslyn and Marsh (1933) did not find this to be true of Banner strawberries, apricots, or peaches although the loss in weight of the sugar-cured fruit was less than that of fruit frozen without such storage. Subsequently, Wiegand (1941) concluded that sugar absorption on delayed freezing is not large. While delayed freezing is not necessary for flavor and color retention in small containers of sirup-packed fruits, it is desirable for barreled berries and advisable for dry-sugar-packed fruits in retail containers.

The substitution of dextrose solutions, invert sirup, or honey for cane or bect sugar solutions has not been found desirable. Fellers and Mack (1929) reported that the substitution of dextrose (cerelose) for cane sugar caused strawberries to darken, to assume an unnatural, purplish-red appearance, and to become flat, unnatural, and objectionable in flavor, and soft and mushy in texture. Observations made in this laboratory have confirmed similar effects for a number of fruits. In recent tests, apricots, peaches, and nectarines frozen in a $40^{\circ} \mathrm{Bal}$. dextrose solution had an objectionable flavor and were more discolored than those frozen in a $40^{\circ}$ sucrose solution.

In addition, the dextrose crystallized out on freezing, and the fruit was covered with an unattractive mass of soft white crystals. Enzyme-converted invert sirup was found to cause a brownish discoloration accompanied by 
an objectionable odor and flavor in both the strawberries and sirup similar to that found in the dextrose packs. Acid-converted invert sirup was found to be satisfactory, provided that the degree of inversion was not above $5^{\circ}$ per cent. Apricots were particularly sensitive to the development of off-flavors in invert sirup and were best in color and flavor at $5^{\circ}$ per cent inversion; peaches were less sensitive, and nectarines least. Commercial glucose sirups (low conversion corn sirups) were found to be superior to dextrose sirups in color retension, but fruit packed in these sirups had a slightly objectionable flavor. The high conversion corn sirups also were satisfactory in color-retentive ability. Several fruits retained more of their natural color in these sirups than in sucrose sirups of the same strength, but developed a noticeable foreign flavor. Mixtures of high conversion corn sirups with cane in the proportion of 1 part corn sirup solids to 3 of sucrose, however, were equal to cane sugar solutions.

Addition of Acids. - It is well known that the $\mathrm{pH}$ (active acidity) of the medium influences enzyme activity. Enzymes usually exhibit an optimum activity at a $\mathrm{pH}$ range characteristic of the source and purity of enzyme, type of substrate, nature of buffer system, and temperature. Their activity decreases in regions of $\mathrm{pH}$ lower or higher than this optimum. Samisch (1935), for example, reported the optimum $\mathrm{pH}$ for the oxidation of catechol by apricot and peach phenolase, respectively, to be 4.9 while, under the same conditions, there was no marked optimum for apple phenolase in the region of $\mathrm{pH}$ of 3.6 to 6.6. Upon acidification, the activity of all three phenolases decreased, that of apricot and peach markedly so.

This behavior of enzymes has been used to advantage in checking browning of lye-peeled peaches during handling. After washing, the fruit is immersed in a 1 per cent solution of citric acid. The addition of citric acid to sweetened fruit purées or to the sirup in which fruit is frozen was found to markedly improve color and flavor retention. As much as 0.5 per cent of citric acid, for example, can be added to fruit purées, or fruits such as apricots and peaches, without making them too sour. The use of added acid is now common in the freezing of fruit products for use in ice cream and ice.

More recently, the use of a combination of citric and ascorbic acid has been suggested for preventing browning of cut fruit (Luther and Cragwall, 1946). In our tests, a sirup containing 0.5 per cent of citric acid and 0.03 per cent of ascorbic has been as satisfactory for color retention in apricots, peaches, and nectarines during freezing storage as one containing o.1 per cent of ascorbic acid alone. The fruit frozen with citric and ascorbic acids, however, does not retain its full fruit flavor so well as fruit frozen with ascorbic acid alone. Upon storage at room temperature after defrosting, the citric-acid-treated fruit, particularly apricots, darkens more rapidly. Citric acid apparently exerts a catalytic effect on discoloration after long storage at room temperature. Added acid was not found objectionable in apricots and peaches. 
Antioxidants or Reducing Substances.-Several antioxidants, which may act either by reducing the free oxygen present in the sirup and the fruit tissues or as phenolase inhibitors, have been used (Sater et al., 1947). Of these, ascorbic acid (vitamin C) is used most widely at present in the packing of frozen fruit for dessert use (Hohl, 1946a). It rapidly reduces dissolved oxygen in the sirup, maintains the phenolic substrates in the fruit tissues in reduced form, and thus prevents browning.

In addition to preventing browning, ascorbic acid has a striking effect on retention of the natural fresh flavor and aroma. Although cut fruit, frozen, completely immerséd in sirup, retains its color during freezing storage almost as well without added ascorbic acid, and is of acceptable color immediately after thawing, the presence of the added ascorbic acid improves color retention as the fruit reaches room temperature. The fruit must be completely covered with ascorbic-acid-containing sirup, otherwise there will not be effective protection even at high concentrations of antioxidant.

The usual range of concentration is from 200-250 mg. of ascorbic acid per pound of fruit. At the upper range, with a 1-pound pack of halved apricots containing 10 ounces of fruit and 6 ounces of sirup, the sirup should contain ${ }_{15} 6 \mathrm{mg}$. of ascorbic acid or 0.0916 per cent. With sliced peaches packed at the rate of 11 ounces to 5 ounces of sirup, the sirup should contain $172 \mathrm{mg}$. of ascorbic acid or $0.14^{2}$ per cent. As a general practice the addition of ascorbic acid to the sirup to the extent of 0.1 per cent by weight with sufficient sirup to cover the fruit, has been found satisfactory. Theoretically, if the oxygen content of the sirup and the fruit, and that diffusing into the fruit and sirup, are known, provision can be made to add the necessary quantity of ascorbic acid, but at present there is but little available data on these points. However, data on the ascorbic acid stability in frozen fruit is being accumulated (DuBois and Colvin, 1945; Bauernfeind et al., 1946).

Such information is necessary if claims are to be made for the added ascorbic acid as vitamin C. The Food and Drug Administration requires that any addition of ascorbic acid be declared on the label. If the packer does not wish to make a claim for reinforcement of the nutritive value, the label may state that the ascorbic acid was added simply to preserve color and flavor. On the other hand, if he wishes to claim that supplementary vitamin $\mathrm{C}$ was added, the label must guarantee that the stated amount is present in the package. The labeling, to comply with the regulations, must also indicate what proportion of the adult daily requirement of vitamin $\mathrm{C}$ is present in a given portion of the contents of the package. All these regulations imply that the packer knows the loss of vitamin C during freezing, during the frozen storage period, and during defrosting, and also that he has some idea of the effect of various preparation methods upon losses of vitamin C during storage.

Its lack of characteristic flavor, other than a mild acidity, the ease with which it blends with fruit flavors as well as the fact that it is an important nutrient (vitamin C) are factors in favor of ascorbic acid. On the other hand, it is still 
relatively expensive, its antioxidant properties are weaker than those of sulfurous acid, and it is not so readily applied because it does not penetrate the fruit tissues so rapidly.

Sulfurous acid and its salts (the sulfites and bisulfites) are among the strongest and best known of antioxidants. It is the most effective chemical inhibitor of browning and can be used in much smaller concentrations than ascorbic acid or thiourea. Sulfurous acid and the sulfites, however, have the disadvantage of bleaching the anthocyanin pigments of berries and cherries and the red pigments at the peach-pit cavity. They have an objectionable flavor

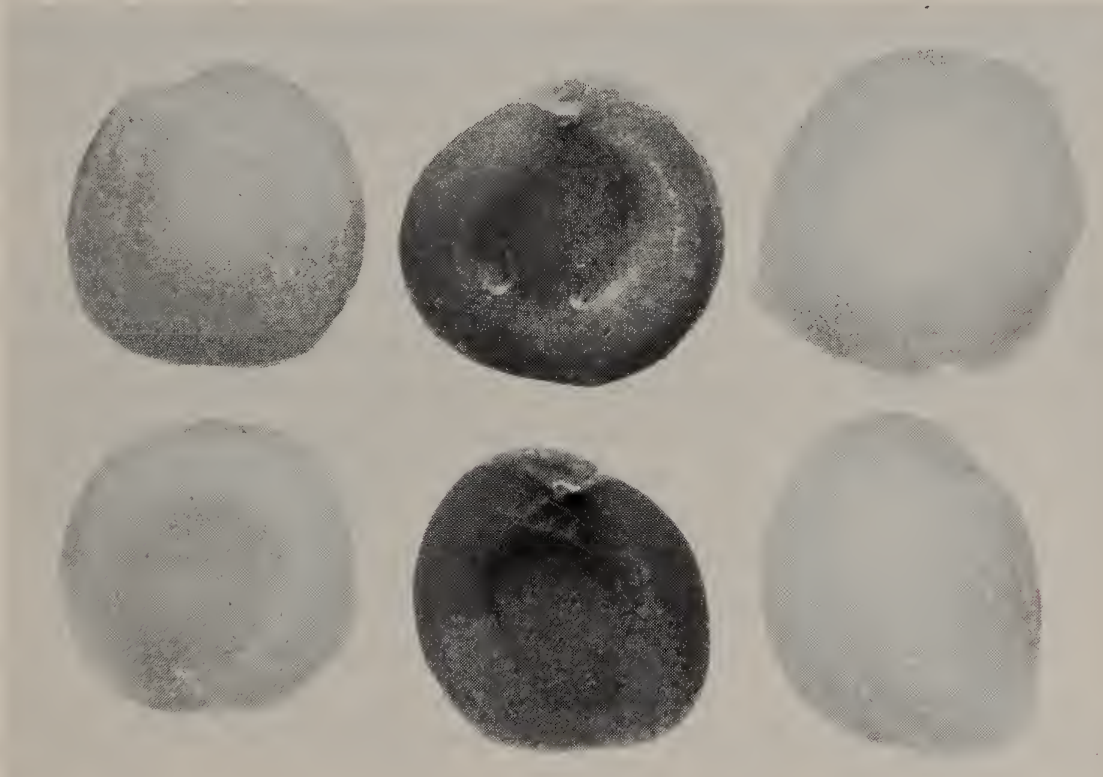

Fig. 1.-Left to right, comparison of sulfited, untreated, and blanched apricots.

which may be easily detected in concentrations above $25^{-5}$ o p.p.m., in frozen fruits, and also have a tendency to destroy the natural fruit aroma. In our experience, apricots are the only fruits for dessert use in which sulfites may be used. Apricots frozen with a sirup initially containing 5o p.p.m. of $\mathrm{SO}_{2}$ retain their color and flavor fairly well. This sirup can be made by dissolving 446 grams of liquid sulfur dioxide, 725 grams of sodium bisulfite $\left(\mathrm{NaHSO}_{3}\right)$, or 662 grams of sodium metabisulfite $\left(\mathrm{Na}_{2} \mathrm{~S}_{2} \mathrm{O}_{5}\right)$ per 100 gallons of $40^{\circ}$ Bal. sirup. (1 gallon of $40^{\circ} \mathrm{Bal}$. sirup weighs $9.809 \mathrm{lbs}$. in air at $68^{\circ} \mathrm{F}$.)

Sulfur dioxide is particularly useful, however, for a pretreatment of fruit, such as apples, apricots, and peaches, to be used for bakery products or jams and preserves. Halved apricots or sliced apples and peaches immersed for 4 minutes in a solution containing 3000 p.p.m. of $\mathrm{SO}_{2}$, or for 3 minutes in one of 4000 p.p.m., drained well and then frozen in sealed containers, will retain their color during storage for over a year, and will retain less than 100 p.p.m. 
of $\mathrm{SO}_{2}$ after storage. If the strength of the sulfite solution is carefully maintained during treatment, the fruit tissue will be penetrated throughout but will not be excessively sulfited. It will also contain the required concentration of $\mathrm{SO}_{2}$ for color retention-50 to 75 p.p.m. for apricots and peaches, and 25 to 50 p.p.m. for apples (Joslyn and Mrak, 1933; Joslyn, 1942). With more dilute solutions, the penetration of $\mathrm{SO}_{2}$ will not be complete and browning will occur in the center portions of the fruit during freezing storage and be accentuated during thawing. The Western Regional Research Laboratory (Anon., 1945a) has recommended that apple slices or rings be dipped for 1 minute in a solution containing 0.2 to 0.25 per cent of $\mathrm{SO}_{2}$, and then held for 8 hours before freezing to allow the $\mathrm{SO}_{2}$ to penetrate. We were not able to confirm this recommendation for holding, in some of our tests with a different variety of apple.

The treating solution containing 3000 p.p.m. of $\mathrm{SO}_{2}$ (o.3 per cent) can be prepared by passing liquid $\mathrm{SO}_{2}$ from a gas cylinder into a wooden or noncorrodable metal container (stainless steel or brass) filled with water, at the rate of 25 pounds per 100 gallons of water. The disagreeable fumes of $\mathrm{SO}_{2}$, where liquid sulfur dioxide is used, can be minimized by keeping the solution cool, placing it in a well-ventilated place, or by adding sufficient flake lye to adjust the $\mathrm{pH}$ to about 4 . The ratio of the weight of lye added to that of $\mathrm{SO}_{2}$ should not be over $2: 3$. Sodium bisulfite or sodium metabisulfite may be used in place of liquid $\mathrm{SO}_{2}$ at the rate of $4^{1}$ pounds or 37 pounds, respectively, per 100 gallons of water. (100 gallons is equivalent to $13.35 \mathrm{cu}$. ft.) The immersion time is best controlled by means of a suitably arranged conveyor system. The $\mathrm{SO}_{2}$ strength of the bath should be adjusted periodically by addition of sulfur dioxide or sulfite after the strength of the bath has been determined. This is done by titration of a carefully taken and measured aliquot with standard iodine solution, using starch indicator. To test the extent of inactivation of the phenolase by sulfur dioxide, and the degree of penetration of sulfur dioxide, select several pieces of fruit, especially the larger ones and those least likely to have been completely immersed, cut them in two with a stainless steel knife, and spread a freshly prepared, 1 per cent solution of catechol in water over the cut surface, with a medicine dropper. After 5 to 10 minutes, the portion of the fruit which still contains active enzymes and is likely to brown on freezing, will turn black (Ponting, 1944b).

Still another antioxidant which has received some attention in the literature is thiourea (thiocarbamide), known by the trade name Frulite (Denny, 1942). It is effective in inhibiting browning if the fruit is immersed in the solution and drained again, before freezing. As a result of the recently announced policy of the Food and Drug Administration its use is not approved because of possibility of injury to humans. Tests with medicinal preparations containing thiouracil have produced serious symptoms in experimental animals. Other disadvantages of this antioxidant are that it adversely affects flavor and is not so effective as $\mathrm{SO}_{2}$. 
Heat Inactivation.-Discoloration may also be prevented by heat inactivation of the phenolases, or blanching (scalding).

When blanching is properly done, no browning can occur, but if blanching is insufficient to destroy the oxidizing enzyme, the browning may be even more severe than in untreated fruit. (This effect is caused by injury to the tissues,

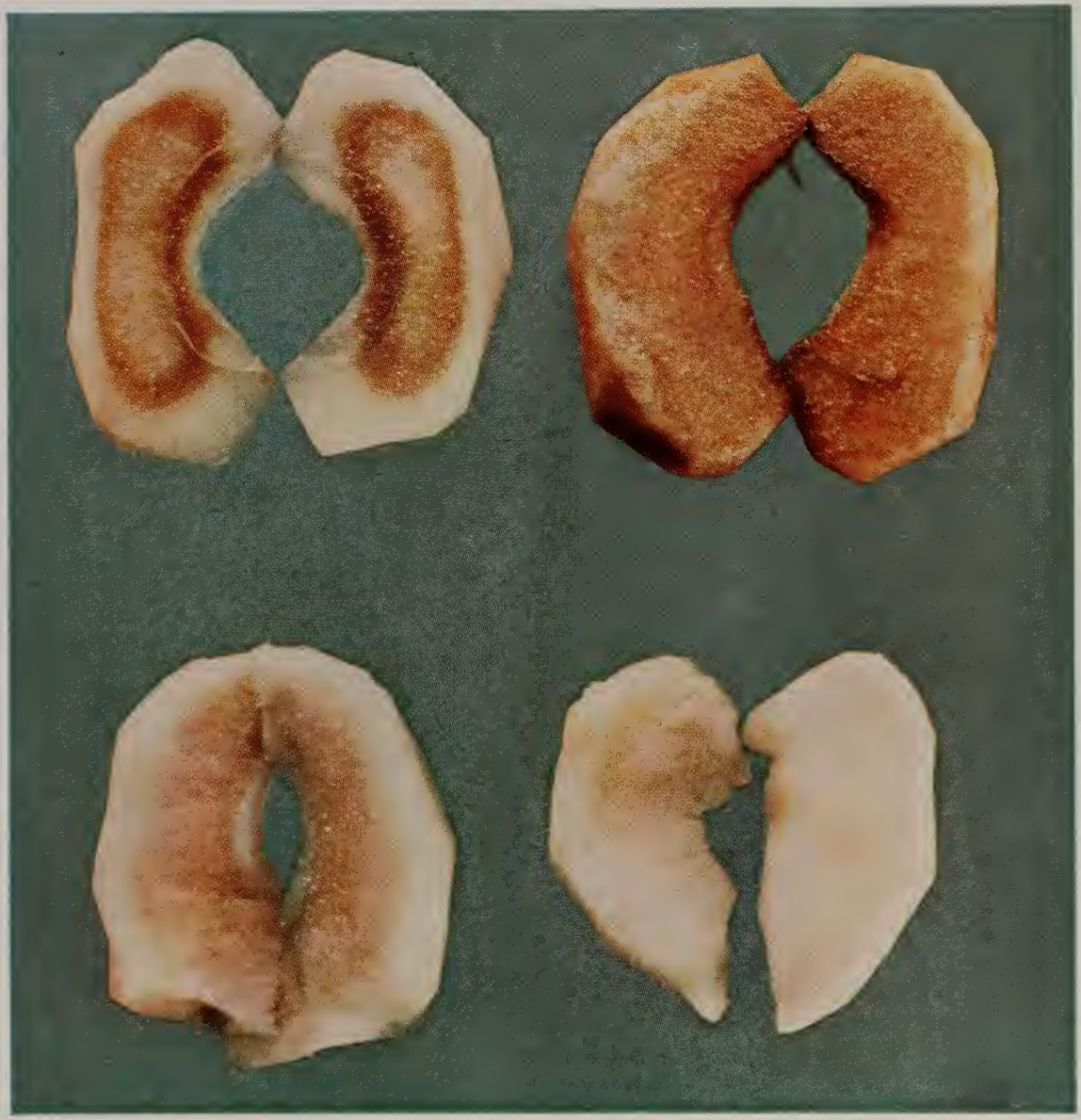

Fig. 2.-Center portions of apple segments after various pretreatments, freezing, thawing, and slicing. Top left, insufficiently blanched; top right, untreated; bottom left, sulfite dip, which did not penetrate properly; bottom right, adequately blanched.

resulting from blanching, which allows the several reactants to be brought together more quickly.) Another advantage is that blanching does not require the addition of a foreign chemical substance, and this eliminates troublesome label declarations.

Disadvantages of blanching are that it tends to give the fruit a cooked flavor and softens its texture. A blanch which is sufficient to inhibit browning and still not precook the fruit is only rarely attainable. Another serious problem in connection with blanching fruit for freezing is that of cooling. To check con- 
tinued cooking effect of the blanch, the fruit must be quickly and thoroughly cooled after blanching. This has been done most frequently with excessive quantities of water either in flumes or sprays. This method has the very obvious disadvantage of causing large losses of soluble nutrients and flavor from the fruit. Air cooling, while somewhat slower, would be far better from the standpoint of saving nutrients and flavor, if practical means of achieving it commercially could be developed.

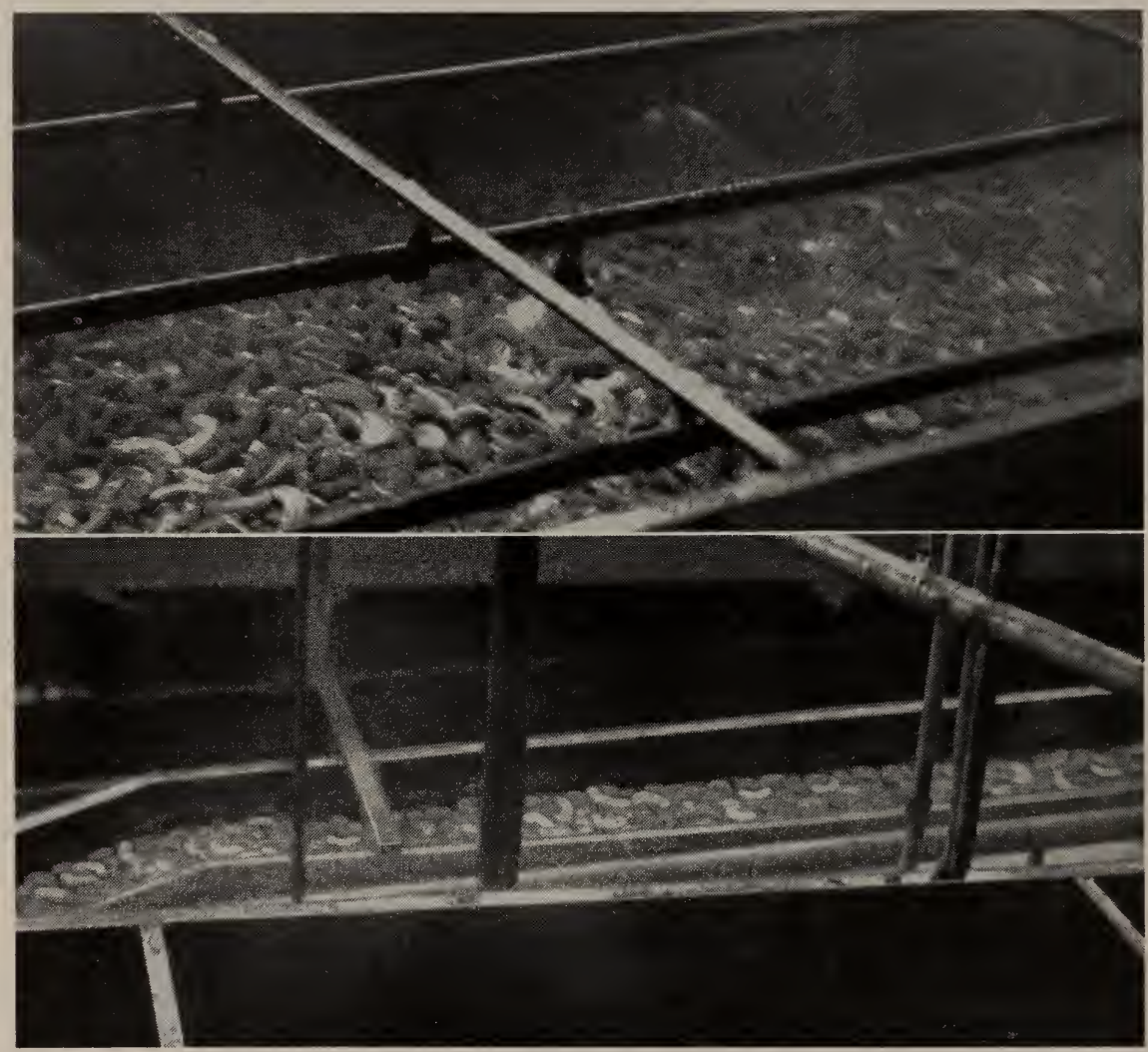

Fig. 3.-Cooling peaches after blanching. Top: Spray cooling, best for retention of flavor and nutritive value. Bottom: Flume cooling, undesirable because of excessive leaching of soluble constituents.

Blanching may be accomplished by means of live steam, hot water, hot sirup, or by electronics. Steam is the most convenient and popular procedure for commercial use.

The period of blanching, whatever the method used, should be long enough to completely inactivate phenolase at all portions of the tissue, particularly in pieces of fruit that are farthest removed from direct contact with the heating medium. The temperature to which the fruit tissues must be brought varies with variety, maturity, and holding period. Heating the fruit throughout, in free-flowing steam, to a temperature of about $185^{\circ} \mathrm{F}$ is usually sufficient. The 
time of blanching for halved, medium-sized apricots exposed to steam in single layers is about 4 minutes; for sliced apples it is about 2. If heat distribution is poor, only the enzymes in the surface layers will be destroyed and internal browning will result. As a test for the adequacy of scalding, select a few pieces of fruit from the blancher, cool to room temperature, cut across, place in a saucer, and add several drops of a 1 per cent tincture of guaiacol, a 1 per cent tincture of guaiacum, or 1 per cent water solution of catechol. If the samples change in color (guaiacol to red, guaiacum to blue, catechol to dark brown or black), the blanching has not been sufficient. Considerably shorter periods of time may be used in sirup blanching, and when this is followed by sirup cooling, the flavor retention will be sufficient for bakers' use. Blanching in boiling water is not recommended. Only fruit for bakers' use should be blanched.

\section{NONENZYMATIC CHEMICAL CHANGES}

Nonenzymatic chemical activity producing changes in flavor and color may occur during preparation for freezing, freezing storage, and subsequent thawing. This may be purely oxidative, but may also include development of off-flavors and increase in tartness. These chemical changes are very difficult to control.

Auto-oxidation, which may be responsible for part of the changes in flavor and color, can be controlled by exclusion of oxygen, or may be minimized by addition of sugar or sirup. Sugar has been shown to reduce oxidation of ascorbic acid, even in acid solutions (Munilla and Vogelsinger, 1937; Shamrai, 1941; Richardson and Mayfield, 1944).

Among the nonoxidative changes is the significant increase in tartness on freezing. This has been ascribed by Pickett (1932) to an increase in titratable acidity, but the increases he found were too small to account for the marked changes observable.

During freezing and subsequent thawing, some fruits acquire a peculiar flavor and an odor which is undesirable and sometimes offensive. Weakflavored fruits, such as cling peaches, apparently lose all of their characteristic flavor upon prolonged storage, even when protected from oxidation. Grapes, apples, berries, and cherries sometimes acquire a rather undesirable flavor which seems to be more apparent in hermetically sealed containers in which the fruits have not been promptly cooled and frozen. It is thought that this may be due to anaerobic respiration which occurs in the closed containers during freezing. Peaches also acquire a pronounced benzaldehyde flavor during long storage. This is more marked in freestones than in clingstones, and in exposed peaches than in those submerged in sirup although it occurs even in the latter. Sometimes off-flavors result from the permeability of the paper containers, which allow absorption of foreign cold-storage odors and flavors, and often they can be traced to absorption of foreign flavors from the containers themselves. These off-flavors are more pronounced after long storage. 
Crystallization of Sugar.-At times, during the storage of frozen fruits, a white, fondantlike material forms on the surface. When the fruit has been thawed, this appears as white patches of partly crystallized material. This condition is particularly noticeable in deeply colored fruits or berries. It is most prevalent under the following conditions: with fruits from which relatively little juice exudes to dilute the sirup; where high original concentrations of sucrose sirup are used; at relatively low freezing storage temperatures; and in containers that permit gradual dehydration of the product in storage. Rabak and Diehl (1944) have described this condition and have shown that it is due to the crystallization of sucrose. We have frequently observed the condition in fruits packed in improperly sealed containers, even at low sirup strengths at $0^{\circ} \mathrm{F}$, and have also observed formation of small rosettes of sucrose crystals throughout the body of fruit purées $(3+1)$, particularly with persimmon pulp. Essentially this is due to the crystallization of the sugar-water eutectic mixture. (The eutectic point is the constant temperature at which a solution of water and a dissolved substance, such as sugar, will change from a liquid state to a solid state upon removal of heat. The eutectic mixture is a solid one of crystals of ice and crystals of solute, such as sucrose.) Mondain-Monval (1925) found that in the system sucrose-water, the eutectic point occurs at a sucrose concentration of 62.4 per cent and the eutectic temperature is $-13.9^{\circ} \mathrm{C}\left(+7^{\circ} \mathrm{F}\right)$. When a solution of sucrose of this strength is cooled to $+7^{\circ} \mathrm{F}$ a single solid phase appears. When solutions of lower concentration are cooled to below their freezing point, ice alone forms until the eutectic temperature is reached, when a mixture of ice and crystalline sugar forms. In addition to sucrose, the other sugars, salts, and acids present in the fruit-sugar system will form eutectics, but there is little information on the condition at which these will occur in the complex mixture.

\section{Physical Changes During Freezing and Thawing}

The most troublesome physical change occurring in frozen fruits is that of texture. This undoubtedly results from changes in the colloidal systems of the fruit, but our present knowledge of the reaction of plant colloids to freezing is incomplete. We do know, however, that an important factor in texture retention is uniformity in the distribution of ice crystals in the frozen product. This section suggests ways of achieving that uniformity. Changes in weight and volume also occur, and must be taken into account in choosing containers.

Texture.-Cellular breakdown, resulting in softening and other changes in texture, is the most striking and troublesome physical change which occurs in fruits, particularly in those frozen for dessert use. This loss in the characteristic crispness and turgidity is grossly similar to that resulting from cooking. It can be minimized by selection of varieties or strains of fruit which are resistant to these changes and particularly by serving fruits immediately after partial 
defrosting. Considerable attention has been given to the effect of rate of freezing, and size and distribution of ice crystals formed during freezing, upon the texture of the final product, and some attention has also been given to conditions of defrosting. ${ }^{8}$ It has been established that the size and distribution of ice crystals can be controlled by the rate of heat removal (or rate of freezing) during the period of maximum ice formation.

When foods are frozen slowly, the ice crystals are large and nonuniformly distributed. In meat products, large ice crystals form between the meat fibers and sometimes cause rupture and dislocation of the fibers. In plant tissues, ice gradually fills the intercellular spaces and eventually forces the cells apart. Rupture of the cells as a result of internal pressure from intracellular ice crystals is not common since the natural elasticity of the cells and their relation to each other within the tissue prevent this. In both animal and plant tissues that are slow-frozen, the water removed during freezing is only partly reabsorbed on thawing; the excess leaks out of the tissues. In both tissues, however, desiccation of the fibers, or cells, as well as mechanical injury, contributes to changes in texture.

When animal or plant tissues are frozen so rapidly that translocation of water does not occur before freezing, many small ice crystals are formed, and these are generally uniformly distributed within the tissues. Such tissues, particularly animal tissues, are much less disorganized, so that a much larger percentage of the water separated as ice is reabsorbed on thawing. In fruit tissues, however, the separation of water is a much more irreversible process, and the improvement in texture as a result of more rapid freezing is not so profound. In general, however, most investigators agree that a uniform distribution of small ice crystals is desirable. The best ways to obtain this uniformity are:

\section{Increase the rate of heat removal.}

\section{Decrease the size of the unit frozen.}

3. Select containers which have the largest surface area per unit volume, thus presenting more surface to the refrigerant.

4. Select the most efficient heat-transferring medium as a refrigerant.

5. Reduce stagnant films and air pockets to a minimum.

6. Use a refrigerant at as low a temperature as is economically justifiable.

\footnotetext{
${ }^{8}$ For discussion of the extensive literature in this field, much of which is still contradictory, see the early excellent discussion by: Glennie, A. E., Index to the literature of food investigation. Dept. of Scientific and Ind. Research, His Majesty's Printing office. London, 1929, pp. 1-9.
Tressler and Evers (1917), and Joslyn (1934).
} 
The early tendency to focus attention upon low temperatures alone as a means of obtaining the desired rate of freezing (at one time quick freezing was restricted to freezing at $-40^{\circ} \mathrm{F}$ ) has given way to a more rational evaluation of heat-transfer factors.

The changes in the colloidal systems involved are undoubtedly the limiting factors in satisfactory texture retention, but unfortunately our knowledge of the response to freezing of colloids such as occur in plants is insufficient. Although the plant cell consists largely of water, it remains firm because the gels are capable of holding large amounts of water in a rigid or semirigid form. During freezing, these gels become progressively dehydrated, and the frozen system may be considered essentially as a dehydrated gel plus ice. Upon thawing, water is not reabsorbed by plant gels so completely as by animal gels, and a disturbed system results. The degree of irreversibility in this process is determined partly by the original concentration of water in the tissues and by its distribution between free and bound forms. The average water content of our common fruits is about 85 per cent as compared with 7 o per cent for fish foods and 60 per cent for meat products. The bound water content in berries, i.e., water that will not be frozen at $-20^{\circ} \mathrm{C}$, was reported by Daughters and Glenn (1946) to vary from 2.2 per cent to 6.7 per cent for 21 samples of strawberries and from 5.6 to 6.1 per cent for two samples of raspberries. There is some evidence that the higher the bound water content, the better the texture retention on freezing.

Our present knowledge of the freezing and thawing of colloid systems can be summarized as follows (for further details, see Clayton, 1932):

When freezing is so rapid as to fix the original spatial distribution of the colloid, thawing may be either rapid or slow and yet reproduce the original structure. With slow freezing, however, resulting in large ice crystals, rapid thawing cannot restore the original condition. If the colloid does not produce a sol or gel with simple contact with water, the rate of thawing is without interest subsequent to slow freezing. But if the sol or gel condition follows contact of colloid with water, thawing of colloid systems should be slow enough to allow the colloid to take up the wat:r r provided during melting.

The behavior of only a few col'nids on freezing and thawing has been studied-eggs, gelatin, and agar agar. Some observations have been made with pectin. The use of low methoxyl pectinic acids was found beneficial by Buck, Baker, and Mottern (1944), and others, in reducing "run-off" in strawberries, and addition of these pectic substances to the sirup in which the berries were frozen produced an improvement in texture. This was not found to be true of other fruits.

The denaturation of colloids by freezing is particularly important in the freezing of cloudy fruit juices where the character of the colloidal material may be so altered that it readily precipitates when the juice is thawed. This effect is particularly noticeable with apple juice, but it has also been observed with grape, berry, and citrus juices (Joslyn and Marsh, 1937). Shrader and 
Johnson (1934) ascribe this change in orange juice to the separation of a viscous sirupy fraction, the metacryotic liquid, containing 8 per cent acid and 64 per cent carbohydrate. The quantity of this metacryotic liquid in quick-frozen orange juice is small, but in slow-frozen fruit juices, and on storage at higher temperatures $\left(5^{\circ}-15^{\circ} \mathrm{F}\right)$, it is formed in significant amounts. In pectinous fruit juices this liquid may form a jelly which will not dissolve upon thawing.

Table 7

EXPANSION OF WATER AND SUGAR SOLUTIONS DURING FREEZING*

\begin{tabular}{|c|c|}
\hline Substance & $\begin{array}{l}\text { Increase in volume } \\
\text { on freezing } \\
\text { at } 0^{\circ} \text { to } 5^{\circ} \mathrm{F}\end{array}$ \\
\hline & per cent \\
\hline Water............. & 8.6 \\
\hline 10 per cent sugar solution. . & 8.7 \\
\hline 20 per cent sugar solution. & 8.2 \\
\hline 30 per cent sugar solution. & 6.2 \\
\hline 40 per cent sugar solution. & 5.2 \\
\hline 50 per cent sugar solution. & 3.9 \\
\hline 60 per cent sugar solution. & None \\
\hline 70 per cent sugar solution. & $\begin{array}{c}1 \text { per cent } \\
\text { decrease in volume }\end{array}$ \\
\hline
\end{tabular}

* From: Joslyn, M. A., and G. L. Marsh. Changes occurring during freezing, storage and thawing of fruits and vegetables. Calif. Agr. Exp. Sta. Bul. 551:16(1933).

Volume.-The increase in volume that occurs during freezing is of importance in selecting the size of container and in determining fill-in weights.

Water, unlike most other liquids, expands on freezing. The increase in volume amounts to about 9 per cent. When water, fruit, fruit juices, and sirups are frozen in sealed containers, it is necessary to allow for the increase in volume on freezing to prevent bursting of the containers.

Fresh fruits generally contain air in the intercellular spaces in which ice is first formed, and when frozen at relatively high temperatures, the fruits contract rather than expand in volume. However, when they are subjected to lower temperatures which freeze the entire fruit rapidly, an expansion in volume occurs.

The increase in volume of sirups of various concentrations, when prepared at room temperature and frozen at $0^{\circ}$ to $5^{\circ} \mathrm{F}$, was determined (see table 7). Apple juice increases about 8.3 per cent on freezing and cooling to $\mathrm{o}^{\circ} \mathrm{F}$; orange juice, about 8 per cent.

An average increase in volume of 4.0 per cent was found for whole raspberries frozen at $0^{\circ} \mathrm{F}$ and of 6.3 per cent for crushed raspberries. At the same temperature, whole strawberries increased 3.0 per cent, strawberries with added sugar in the ratio of $2: 1$ increased 1.2 per cent, and crushed strawberries increased 8.2 per cent. 
Owing to the collapse of fruit, release of intercellular gases, and osmotic action of the added sugar or sirup, a decrease in volume occurs upon thawing. The volume occupied by fruit which has been subjected to freezing and thawing is considerably less than that occupied by the fruit when fresh. The average decrease in volume of untreated strawberries was found to be about 6.8 per cent; of raspberries without sirup, 5.6 per cent; and of strawberries packed with sugar in the ratio of $2: 1,4.2$ per cent. This decrease is responsible for the apparent "slack fill" in containers of frozen-pack berries. These results represent actual changes in volume of the fruits.

Owing to shrinkage in volume upon thawing, a decrease in the depth of berries in the container occurs. The reduction in depth is naturally more pronounced for whole, untreated berries than for berries packed in sirup. The apparent decrease in volume of blackberries, loganberries, raspberries, and strawberries in No. 10 friction-top cans, after thawing, was found to be 31.5 , 27.8 , 38.2, and 26.4 per cent, respectively. In berries packed in sirup, the decrease in volume varied from none to 3 per cent. In berries packed with sugar, it varied from 4 to 6 per cent, based on the initial volume before freezing.

An allowance of 10 per cent of the volume in a given container is usually sufficient when freezing occurs uniformly throughout. Nonuniform freezing, however, may burst even a slack filled and lightly closed container. Ice formation occurs in regions of lowest temperature and continues into regions of higher temperature. In large containers, ice forms at the inner surfaces exposed to the refrigerant and moves toward the center, and in liquid products, such as juices, the soluble solids concentrate in the warmer section. It is desirable to fill the container and freeze it so that it is completely full when freezing is completed, with no air voids present. In partially filled containers, desiccation may occur during freezing storage, with movement of water vapor, by sublimation, from the exposed surfaces though the air voids to the coldest surface in the container-usually the upper surfaces-where ice formation will occur. In paperboard boxes, freezing under pressure is the most efficient method of obtaining complete fill and full protection against in-the-package desiccation. Prepackaged foods, quick-frozen under pressure, will be more uniformly frozen, and occupy less volume per unit weight. They will freeze faster than those frozen without pressure, and the packages will retain their shape better even when made with lighter weight chipboard, thus facilitating casing.

Weight.-A decrease in the weight of frozen fruit occurs during and after thawing. This decrease is caused by the water which separated as ice during freezing and was not reabsorbed during thawing, by leakage of fluids through tissues injured by freezing, and by the osmotic action of the sugar or sirup. It does not depend entirely upon tissue disorganization, since it is offset in part by absorption of sugar in the case of sugar- and sirup-pack fruits, but it does depend, to a large extent, upon the handling of the product during thawing 
and draining. It is difficult to remove all of the added and exuded juice, sirup, or water from the product by draining after thawing. This loss in weight also depends on length of storage and on storage conditions, and usually increases with length of storage. It amounts to about 20 per cent to 40 per cent in samples stored at $0^{\circ} \mathrm{F}$ for a year, thawed for about 16 hours at room temperature, and drained 2 minutes over a $1 / 8^{-i n c h}$ mesh screen (Joslyn and Marsh, 1933).

\section{Table 8}

COMPARISON OF LOSS IN WEIGHT OF BANNER STRAWBERRIES
IN CANE-SUGAR SIRUP AND IN INVERT-SUGAR SIRUP*

\begin{tabular}{|c|c|c|}
\hline \multirow{2}{*}{ Concentration of sirup } & \multicolumn{2}{|c|}{ Loss in weight } \\
\hline & Cane-sugar sirup & Invert-sugar sirup \\
\hline degrees Balling & per cent & per cent \\
\hline 10. & 37.4 & 34.3 \\
\hline 20. & 34.1 & 31.3 \\
\hline 30. & 27.5 & 30.2 \\
\hline 40. & 29.1 & 29.3 \\
\hline $50 \ldots \ldots \ldots \ldots \ldots$ & 26.5 & 27.8 \\
\hline $60 \ldots \ldots \ldots \ldots \ldots \ldots \ldots$ & 31.7 & 28.8 \\
\hline $65 \ldots \ldots \ldots \ldots \ldots \ldots \ldots$ & 26.2 & 32.3 \\
\hline
\end{tabular}

* From: Joslyn, M. A., and G. L. Marsh. Changes occurring during freezing storage and thawing of fruits and vegetables. Calif. Agr. Exp. Sta. Bul. 551:22(1933).

In general, in results reported by Joslyn (1930b) and Joslyn and Marsh (1933), the loss varied with the kind and character of fruit and was greatest in water and least in sirups of certain concentrations. The change in Balling degree of sirup was greater where the change in weight was greater. The loss in weight as a result of the freezing and thawing did not vary in a regular manner with the concentration of sirup and there was no definite relation between loss in weight and concentration of sirup, such as would be expected if osmotic action alone were responsible for the loss in weight. The loss in weight of apricots decreased with increase in the ratio of fruit to added cane sugar, but the results for Banner strawberries were rather variable. The substitution of cerelose for cane sugar increased the loss in weight to some extent. The substitution of invert sugar testing $76.3^{\circ} \mathrm{Bal}$. also decreased the loss in weight. However, in these tests there was no direct relation between the ratio of fruit to sugar and the loss in weight. The data reported by Wiegand (1931) indicate that, in some instances, the loss in weight of berries frozen with sugar increased as the ratio of fruit to sugar decreased, and in others there was no continuous and regular increase. Diehl et al. (1930) report that an increase in the concentration of cane sugar resulted in an increase in the amount of water extracted as shown by increased percentages of soluble solids in the fruit.

A further comparison between invert and cane sugar, made up in sirups, is 
shown in table 8 . The increase in loss of weight in strawberries, in some but not all of the concentrations of sirups used, however, was not so large as would be expected from the molecular size of the two sugars. The osmotic pressure of invert-sugar sirup is roughly twice that of cane-sugar sirup. Apparently other factors besides osmotic pressure are involved in loss in weight upon thawing.

Similar erratic results were obtained in a test with sliced Phillips Cling peaches. In two cases, the loss in weight in invert-sugar sirup solutions was about three times that in cane-sugar solutions of the same concentration, but in other cases, the loss in weight in invert-sugar sirup was less than in cane- or beet-sugar sirup. The variety of fruit markedly affects loss in weight. With strawberries, it was found to be less in Banner and greatest in Capitola. With freestone peaches, it is greater in Elberta and least in Rio Oso Gem. Clingstone peaches, in general, show less loss in weight than freestones. The loss in weight also increases with increase in length of storage.

Relations of Loss in Weight to Texture--The free drip, or loss in weight during thawing, has often been used as an acceptable index of the change in the colloidal state and degree of disorganization of flesh products. Woodroof (1936) reported that "the quantity of fluid lost by the cell through leakage to the outside, loss of original turgidity and degree of fragmentation of the precipitated protoplasm were in direct proportion." Joslyn and Marsh (1933) found that, in general, there was a complete loss of crispness upon freezing; the juicy portions became soft and flabby, and the fibrous portions became tough. There was not an even distribution of tenderness such as has been reported for flesh products. There was some relation between the degree of retention of original shape and turgidity, and loss in weight. The greater the loss in weight, the more severely was the texture disorganized. Fruits packed in sirup retained their structure better than those packed with dry sugar, even though the loss in weight for the latter may have been less.

\section{HEAT-TRANSFER DETERMINANTS}

The temperature changes in the product at the point of slowest rate of cooling are a measure of the suitability of conditions to the preservation of the product and are useful in evaluating the method of freezing used. If the product cools too slowly, it may spoil before it is completely frozen; if it warms too rapidly on thawing, it may spoil during distribution unless rigorous care is taken to insure proper refrigeration.

The rate at which a commodity freezes is dependent upon two sets of factors, those concerned with the nature of the product-its thermal properties, dimensions, and initial temperature-and those concerned with the freezing medium -its thermal properties, temperature, and velocity. Extensive investigations of the thermal properties of fruit products were conducted in this division in 1930-1932, and the results obtained have been reported previously (Joslyn and 
Marsh, 1930, 1932b, 1932c). The data, together with other information, are summarized in the following discussion.

Stages of Freezing.-Temperature measurements show, as indicated in figure 4 , that the temperature changes in the center of a container of food during freezing are naturally divided into three intervals. During the first interval,

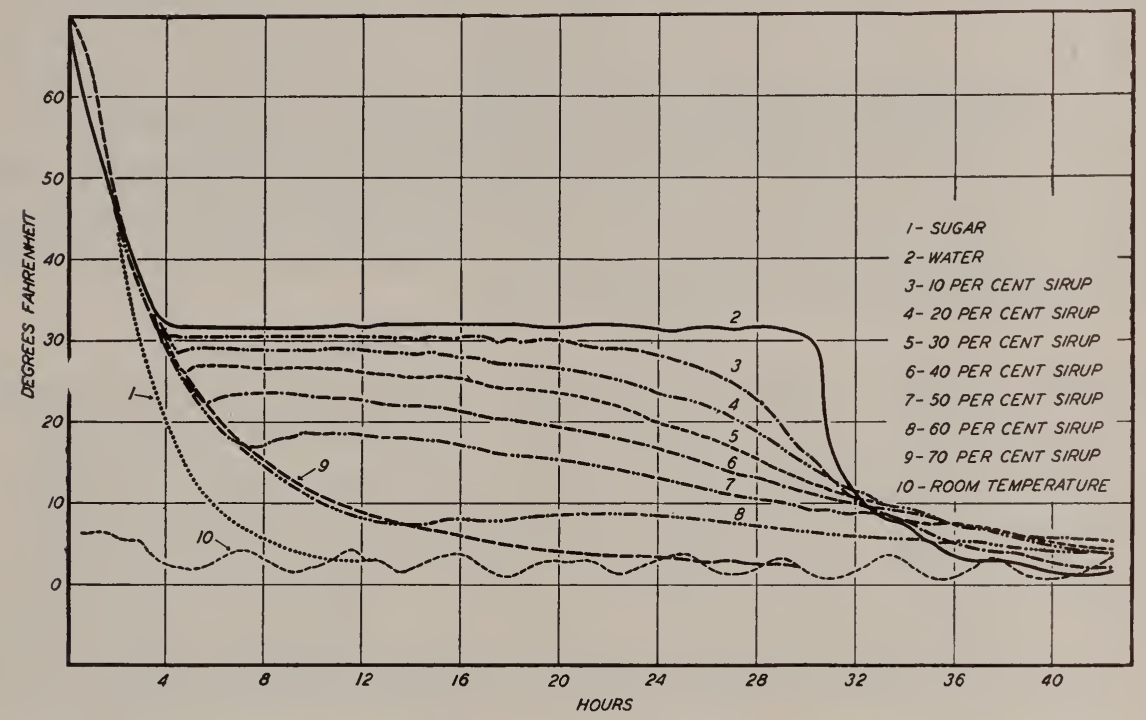

Fig. 4. - Temperature changes in No. 10 cans of water, cane sugar, and sirups during freezing. (From Bul. 551.)

the chilling stage, the temperature is lowered gradually to the initial freezing point, i.e., initial stage of ice formation. Heat transfer, even in this initial stage, is mainly by conduction, so that the specific heat and over-all heat conductivity are the limiting factors at a constant temperature gradient. It is for this reason that, unlike heat transfer during heat processing, the rate of cooling is faster as the sugar content is increased. The specific heat of water and sugar solutions, in the range of $32^{\circ}-80^{\circ} \mathrm{F}$, was found by Short (1944) to be as follows:

PRODUCT SPECIFIC HEAT

Water ................ $\mathbf{1 . 0 0}$

5 per cent sugar solution........ 0.97

10 per cent sugar solution......... 0.94

15 per cent sugar solution.......... 0.92

20 per cent sugar solution......... 0.86

30 per cent sugar solution. . . . . . . 0.85

50 per cent sugar solution......... 0.76

The specific heat for several fruits was reported as follows: apples $(83.7$ per cent water), -0.89 ; grapes (79.3 per cent water), -0.85 ; oranges (80.7 per cent 
water), -0.91 ; peaches (89.6 per cent water), -0.91 ; strawberries (90.9 per cent water), -0.96 ; figs (9o per cent water), -0.71 .

As cooling proceeds, a temperature is finally reached at which ice separates, and in the second interval, the zone of maximum ice formation, the center of the mass is at a fairly constant temperature since the material has cooled to its freezing zone and heat is liberated by change of water to ice. The extent of ice formation in this zone is illustrated by the following data for sugar solutions obtained by Short.

\begin{tabular}{|c|c|c|}
\hline $\begin{array}{l}\text { PER CENT } \\
\text { CONCENTRATION }\end{array}$ & & PER CENT FROZEN IN \\
\hline $\begin{array}{l}\text { CONCENTRATION } \\
\text { OF SUGAR }\end{array}$ & $\begin{array}{l}\text { FREEZING } \\
\text { POINT }\end{array}$ & $\begin{array}{l}\text { REGION OF FREEZING } \\
\text { POINT TO } 20^{\circ} \mathrm{F}\end{array}$ \\
\hline 0 (water) & 32 & 100 \\
\hline 5 & 31.4 & 96.7 \\
\hline 10 & 30.9 & 93.4 \\
\hline 15 & 29.8 & 91.2 \\
\hline 20 & 29.5 & 85.6 \\
\hline 30 & 27.5 & 75.1 \\
\hline 50 & . 24.9 & 53.8 \\
\hline
\end{tabular}

In general, as the sugar content increases, the freezing zone becomes lower in temperature, and the period of fairly constant temperature is shorter. The heat evolved during ice formation for water is 143.4 B.T.U. per pound; the latent heat of fusion for foods was found by Woolrich (1933) to be the latent heat of water multiplied by the percentage of water present in the food. Thus, for fruits of 90 per cent moisture content, it would be $143.4 \times 90 / 100$ or 129 B.T.U. per pound.

In the third interval, during which ice formation continues but at a lower rate, the temperature drops and gradually approaches that of the refrigerant. This zone represents essentially the cooling of the frozen product and temperature changes in it are slower than in that above freezing. In this stage, the cooling of frozen sirups is slower than that of ice and decreases as the sugar concentration increases. The slow cooling in this stage is due not only to the lowered specific heat, and heat conductivity, but also to the lower temperature gradient. The specific heat of the frozen sirup is not constant in this range, but decreases with decrease in temperature. At $0^{\circ} \mathrm{F}$, Short (1944) gives the specific heat of the frozen sirups, and several fruits, as follows:

\begin{tabular}{|c|c|c|c|}
\hline SIRUPS, PER CENT & SPECIFIC HEAT & FRUIT & SPECIFIC HEAT \\
\hline 0 (ice) $\ldots$ & $\ldots 0.50$ & Apples & 0.69 \\
\hline $5 \ldots$ & 0.52 & Grapes & 1.01 \\
\hline 10 & 0.63 & Peaches & 0.77 \\
\hline 15 & 0.70 & Figs & 0.76 \\
\hline 20 & 0.77 & Oranges & 0.76 \\
\hline 30 & 0.92 & Strawberries & 0.68 \\
\hline 50 & 1.07 & & \\
\hline
\end{tabular}




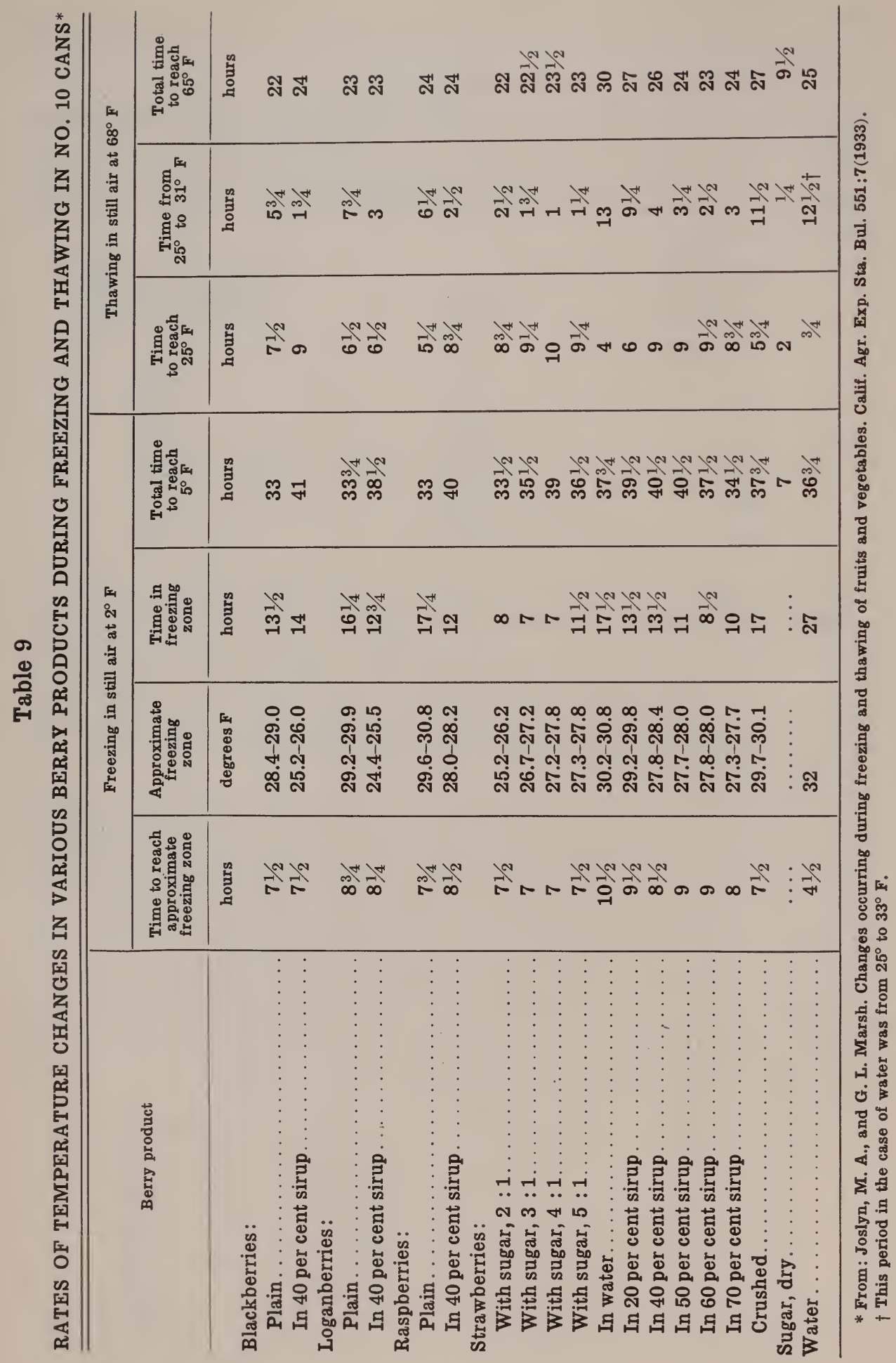


In general, the concentration and type of soluble solids present influence the thermal properties of fruit and fruit products more than cellular structure.

During defrosting in No. 10 cans, the rates of temperature change in water and sugar solutions, which are typical of other products, are shown in figure 5 . The rate of temperature rise in general was affected by soluble solids, as above.

Temperature Changes in Various Products.-In general, the rate and nature of temperature changes were found to be similar to those in sugar solutions. The solid and semisolid products cooled more slowly to the freezing zone, and

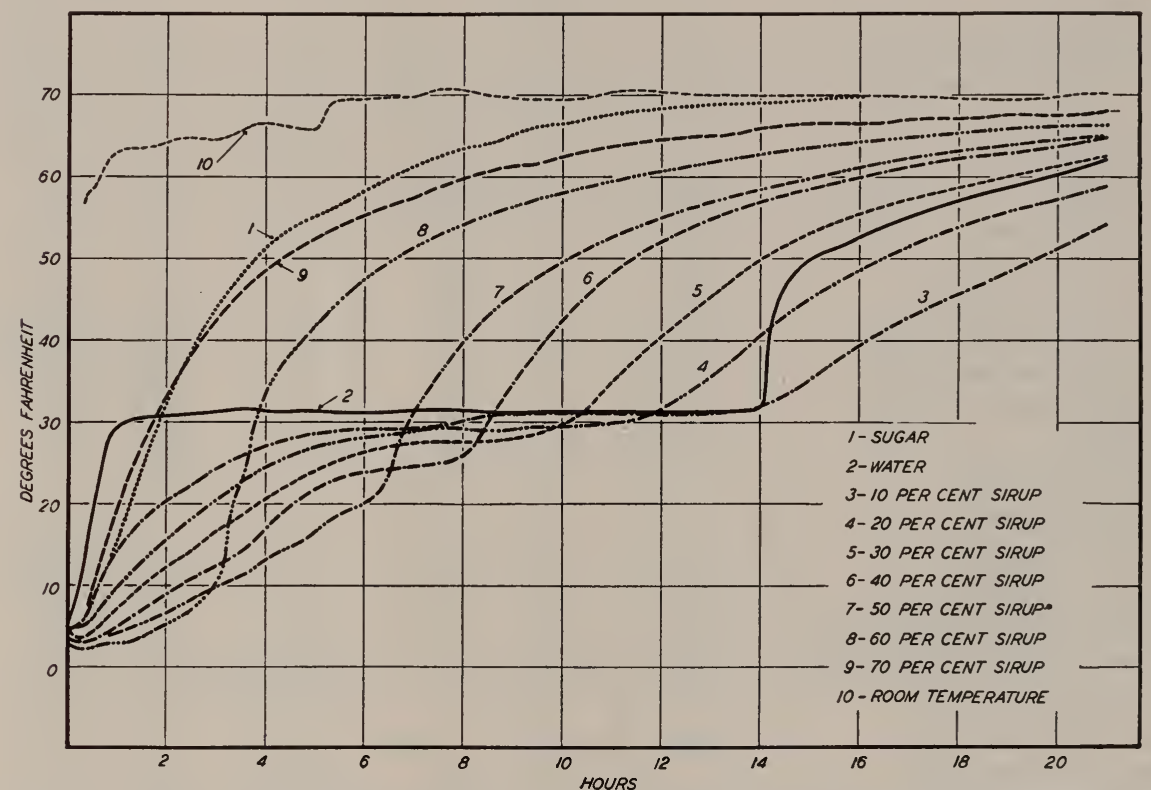

Fig. 5.-Temperature changes in No. 10 cans of water, cane sugar, and sirups during thawing. (From Bul. 551.)

below, than did water. Where the separation of much ice occurred, the products thawed more slowly than did water. Products such as Royal Anne cherries in sirup did not differ appreciably in behavior from pasty products, such as prune pulp. Typical of the data are the rates of temperature change in berries packed with sugar or sirup, in No. 10 cans in still air, shown in table 9. The data indicate how the proportion of fruit to sugar or the concentration of sirup used affects the rate of heat transfer. No very marked differences were found in the rates of temperature change of the various berries in $40^{\circ} \mathrm{Bal}$. sirup. The rates of temperature change increased somewhat with increase in the proportion of sugar to fruit and with the concentration of sirup used. The increase in rate of temperature change with increase of concentration of sirup in the presence of berries was not so great as for the sugar solutions that did not contain berries. 


\section{Table 10}

RATES OF TEMPERATURE CHANGES IN 40 PER CENT SIRUP IN TIN, PAPER, AND GLASS CONTAINERS OF VARIOUS SIZES IN STILL AIR*

\begin{tabular}{|c|c|c|c|c|c|c|}
\hline \multirow[b]{2}{*}{ Container } & \multicolumn{3}{|c|}{ Freezing period at $2^{\circ} \mathrm{F}$} & \multicolumn{3}{|c|}{ Thawing period at $68^{\circ} \mathrm{F}$} \\
\hline & $\begin{array}{l}\text { Time } \\
\text { to reach } \\
31^{\circ} \mathrm{F}\end{array}$ & $\begin{array}{l}\text { Time } \\
\text { from } 31^{\circ} \\
\text { to } 25^{\circ} \mathrm{F}\end{array}$ & $\begin{array}{c}\text { Time } \\
\text { to reach } \\
5^{\circ} \mathrm{F}\end{array}$ & $\begin{array}{c}\text { Time } \\
\text { to reach } \\
25^{\circ} \mathrm{F}\end{array}$ & $\begin{array}{l}\text { Time } \\
\text { from } 25^{\circ} \\
\text { to } 31^{\circ} \mathrm{F}\end{array}$ & $\begin{array}{c}\text { Time } \\
\text { to reach } \\
65^{\circ} \mathrm{F}\end{array}$ \\
\hline & hours & hours & hours & hours & hours & hours \\
\hline 4-ounce can. . & $3 / 4$ & $1 / 4$ & 6 & $11 / 4$ & $1 / 2$ & 6 \\
\hline 8 -ounce can............. & $11 / 4$ & $1 / 4$ & $81 / 2$ & 2 & $1 / 4$ & $61 / 2$ \\
\hline 6-ounce flat can.......... & $11 / 4$ & $1 / 4$ & $73 / 4$ & 2 & $1 / 2$ & $61 / 2$ \\
\hline No. 1 Eastern oyster can.... & $11 / 4$ & $1 / 4$ & $81 / 2$ & 2 & $1 / 2$ & $61 / 2$ \\
\hline No. 1 tall can........... & $11 / 2$ & $1 / 4$ & $111 / 2$ & $23 / 4$ & $1 / 2$ & $81 / 2$ \\
\hline No. 2 tall can......... & $11 / 2$ & $1 / 2$ & 13 & $23 / 4$ & $3 / 4$ & $91 / 2$ \\
\hline No. $2 \frac{1}{2}$ can......... & $13 / 4$ & $1 / 2$ & 15 & $33 / 4$ & 1 & 12 \\
\hline 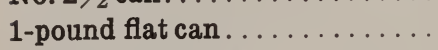 & $11 / 4$ & $1 / 4$ & 12 & $21 / 2$ & $1 / 2$ & $81 / 2$ \\
\hline No. 10 Sanitary can. ....... & $31 / 2$ & 1 & 31 & 8 & 1 & 24 \\
\hline No. 10 friction-top can..... & $31 / 4$ & $11 / 4$ & 30 & $71 / 2$ & $11 / 4$ & $231 / 2$ \\
\hline 10-pound friction-top can. . & $41 / 4$ & $11 / 2$ & 40 & $101 / 2$ & $11 / 2$ & $281 / 2$ \\
\hline 15-pound friction-top can. . & $43 / 4$ & $11 / 2$ & 45 & $91 / 2$ & $21 / 2$ & 30 \\
\hline 30-pound friction-top can. . & 7 & 2 & 65 & 15 & $41 / 2$ & 47 \\
\hline 5 -gallon can .............. & $53 / 4$ & $11 / 2$ & 61 & 16 & $51 / 2$ & 46 \\
\hline 4-ounce Mono tub. . . . . . . . . & $3 / 4$ & $1 / 4$ & $61 / 2$ & 1 & $1 / 2$ & 6 \\
\hline 8-ounce Mono tub. . . . . . . . & 1 & $1 / 4$ & $73 / 4$ & $11 / 2$ & $3 / 4$ & 7 \\
\hline 16-ounce Mono tub. . . . . . . . & 1 & $3 / 4$ & $101 / 2$ & $21 / 4$ & $1 / 2$ & $91 / 2$ \\
\hline 32-ounce Mono tub. . . . . . . & 2 & $3 / 4$ & $131 / 2$ & $33 / 4$ & $11 / 2$ & 13 \\
\hline 16-ounce Tulip Nestrite cup. . & $1 \frac{1}{4}$ & $1 / 2$ & $101 / 2$ & $23 / 4$ & $1 / 2$ & 9 \\
\hline 32-ounce Tulip Nestrite cup. . . & $13 / 4$ & $3 / 4$ & 13 & $21 / 4$ & 1 & $123 / 4$ \\
\hline 8-ounce Purity P. B......... & $11 / 4$ & $1 / 4$ & 5 & $13 / 4$ & 1 & 8 \\
\hline 16-ounce Purity P. B........ & $11 / 2$ & $1 / 2$ & $11 \frac{1}{2}$ & 3 & $3 / 4$ & $101 / 2$ \\
\hline 32-ounce Purity P. B....... & 2 & $3 / 4$ & 14 & $33 / 4$ & $3 / 4$ & 15 \\
\hline 64-ounce Purity P. B....... & $23 / 4$ & 1 & 20 & $51 / 2$ & $1 / 2$ & 19 \\
\hline 4-ounce glass bottle..... & $3 / 4$ & $1 / 4$ & $61 / 4$ & $11 / 4$ & $1 / 2$ & 5 \\
\hline 8 -ounce glass bottle......... & 1 & $1 / 4$ & 8 & $13 / 4$ & $1 / 4$ & 7 \\
\hline 12-ounce glass bottle. . . . . . . & $11 / 4$ & $1 / 2$ & 9 & $2 \frac{1}{4}$ & $1 / 4$ & 7 \\
\hline 32-ounce glass bottle. . . . . . . . & $13 / 4$ & $1 / 2$ & $12 \frac{1}{2}$ & $31 / 2$ & $1 / 4$ & $101 / 2$ \\
\hline 16-ounce Mason jar. . . . . . . . . & $11 / 4$ & $1 / 2$ & $91 / 4$ & $23 / 4$ & $1 / 4$ & $71 / 2$ \\
\hline 32-ounce Mason jar......... & $13 / 4$ & $1 / 2$ & 12 & $31 / 2$ & $1 / 4$ & 10 \\
\hline 1-gallon jug. . . . . . . . . . . & $31 / 4$ & $11 / 4$ & $281 / 2$ & 8 & $11 / 4$ & 22 \\
\hline 5 -gallon jug . . . . . . . . . . . . & $53 / 4$ & $11 / 4$ & 63 & 17 & 3 & 45 \\
\hline 4-ounce milk bottle . . . . . . . & 1 & $1 / 4$ & $61 / 4$ & $11 / 4$ & $1 / 4$ & $41 / 2$ \\
\hline
\end{tabular}

* From: Joslyn, M.A., and G.L. Marsh. Changes occurring during freezing storage and thawing of fruits and vegetables. Calif. Agr. Exp. Sta. Bul. 551:10(1933).

Effect of Type, Size, and Shape of Container.-The rate of heat transfer, especially where it is limited to conduction, depends to a large extent on the size and shape of the container. In containers of equal capacity, the greater the surface exposed to the refrigerating medium, the more rapid is the cooling. The rate of heat transfer in 40 per cent sirup in tin cans of various sizes was 
found not to be directly proportional to the surface exposed per unit volume of contents, but to increase progressively with increase in the size of the container and with increase in surface exposed per unit volume. The extent of the difference in rate of temperature change between containers of various size and kind is shown in table 10.

The rates of temperature change in various paper and glass containers decreased progressively as the size of the container increased. It is impossible, however, from the above data, to show whether the size, shape, or the material from which the container was constructed was most important in determining the rate of temperature change. It was found that the rates of cooling and

Table 11

RATE OF TEMPERATURE CHANGES IN BERRY PRODUCTS DURING FREEZING IN BARRELS AT $0^{\circ} \mathrm{F}^{*}$

\begin{tabular}{|c|c|c|c|c|}
\hline Berry product & $\begin{array}{l}\text { Time to reach } \\
\text { approximate } \\
\text { freezing zone }\end{array}$ & $\begin{array}{l}\text { Approximate } \\
\text { freezing zone }\end{array}$ & $\begin{array}{l}\text { Time } \\
\text { in freezing } \\
\text { zone }\end{array}$ & $\begin{array}{c}\text { Total time } \\
\text { to reach } \\
10^{\circ} \mathrm{F}\end{array}$ \\
\hline & days & degrees $F$ & days & days \\
\hline Strawberries: & & & & \\
\hline Without sugar. . & & $27.5-28.5$ & & \\
\hline With sugar $1: 1$. & 3 & 20-22 & 2 & 7 \\
\hline $2: 1$ & $31 / 2$ & $23-25$ & $4-5$ & over 9 \\
\hline $3: 1$ & $31 / 2$ & $25-26$ & 5 & $\ldots \ldots$ \\
\hline $4: 1 \ldots$ & $\ldots \ldots$ & $\ldots \ldots$ & $\ldots \ldots$ & $\ldots \ldots$ \\
\hline Raspberries: & & & & \\
\hline With sugar $2: 1$. & $3 \frac{1}{2}-4$ & 23-25 & 4 & over 9 \\
\hline Without sugar.... & 4 & $27.5-28.5$ & 4 & $\ldots \ldots$ \\
\hline
\end{tabular}

* Source of data: Diehl, H. C., et al. The frozen-pack method of preserving berries in the Pacific North west. U. S. Dept. Agr. Tech. Bul. 148.

warming in the pint cylindrical Purity Paper Bottles, the pint, tall Nestrite cup, the squat, 16 -ounce Kleen Kup, and the 16 -ounce flat tin can used by the industry for freezing storage of fruits did not vary materially from each other. Because the small containers were of different shapes and wall thicknesses, the effect of the materials, such as paper, glass, and tin, could not be determined accurately. However, it appeared that there was little difference in the rates of cooling and thawing of products in containers of similar size and shape.

Effect of Initial Temperature.-The data presented in table 12 indicate the extent to which increasing the initial temperature increases the time necessary to reach the freezing temperature. This effect is more marked in larger containers, and precooling of fruit to be frozen in $5^{0}$-gallon barrels is necessary to minimize danger of fermentation during freezing. In any case, the fruit should be below $70^{\circ} \mathrm{F}$ at the time of packing. In larger containers, however, the rate of cooling in still air at $o^{\circ} \mathrm{F}$ is very slow. Temperature changes in barreled berries are shown in table 11 . In these, the temperature of the fruit at the center may remain above $40^{\circ} \mathrm{F}$ for over 36 hours. Loss by fermentation 
occasionally occurs in fruits packed in this manner, especially when sugar is not added. In 5-gallon cans, 14 to 23 hours are required to cool the contents at the center from $70^{\circ} \mathrm{F}$ to the freezing zone, and the period of time in the freezing zone is from 4 to 11 hours depending on sugar content, and the total freezing time is over 36 hours. In 5 -gallon barrels, about 20 hours are required

Table 12

EFFECT OF INITIAL TEMPERATURE ON RATE OF TEMPERATURE CHANGE IN WATER, SIRUP, AND PRUNE PULP DURING FREEZING*

\begin{tabular}{|c|c|c|c|c|c|}
\hline Product & $\underset{\text { tempera- }}{\text { Initial }}$ & $\begin{array}{l}\text { Time } \\
\text { to reach } \\
\text { freezing } \\
\text { zone }\end{array}$ & $\begin{array}{l}\text { Freezing } \\
\text { zone }\end{array}$ & $\begin{array}{c}\underset{\text { Time }}{\text { in }} \\
\text { freezing } \\
\text { zone }\end{array}$ & $\begin{array}{l}\text { Time } \\
\text { to } \\
\text { reach } \\
0^{\circ} \mathrm{F}\end{array}$ \\
\hline \multirow{7}{*}{ Water. } & degrees $F$ & hours & degrees $F$ & hours & hours \\
\hline & 179.0 & $81 / 2$ & 32 & $181 / 2$ & 30 \\
\hline & 139.3 & 8 & 32 & 19 & $291 / 2$ \\
\hline & 110.6 & $71 / 2$ & 32 & 19 & $283 / 4$ \\
\hline & 73.1 & $43 / 4$ & 32 & $18 \frac{3}{4}$ & $261 / 2$ \\
\hline & 54.8 & $31 / 4$ & 32 & 19 & $261 / 4$ \\
\hline & 39.2 & $13 / 4$ & 32 & 20 & $253 / 4$ \\
\hline \multirow{6}{*}{ Sirup, 40 per cent. } & 181.3 & 10 & $16.0-16.3$ & $41 / 2$ & 29 \\
\hline & 139.7 & $91 / 2$ & $18.5-20.0$ & 7 & $293 / 4$ \\
\hline & 112.6 & 8 & $18.7-21.0$ & $91 / 2$ & $281 / 4$ \\
\hline & 73.1 & $61 / 2$ & $18.7-21.2$ & $121 / 2$ & 29 \\
\hline & 56.1 & $51 / 2$ & $18.7-21.2$ & $12 \frac{1}{2}$ & 28 \\
\hline & 40.2 & $43 / 4$ & $18.8-21.2$ & 10 & $23 \frac{3}{4}$ \\
\hline \multirow{6}{*}{ Prune pulp. . } & 161.9 & 16 & $15.7-16.3$ & 4 & $31 \frac{1}{2}$ \\
\hline & 134.3 & 14 & $15.7-16.3$ & 6 & $283 / 4$ \\
\hline & 106.5 & 12 & $15.7-16.3$ & 7 & 28 \\
\hline & 73.7 & 11 & $15.7-16.3$ & $71 / 2$ & $301 / 2$ \\
\hline & 53.6 & 9 & $15.7-16.3$ & $71 / 2$ & $263 / 4$ \\
\hline & 34.1 & $71 / 2$ & $15.7-16.3$ & $51 / 2$ & $271 / 2$ \\
\hline
\end{tabular}

* From: Joslyn, M. A., and G. L. Marsh. Changes occurring during freezing storage and thawing of fruits and vegetables. Calif. Agr. Exp. Sta. Bul. 551:11(1933).

to cool to freezing, 28 hours in the freezing zone, and 108 hours to freeze from $70^{\circ} \mathrm{F}$ to $10^{\circ} \mathrm{F}$. In 10-gallon barrels, the times for these periods are 36,32 , and 124 hours, respectively. Agitation during freezing, such as by rolling, markedly reduces the freezing time.

The presence of air spaces in the container, particularly between the inner surfaces and the product, and in the outer wrapper, markedly reduce freezing time. Care should be taken to fill the container completely; have the inner lining, or bag, and the outer wrapper as tight as possible. In plate freezers and in air freezing in. a suitably constructed frame, freezing under pressure will reduce the freezing time from one third to one half of that required for freezing without pressure. 
Diehl et al. (1930) reported that the addition of 5 pounds of ice to the center of a 5 o-gallon barrel of raspberries reduced the temperature at the center and increased rate of cooling. The fruit at the center of the barrel packed with ice reached $40^{\circ} \mathrm{F}$ in one and one-half days, while that in the barrel without ice required more than two and one-half days to reach the same temperature. Precooling the berries before packing is a more desirable practice.

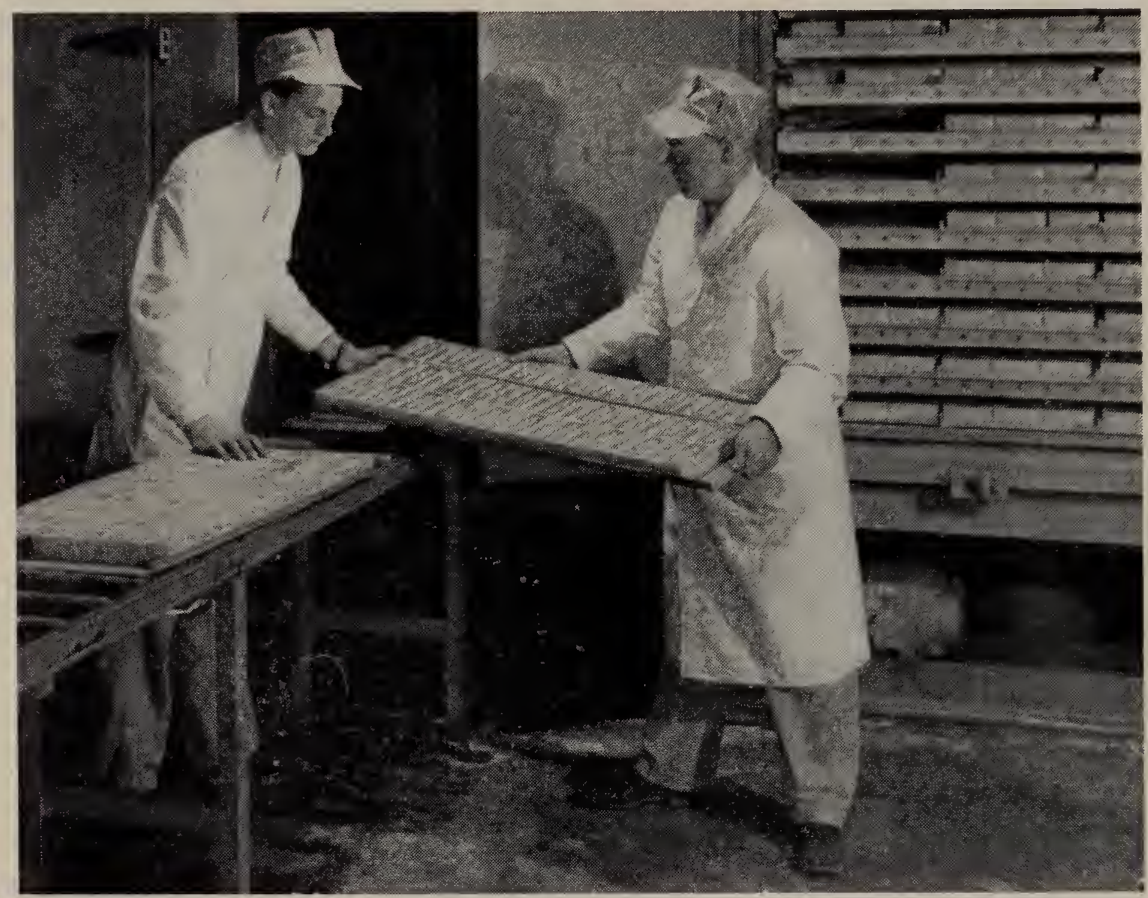

Fig. 6.-Multiplate quick freezer in loading position. (Courtesy of Birdseye Frosted Foods.)

Effect of Freezing Medium.-Except in the case of fruit frozen in barrels for preservers' use, still air is not used commercially in freezing as it is a particularly poor heat-transferring medium. Air blast freezers, either of the short tunnel type, or the more efficient, progressive cross-draft type, and contact freezers, such as plate or immersion freezers, are commonly used. In the air freezers, advantage is taken of the increase in rate of freezing with increase in air velocity. Perry (1938) has shown that doubling the air velocity can be expected to increase the heat transfer coefficient about 60 per cent and to reduce the freezing time between 27 and 40 per cent. Doubling the air velocity, however, produces four times the velocity energy and friction loss and requires eight times the fan power. Not only is the initial and power cost of fans greater, but the fan energy which is dissipated as heat must be removed by the refrigeration system. In commercial practice the most economical air velocity for small packages (about 1 or 2 pounds) and for tray or belt freezing is $6_{5} \mathrm{o}$ lineal 
feet per minute. For larger containers (about 20 pounds) air velocities as high as 2,00o lineal feet per minute have been suggested. Where air is used as a freezing medium, particular care should be taken to obtain uniform distribution of air over all the exposed surfaces of the product to be frozen, otherwise much of its effectiveness will be lost.

The temperature of the air also affects rate of freezing but its greatest effect is in the zone of maximum ice formation and in the final cooling. In the initial stages, lower temperatures do not accelerate cooling so much. Thus Perry found that an air temperature of $-10^{\circ} \mathrm{F}$ will give about 18 per cent faster initial cooling, 28 per cent faster freezing, and $4^{8}$ per cent faster final cooling than an air temperature of $o^{\circ} \mathrm{F}$. This effect is used to advantage in the multistage, cross-draft freezers in which the air temperature is progressively decreased in each succeeding stage (Finnegan, 1938). In air blast freezers of the tunnel type, air temperatures of $-30^{\circ} \mathrm{F}$ are used to obtain freezing times of about 3 hours for 1-pound packages, and 6 to 8 for 2- to 5 -pound ones.

Air as a freczing medium is poor in comparison with liquid refrigerants. Because of its relatively low specific heat (0.238), a large volume of air must be recirculated (approximately $50 \mathrm{cu}$. ft. to remove 1 B.T.U. per degree of air temperature rise) to maintain a desirable rise of the air temperature $\left(4^{\circ} \mathrm{F}\right)$ during its passage over the food being frozen. Liquid refrigerants, such as brine or alcohol, are more efficient, but their use is limited to rigid, liquidtight containers (Finnegan, 1935). Canned fruits and fruit products may be quickly and economically frozen either in a tubular freezer, in which the liquid refrigerant is rapidly passed over the surface of the can as it moves through, or in an agitating immersion freezer, in which the cans are rolled or carried through the refrigerant by a spiral conveyor. The freezing medium used in these immersion freezers is a denatured alcohol of the following composition: 100 gallons of ethyl alcohol, 5 gallons of methyl alcohol, 5 gallons of ethyl acetate, and 1 gallon of aviation gasoline. This alcohol medium evaporates from the surface of the container without leaving an objectionable residue such as brine does.

The freezing of food in sealed tin cans, by immersion in alcohol, makes possible a considerable reduction in freezing time as compared with an air blast freezer. The viscosity of alcohol (Wells, 1946), in contrast to that of brine, remains low at temperatures as low as $-100^{\circ} \mathrm{F}$ and thus reduces the cost of pumping. Although the specific heat of alcohol is low, and large volumes must be circulated per ton of refrigeration, the rate of heat transfer is much higher for alcohol than for brine at $-30^{\circ} \mathrm{F}$. Calcium and sodium chloride brines are corrosive both to the freezing equipment and the cans, and leave a residue which makes them sticky and rusty. Alcohol, on the other hand, evaporates rapidly and is noncorrosive. Ethyl alcohol is usually adulterated with methyl alcohol for use in freezing plants. Methyl alcohol has a high specific heat, but must be used with care because of its toxicity. The alcohol residue should be removed from the cans before casing. 
Freezing by direct immersion of fruit in a refrigerant, such as a 57 per cent sirup at $o^{\circ} \mathrm{F}$, can also be used, but at present such use is limited (Woodroof, 1939).

\section{FREEZING STORAGE CONDITIONS}

\section{Fluctuations in temperature of frozen fruits during storage may cause changes in texture, appearance, and palatability. Storage temperature should therefore be maintained as constant as possible in the storage room, in transit by refrigerated cars, in the warehouse, and at the retail outlet.}

Although frozen fruit and fruit products packed with sugar or sirup may be stored at $10^{\circ} \mathrm{F}$ for considerable periods of time, storage at $-5^{\circ} \mathrm{F}$ or $0^{\circ} \mathrm{F}$ is preferred, particularly for the product packed in consumer-size containers. Fluctuations of temperatures during storage, sufficient to cause defrosting and refreezing, should be avoided, as this will cause growth of ice crystals and damage to texture. The degree of fluctuation which produces such damage, however, is not definitely known. It will depend, in general, on the percentage of water remaining unfrozen in the product and the rate at which it changes with change in temperature. In general, the lower the storage temperature, the less will be the change in percentage of water unfrozen with change of temperature. The temperature of the air surrounding the frozen product, particularly if it is packed in large containers or in well-insulated fiberboard cases stacked closely, may fluctuate appreciably without producing significant fluctuation in temperature of the product (in the center of the case or interior of the stack) owing to the slow rate of heat transfer. Rapid fluctuations in temperature are less harmful than slow fluctuations occurring in long cycles. Hustrulid and Winter (1943) reported that fluctuations of $8^{\circ}$ to $10^{\circ} \mathrm{F}$ in air temperatures do not cause appreciable changes in appearance and palatability of frozen fruits and vegetables stored at $5^{\circ} \mathrm{F}$ or below.

Fluctuations in storage temperature are also undesirable because they produce desiccation of the product even in hermetically sealed containers. There will be an appreciable transfer of moisture vapor from the warmer surfaces of the contents to the colder surfaces of the inner walls where it will deposit as ice. The water so lost by sublimation will not be reabsorbed by the product. The storage temperature should be maintained as constant as possible, preferably within $\pm 2^{\circ} \mathrm{F}$, and the temperatures at all points in the stacks and in the room should be uniform. If the storage room is refrigerated with coils (overhead or side), the temperature of the refrigerant in the coils should not be more than $5^{\circ} \mathrm{F}$ below that of the air. Where temperature differences exist, there will be conditions conducive to moisture transfer, by sublimation, from the ice surfaces at higher temperature to the colder surfaces. In-the-package desiccation can be further decreased by eliminating air voids in the container, and filling and freezing under conditions which assure that the container is completely filled after expansion in volume on freezing has occurred. The 
more uniform the temperatures at all points in the product and in the freezing storage room, and the less these temperatures are allowed to fluctuate, the less will be the water loss in the product. The desiccation problem is more important in frozen vegetables than in fruits packed in sirup.

Woodroof and Shelor (1947) recently reported that strawberries, blackberries, raspberries, and peaches frozen without sugar retained their color, flavor, and texture better after 12 months in storage at $-10^{\circ} \mathrm{F}$ than at $-20^{\circ}$

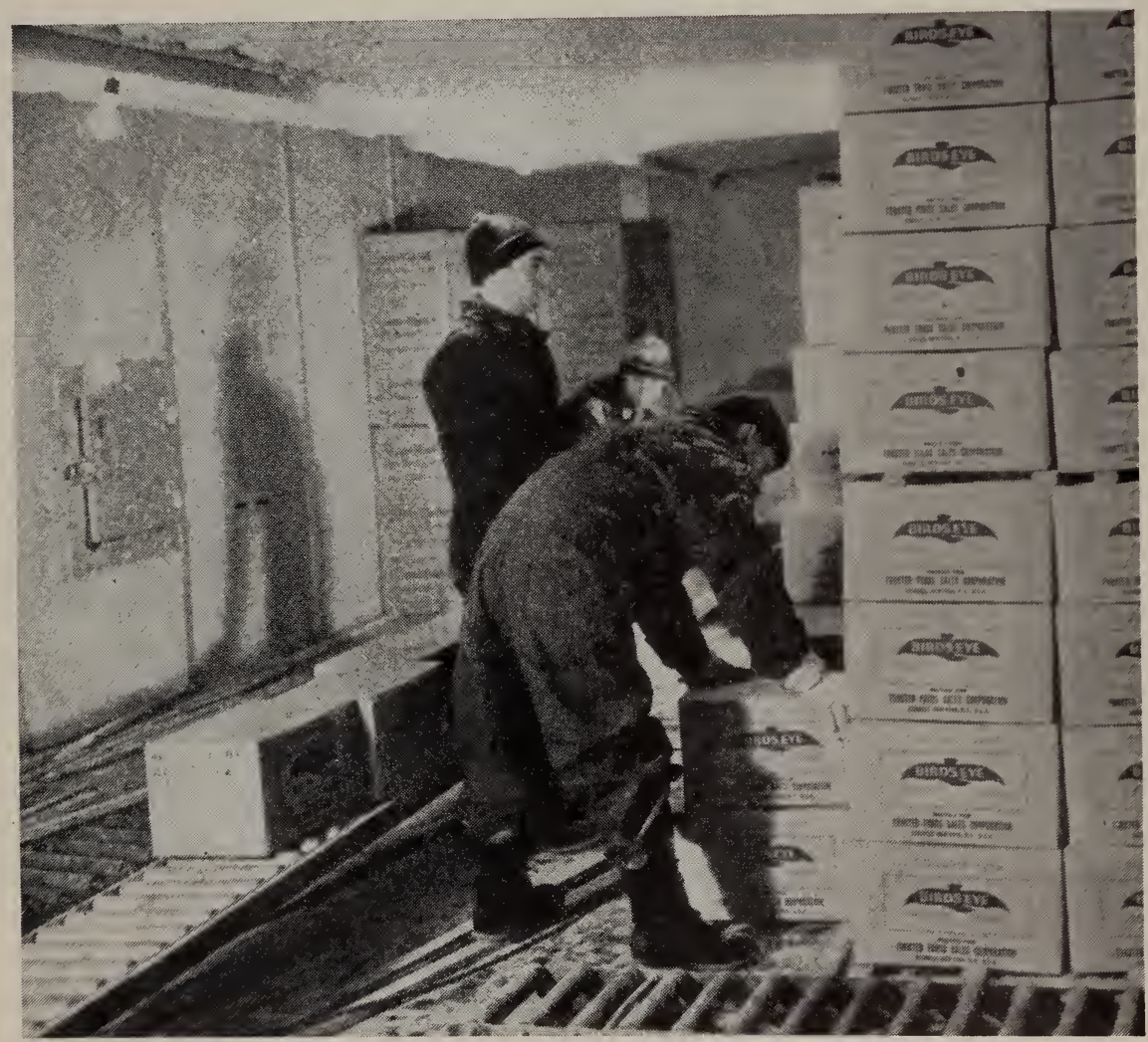

Fig. 7.-Freezing storage of cased products, showing method of stacking and use of dunnage. (Courtesy of Birdseye Frosted Foods.)

to $0^{\circ} \mathrm{F}, 0^{\circ}$ to $10^{\circ} \mathrm{F}$, or $10^{\circ} \mathrm{F}$. Strawberries were in better condition after 12 months' storage at $-10^{\circ} \mathrm{F}$ than after six months at $10^{\circ} \mathrm{F}$. All of the fruits deteriorated more rapidly at a temperature fluctuating from $0^{\circ}$ to $10^{\circ} \mathrm{F}$ than when held constant at $10^{\circ} \mathrm{F}$. Blackberries and raspberries stored at $-10^{\circ} \mathrm{F}$ were superior to those stored at higher temperatures, but the differences were not so great as with strawberries and peaches. Peaches at fluctuating temperatures deteriorated more rapidly in flavor and color than did other fruits and also lost quality more rapidly.

Frozen foods should be protected against temperature rise during transit from processing plant to central warehouses and from warehouse to distrib- 
utor. To minimize this factor, insulated refrigerated cars and trucks should be used for transit and distribution. The product should be cooled to as close to $-10^{\circ} \mathrm{F}$ as possible before loading into the precooled, refrigerated car. Refrigerated cars for fruit express are satisfactory for shipment of frozen food if salt is added to the ice in the bunkers.

In recent investigations (Johnson, 1943) on the the most efficient refrigeration to be used for the rail shipment of frozen foods at different seasons of the year, it was found that in summer, for both end-bunker and top-bunker refrigerated cars, best results were obtained by precooling the cars for 24 hours before loading, by filling the bunkers with ice (crushed ice for overhead bunker cars, and coarse ice for end-bunker cars), and by adding $3^{\circ}$ per cent salt. Under these conditions, an average air temperature of about $15^{\circ} \mathrm{F}$ could be obtained before loading. Loss of refrigeration, ranging from $3^{\circ} \mathrm{F}$ to $16^{\circ} \mathrm{F}$ occurred during loading, but this could be avoided by using a portable tunnel of kapok or dry zero insulation which has a tight fit from the opening in the cold storage warehouse into the car. With 20 per cent added salt, the air temperature was about $5^{\circ} \mathrm{F}$ higher. The cars were 15 days in transit, under standard refrigeration, and the bunkers were filled to capacity with ice and salt at all regular icing stations. These were located at approximately 24 hours of running time apart. The commodities shipped reached New Jersey with a maximum temperature of $15^{\circ} \mathrm{F}$ in the top-bunker cars with $3^{\circ}$ per cent salt, as compared with $20^{\circ} \mathrm{F}$ for the same type car with 20 per cent salt. In the end-bunker cars, the maximum temperatures were about $5^{\circ} \mathrm{F}$ higher in these tests. During shipment in winter, 20 per cent salt would be sufficient.

Recent investigations made by the U. S. Department of Agriculture Bureau of Plant Industries have stressed the importance of zero precooling of frozen foods before shipping them over long hauls by freight. The use of 2,ooo pounds of dry ice per car, in addition to the regular ice and salt refrigeration placed in cartons on the top layer of a carload, failed to lower appreciably the over-all temperature and actually resulted in the subnormal functioning of the car. No marked benefit was obtained by covering the top and bottom of the load with heavy paper so that air would circulate around rather than between the cars.

A temperature rise from $-10^{\circ}$ to $+10^{\circ} \mathrm{F}$ in transit is permissible if the product is quick-frozen upon arrival to an average temperature of $0^{\circ} \mathrm{F}$ by storage in a sharp-freezer room at $-20^{\circ} \mathrm{F}$. Cased frozen foods should be stored so that they are protected by an insulating layer of air from warmer surfaces, such as the walls, doors, or floors. Dunnage or pallets should be used to provide such air spaces during transportation in refrigerated cars. If it is necessary to sharp-freeze upon arrival at central warehouses, circulation of air about the stacks should be facilitated. If this is not possible, loose stacking is best. For best color, flavor, and texture retention, the fruit frozen for consumer use should be maintained in the frozen condition until ready for serving and should be served immediately after defrosting, while it is still cold. 


\section{CONTAINERS AND PACKAGING MATERIALS AND PRACTICES}

Containers for frozen fruit products should prevent absorption of flavors and odors from the storage atmosphere; keep out oxygen; and prevent loss of volatile flavors and moisture. They should also be liquidtight and rigid, for ease of handling. The inner surfaces must not flavor the product nor give it an objectionable odor, and must be acidresistant. Containers must also be easy to fill, shaped to freeze quickly, and easily stacked. This section discusses various types of containers from the standpoint of these requirements.

In our experience, no container fulfills these requirements so well as the hermetically sealed can, particularly one of rectangular shape. Although cans were introduced very early in the history of the industry, and the 3o-pound enameled can with slip-over or wide push-in cover is still favored for the freezing of fruit products for subsequent processing, cartons are very generally used for retail-sized packages. The smaller sized cans for retail distribution, at first, did not meet consumer acceptance. Their early use caused some losses because consumers tended to associate cans with imperishability and stored them at room temperatures. For this reason, a wide variety of paraffined, paperboard containers (cylindrical or cup-shaped) and folding, rectangular paperboard cartons with inner bags, or liners, and overwraps were introduced and have come into wide use for a variety of products. These containers, however, are not so airtight, nor so moisture-vapor-proof, and do not lend themselves to automatic filling and mechanical handling. During the period 1931-1941, cans were used for the freezing of citrus juices, and both the consuming public and retail distributors were gradually instructed in the proper storage and use of frozen foods. During the war as a result of a shortage of tin plate, glass containers were used to a limited extent, and fiberboard cartons were introduced as a substitute for the 30-pound can. At present there is a growing interest in the use of cans for consumer-sized packages of frozen-fruit products, and one California processor of fruit filled his entire 1946 pack in rectangular cans which were frozen by immersion in refrigerated alcohol. A new, composite fibermetal container has a rectangular, paraffined fiberboard body with metal ends which are automatically sealed by roller-sealers. This was introduced during the 1946 season and proved to be an acceptable semirigid substitute for the tin can.

A large proportion of "frozen-pack" fruits is packed in paraffin-coated fir

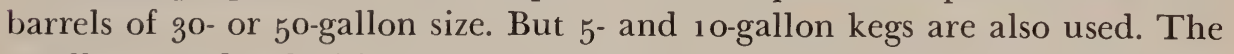
5 -gallon can, fitted with a 6-inch friction seal in the top and coated inside and out with a protective enamel (usually berry enamel), and the 30 -pound and smaller sized cans are in wide use. During the war years, a 30 -pound fiberboard carton came into use. This has an inner bag of heat-sealing, double-walled, 

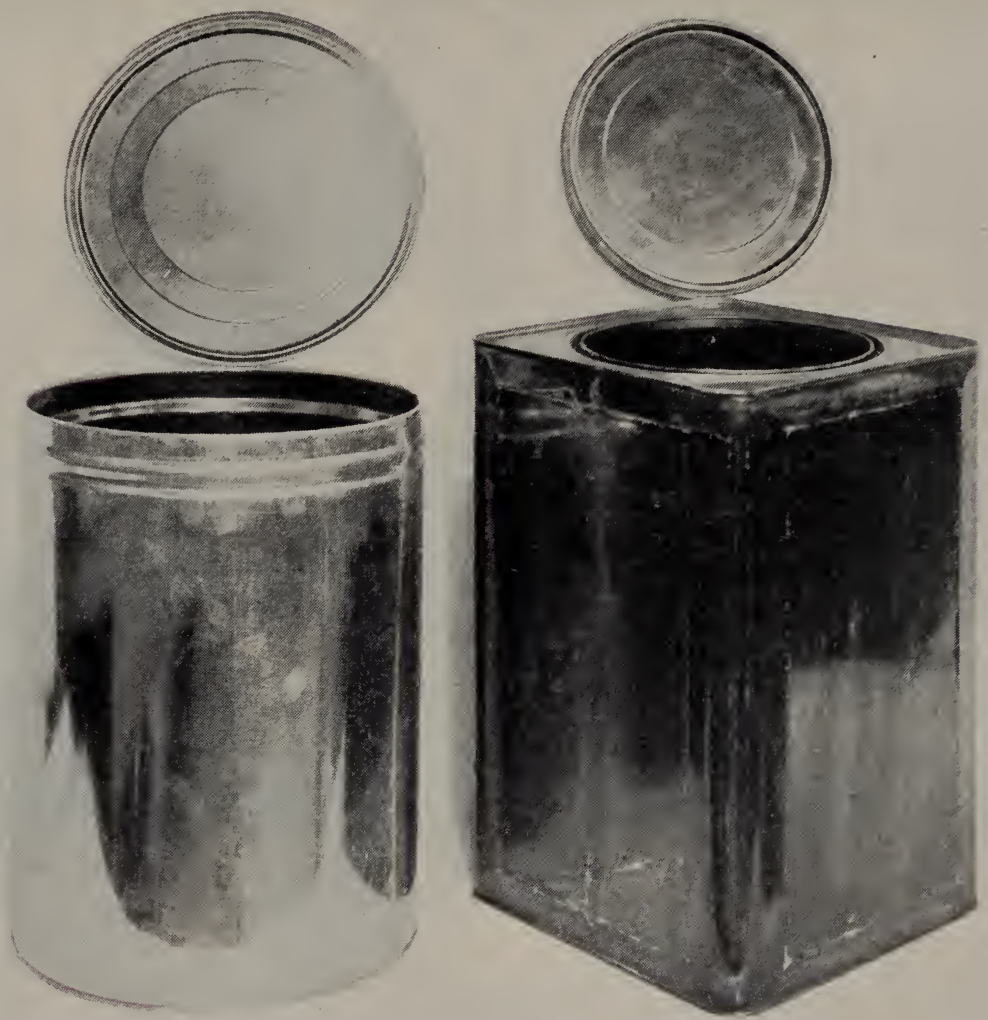

Fig. 8.-Closures for the 30-pound and 5-gallon can developed for freezing fruit. (From Cir. 320.)

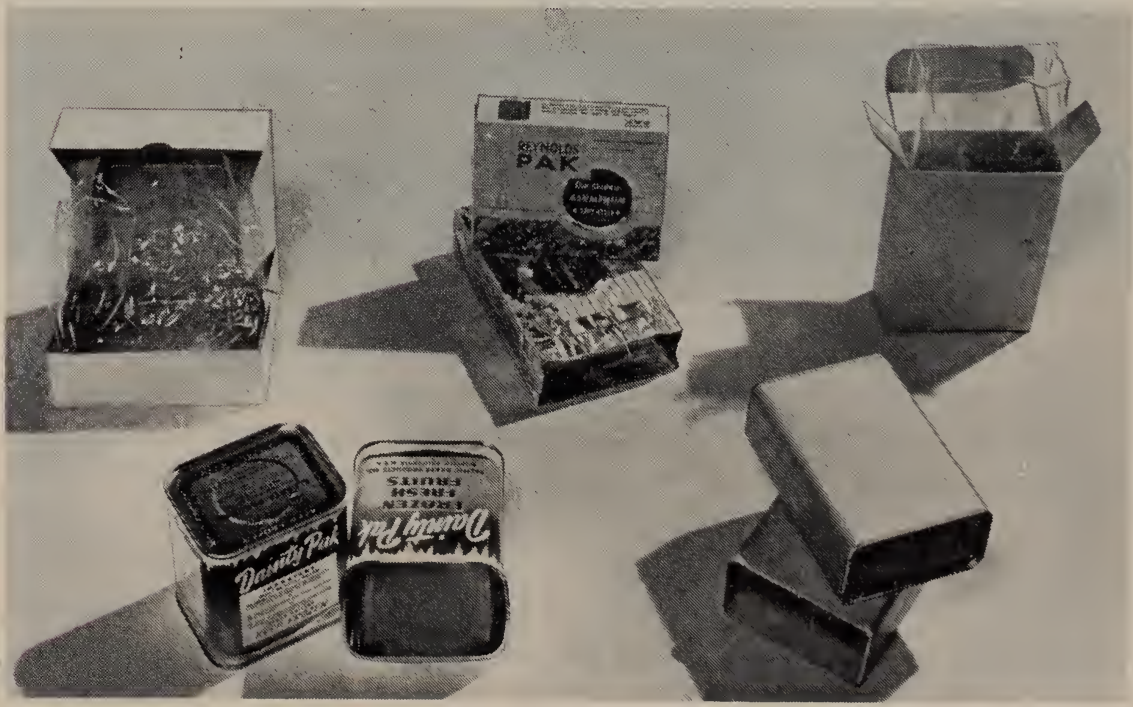

Fig. 9.-Types of containers used for retail-sized packages. 


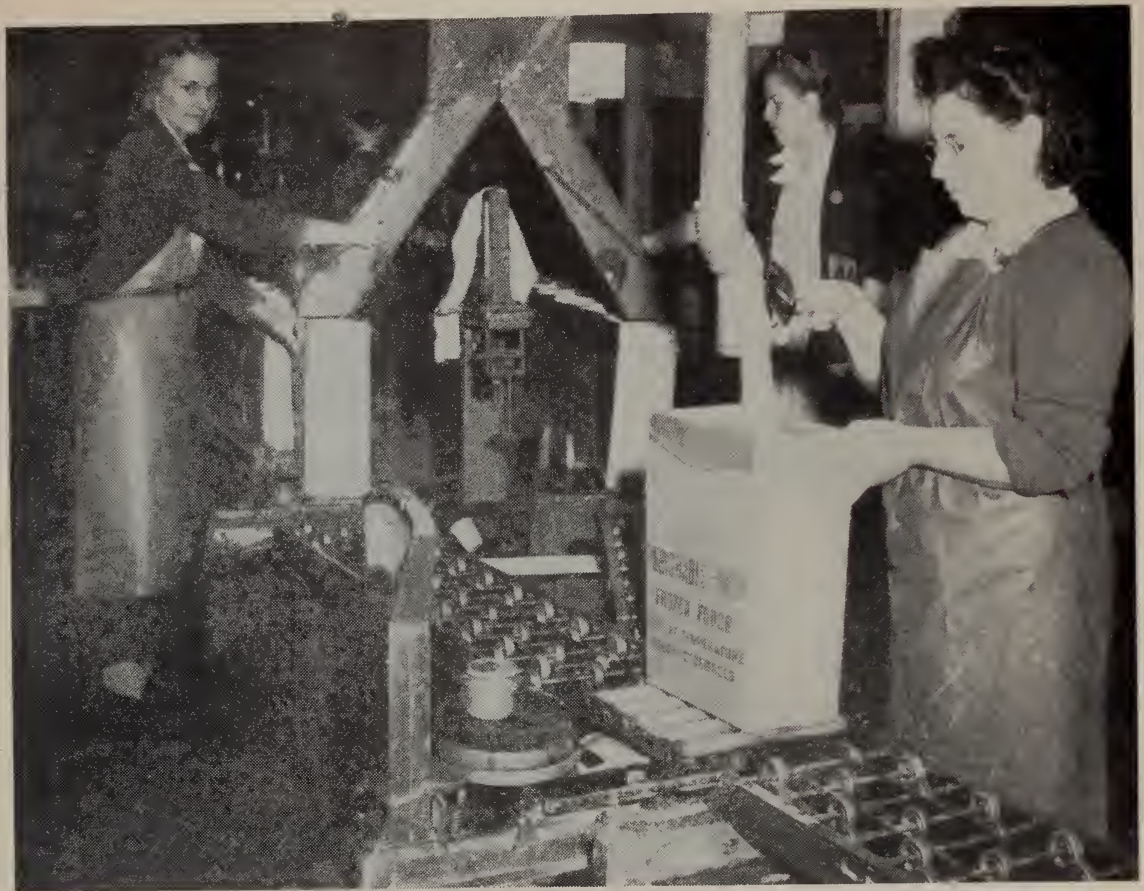

Fig. 10.-Filling and sugaring 25-pound packs of apricots, in large cartons. (Courtesy of Western Canner and Packer.)

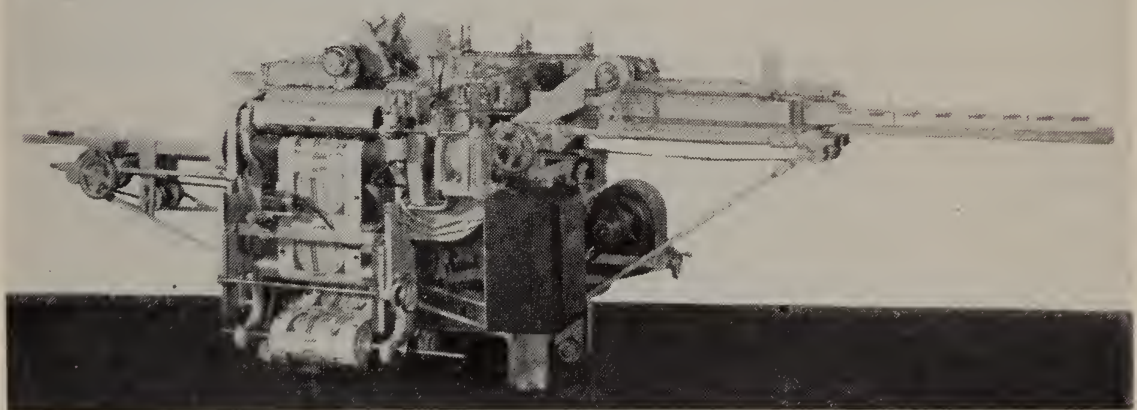

Fig. 11.-Wrapping machine for cartons, with photoelectric cell for overwrap adjustment. (Courtesy of Battle Creek Bread-wrapping Machine Co.)

moisture-vapor-proof, laminated, regenerated cellulose film. When properly sealed, it is fairly satisfactory although not so rigid and sturdy as the can. It is rectangular in shape and lends itself well to stacking. The outside dimensions are $63 / 4^{\prime \prime} \times 12^{\prime \prime} \times 131 / 2^{\prime \prime}$ and the volume is approximately $1090 \mathrm{cu}$. in., or $36 \mathrm{cu}$. in. per pound of fruit.

The bulk of fruit in the consumer-sized packages is frozen in folding paraffined paperboard cartons, usually of the top-opening or top-fill type. These are used with a heat-sealing inner bag of moisture-vapor-proof plastic film 
or with an inner liner. A wide variety of plastic films has been developed. They have good water-vapor resistance and are flexible at low temperatures (Aikeen, 1946; Rabak and Stork, 1946). The more important of these are the regenerated cellulose films coated, to make them heat-sealing and water-vaporresistant, with cellulose acetate or polyvinylidine chloride (cellophane or Saran-coated cellophane), rubber hydrochloride film (pliofilm), and rubber films (cryovac). To improve the water-vapor-proof qualities of this container, it should be overwrapped with a suitable grade of paraffined wax paper (McCoy et al., 1946). Paraffined paper is preferred for overwrap as the label can be printed on it. The quality of the seal as well as the water-vapor resistance

Table 13

\section{EFFECT OF PRESSURE FREEZING ON PACKAGE SIZE FOR STRAWBERRIES IN 1-POUND CONTAINERS}

\begin{tabular}{|c|c|c|c|c|}
\hline $\begin{array}{l}\text { Method of freezing and dimensions } \\
\text { of container }\end{array}$ & $\begin{array}{l}\text { Exposed } \\
\text { area }\end{array}$ & $\begin{array}{l}\text { Total carton } \\
\text { area }\end{array}$ & Volume & $\begin{array}{l}\text { Area per unit } \\
\text { volume }\end{array}$ \\
\hline Pressure-frozen in plate freezer: & sq. in. & sq. in. & cu. in. & sq. in /cu. in. \\
\hline $51 / 8^{\prime \prime} \times 3 " \times 2^{\prime \prime} \ldots \ldots \ldots \ldots$ & 63.3 & 89.8 & 30.7 & 2.06 \\
\hline Air blast freezer : & & & & \\
\hline $51 / 4 " x 41 / 8 " \times 43 / 4 "$. & 76.1 & 101.6 & 37.9 & 2.02 \\
\hline $47 / 8$ " x $4 \frac{1}{2} 2^{\prime \prime} \times 13 / 4 "$. & 76.6 & 100.9 & 38.4 & 1.99 \\
\hline $51 / 2 " \times 41 / 4^{\prime \prime} \times 13 / 4^{\prime \prime}$. & 80.4 & 106.8 & 40.9 & 1.97 \\
\hline $6^{\prime \prime} \times 3 \frac{1}{2} 2^{\prime \prime} \times 13 / 4 " \ldots$ & 75.3 & 98.0 & 36.8 & 2.05 \\
\hline
\end{tabular}

of the film affects moisture vapor loss, and too often in practice, the value of the liner or overwrap is lost by faulty sealing.

There is a wide variation in the type and dimensions of packages used for frozen fruit. Thus in a recent survey (Anon., 1946a), 9 sizes of 1-pound containers were reported, ranging from $51^{1 / 4^{\prime \prime}} \times 4^{\prime \prime} \times 11 / 4^{\prime \prime}$ to $6^{\prime \prime} \times 4^{\prime \prime} \times 13 / 4^{\prime \prime}$. Most of the packers freezing in the package without pressure use a 1-pound carton having the dimensions of $51 / 4^{\prime \prime} \times 4^{\prime \prime} \times 13 / 4^{\prime \prime}$, containing $37 \mathrm{cu}$. in. per pound of fruit. The 5 -pound carton is $12^{\prime \prime} \times 81 / 8^{\prime \prime} \times 3^{\prime \prime}\left(282 \mathrm{cu}\right.$. in., or $5^{6} \mathrm{cu}$. in. per pound) and the 1o-pound carton is $101 / 2^{\prime \prime} \times 12^{\prime \prime} \times 4^{\prime \prime}\left(5^{0} 4 \mathrm{cu}\right.$. in., or $5^{\circ} \mathrm{cu}$. in. per pound).

The effect of pressure freezing on size of container is shown in the analysis of several packers' containers shown in table 13. The data presented here indicate that pressure freezing results in a saving of 19 to 25 per cent in volume per pound and from 11 to 16 per cent in total carton area for a top-opening carton.

The Eastern Frozen Food Association, after a nationwide survey among 700 processors and packers to determine the dimensions of a standard, complete functional carton for frozen foods, proposed that the following types of cartons be used (Fabian, 1946). 
1. A 12-ounce package measuring $6^{\prime \prime}$ long by $31 / 2^{\prime \prime}$ wide by $13 / 4^{\prime \prime}$ high containing 36.75 cubic inches and holding 12 ounces of frozen vegetables or 16 ounces of fruit.

2. A 40 -ounce package measuring $10 \frac{1}{2} 2^{\prime \prime}$ long by $3 \frac{1}{2}{ }^{\prime \prime}$ wide by $2^{\prime \prime}$ high containing 126 cubic inches.

3. A 10-pound package measuring $101 / 2^{\prime \prime}$ long by $12^{\prime \prime}$ wide by 4 " high containing 504 cubic inches.

All of the above sizes are multiples in size and shape so that it is possible to provide a single carton holding a given quantity of the various sizes, and to pack combinations of standardized retail packages in the same carton without loss of space. For example, a carton $12^{\prime \prime} \times 101 / 2^{\prime \prime} \times 16^{\prime \prime}$ would hold four 10pound packages, twenty-four 40 -ounce, or fifty-four 12-ounce packages.

Standardization of the above type in size and shape would result in a rec tangular package capable of being filled economically, and in space conservation during transportation, storage in low-temperature warehouses, in retail storage and display cabinets, and in home lockers and refrigerators containing $\mathrm{O}^{\circ} \mathrm{F}$ storage units.

In addition to the rectangular cartons, paraffined tubs and cups with slip-in covers are used to a limited extent. These have a tendency to leak, particularly when the lid is improperly inserted, and are not so economical of casing requirements.

The packaged frozen fruits are placed in fiberboard cases for shipment. Usually a 1oo-pound test, solid fiberboard is used as this has proved stronger than the corrugated fiberboard container. These cases should be so designed as to minimize air spaces between individual cartons and to allow complete filling. The side and end flaps on top and bottom should be cut so that they just meet in the center without gaps, and a good grade of low-temperatureproof adhesive should be used in sealing them. As an added precaution, particularly for long storage, the edges and sides of the case should be sealed with a wide, moisture-vapor-proof adhesive tape; the asphalt-laminated kraft type has been used for this purpose. If the containers are overfilled or the freezing conducted so that ice formation begins at one localized surface and subsequently extends throughout, bulging will occur. This bulging will cause diffculties in casing and subsequent storage and will necessitate the use of oversize packing cases. Bulging can be prevented by selecting the fill-in weights, size of container, and rigidity of container walls suited to the particular freezing system used. Where inner bags are used, air must be squeezed out of the top surface just before the bags are passed through the heat sealer. The heat-sealing units should be located on the conveyor belt so that a minimum of headspace is present in the sealed bag. Where freezing is carried out under pressure, lighter, less rigid paperboard and smaller containers and packing cases may be used. 


\section{THE FREEZING OF FRUITS}

The remainder of this bulletin is a handbook of freezing practices and processes for individual fruits and for purées, jelly and jam bases, juices, and juice concentrates. (Tropical and subtropical fruits are listed alphabetically in the section beginning on page 83.)

The more important kinds of California fruits commonly frozen, the recom mended varieties, average yields per acre, production districts and harvesting seasons are given in table 14 . Table 15 shows the percentage losses in weight of fruit during preparation for processing, from which the general yields may be estimated.

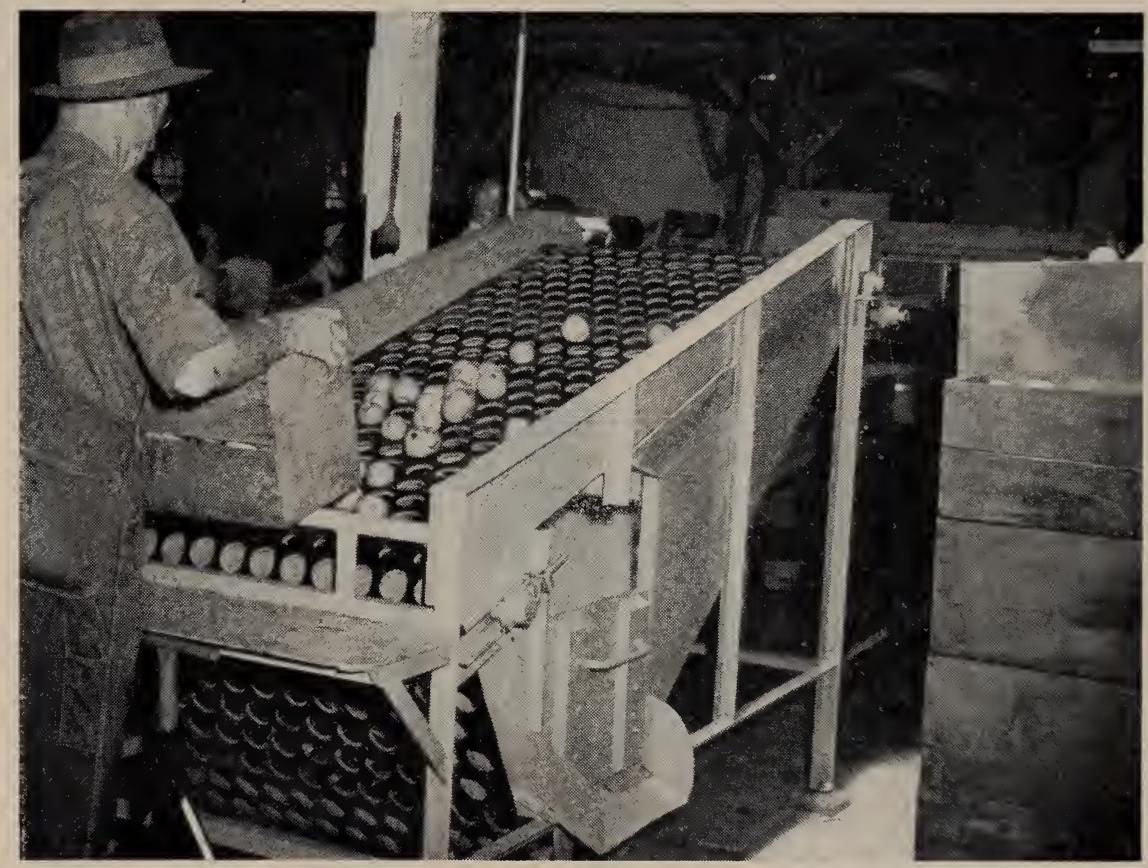

Fig. 12.-Unloading apples preparatory to inspection.

(Courtesy of Western Canner and Packer.)

\section{APPLES}

Varieties.-Since apples are chiefly frozen in slices for use in pies, only varieties which make good pies should be chosen. Tressler and Evers (1947) state that the Greening is the best variety to freeze in the eastern states, but Baldwin, Northern Spy, Winesap, Stark, Jonathan, Rome Beauty, and Cortland are also good. In the Pacific Northwest, Yellow Newtown, Winesap, Spitzenburg, Stayman, and Jonathan are considered superior to the other varieties for freezing. In Utah, chiefly Yellow Newtown, Rome Beauty, and Winesap are used. In 


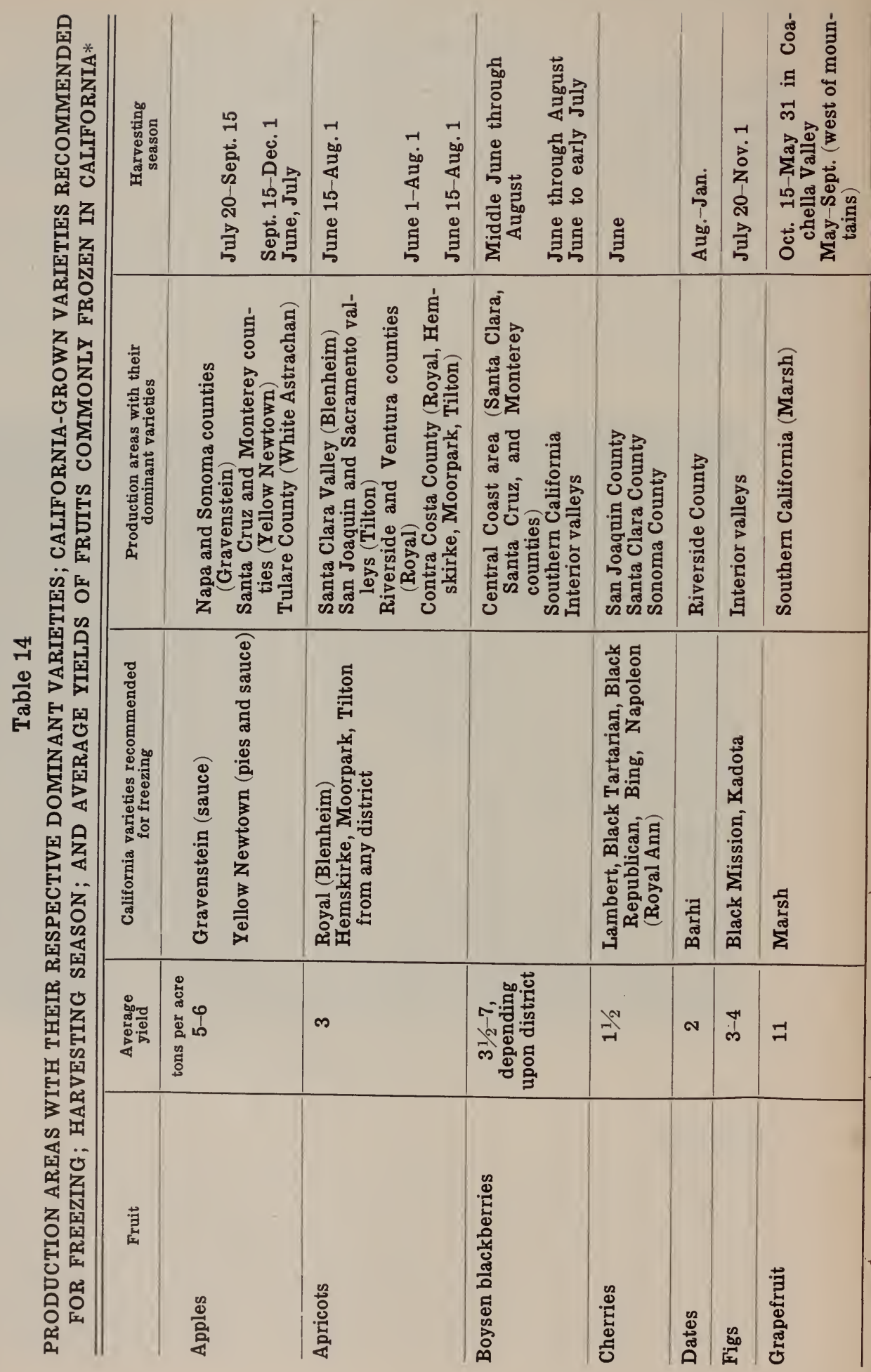




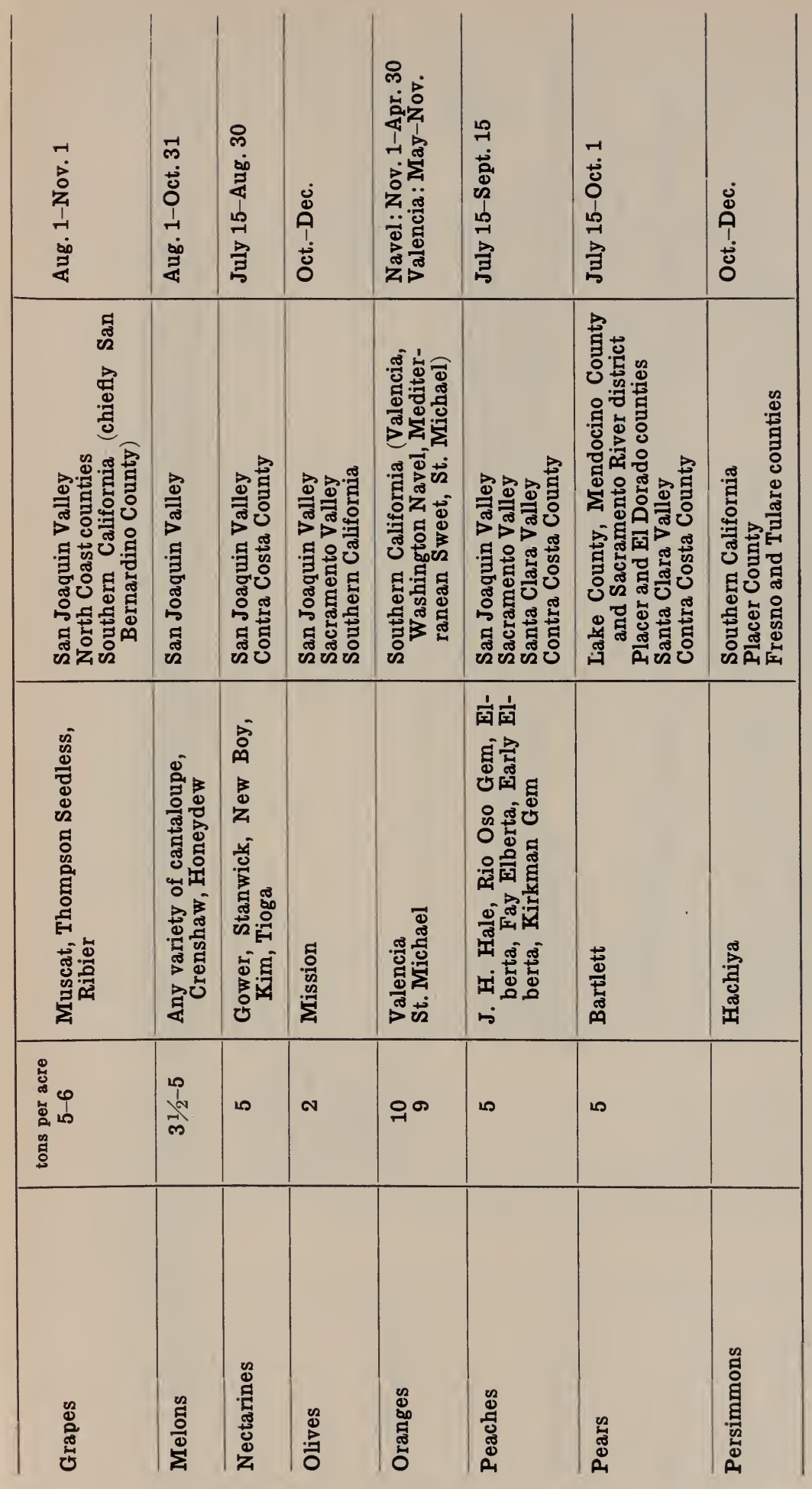




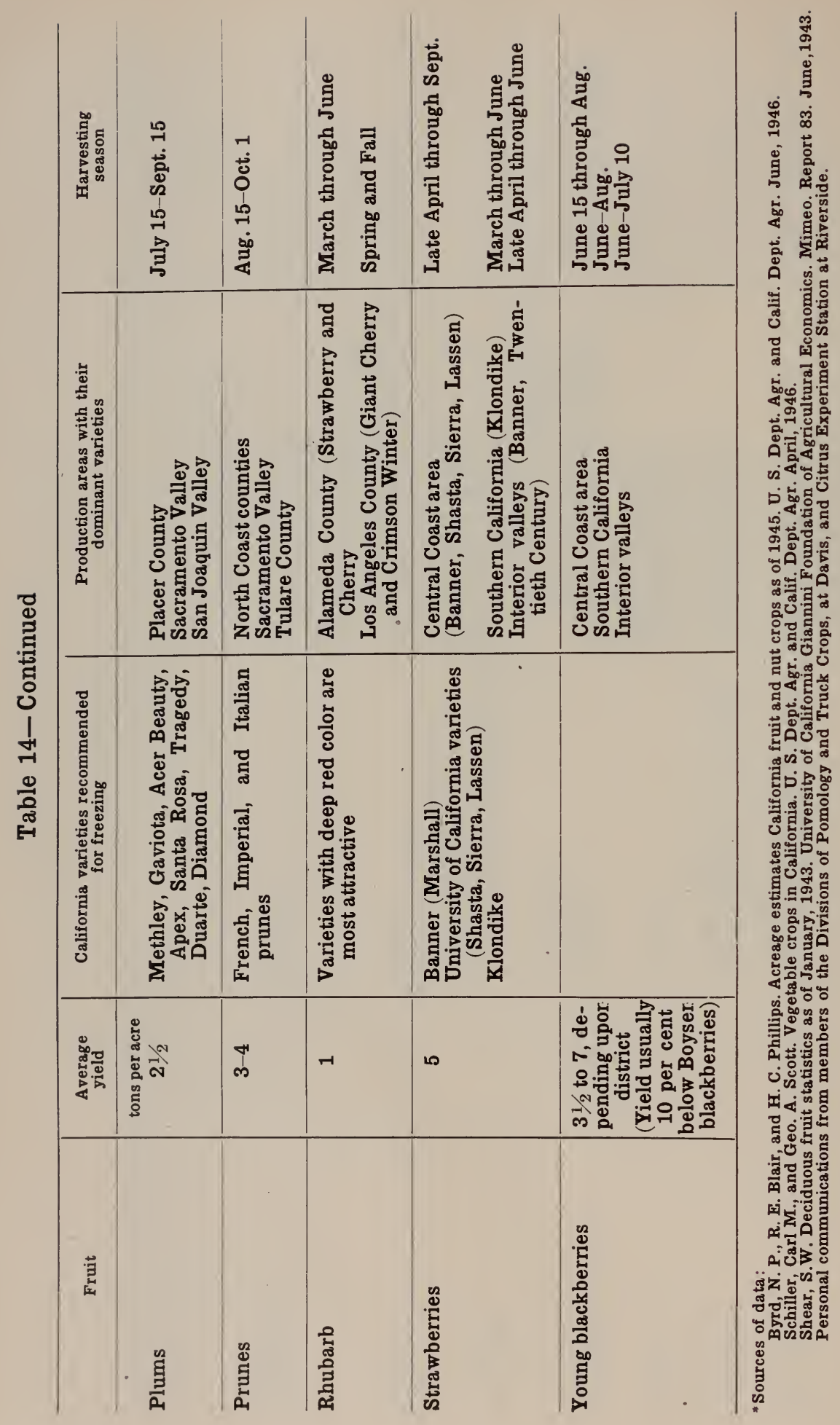


California, the Yellow Newtown is the only important commercial variety suitable for freezing for pie stock. Gravenstein is generally not considered suitable and has recently been frozen chiefly as apple sauce.

\section{Table 15}

RELATION BETWEEN FARM AND PROCESSED WEIGHT*

\begin{tabular}{|c|c|c|c|c|}
\hline \multirow[b]{2}{*}{ Fruit } & \multirow{2}{*}{$\begin{array}{c}\text { Percentage } \\
\text { loss } \\
\text { in weight } \\
\text { of fruit } \\
\text { during } \\
\text { processing }\end{array}$} & \multicolumn{2}{|c|}{ Factors for obtaining } & \multirow{2}{*}{$\begin{array}{c}\text { Approximate } \\
\text { fruit-to-sugar } \\
\text { ratio }\end{array}$} \\
\hline & & $\begin{array}{l}\text { Farm weight } \\
\text { from } \\
\text { frozen weight } \dagger\end{array}$ & $\begin{array}{l}\text { Frozen weight } \\
\text { from } \\
\text { farm weight } \dagger\end{array}$ & \\
\hline & per cent & & & \\
\hline Apples . . . . & 50 & 1.67 & .60 & $5: 1$ \\
\hline Apricots . . . . . . . . & 22 & .96 & 1.04 & $3: 1$ \\
\hline Berries-average...... & . & 1.05 & .95 & $\ldots$ \\
\hline Blackberries. . . . . . . . . . . . & 5 & 1.05 & .95 & 0 or $4: 1$ \\
\hline Gooseberries . . . . . . . . . . & 8 & 1.09 & .92 & 0 \\
\hline Huckleberries . . . . . . . . . & 11 & 1.12 & .89 & 0 \\
\hline Strawberries - with stems . . . & 12 & .85 & 1.17 & $3: 1$ \\
\hline hulled ....... & 7 & .81 & 1.24 & $3: 1$ \\
\hline Youngberries and dewberries & 5 & 1.05 & .95 & 0 or $4: 1$ \\
\hline Cherries-red sour pitted . . . . . & 25 & 1.06 & .94 & $4: 1$ \\
\hline sweet. . . . . . . . . & 16 & .95 & 1.05 & $4: 1$ \\
\hline Currants . . . . . . . . . . . & 5 & 1.05 & .95 & 0 \\
\hline Grapes.................. & 15 & 1.18 & .85 & 0 \\
\hline Grapefruit segments . . . . . . . & . & 2.00 & .50 & $\ldots$ \\
\hline Peaches $\ldots \ldots \ldots \ldots \ldots \ldots \ldots$ & 33 & 1.12 & .89 & $3: 1$ \\
\hline Pineapple . . . . . . . . . . & 50 & 1.60 & .625 & $4: 1$ \\
\hline Prunes-with pits . . . . . . . . . & 4 & 1.04 & .96 & 0 or $4: 1$ \\
\hline without pits ......... & 15 & 1.18 & .85 & 0 or $4: 1$ \\
\hline
\end{tabular}

* Source of data: U. S. Dept. Agr. Production and Marketing Administration. Conversion factors and weights and measures for Agricultural Commodities and their products. Washington, D.C., 1947. Unnumbered mimeo.: 1-83 (especially p. 50).

t Frozen weight is weight of frozen commodity plus sugar content, except that factors for blackberries, prunes, and Youngberries are based on zero sugar content.

Apples for Bakers.-The apple freezing industry developed as a modification and extension of the commercial preparation and distribution of apples to bakers. The fresh fruit was peeled, cored, quartered, or sliced and treated with common salt and sulfite or sulfurous acid solutions (Joslyn and Mrak, 1930, 1933).

In present commercial practice, apples are prepared for freezing by mechanical paring, coring, and slicing. Trimming is usually done by hand before slicing. If a delay is necessary at any point between paring and subsequent treatment, the apples are held in a weak salt solution (not over 3 per cent $\mathrm{NaCl}$ ) to prevent browning.

Sulfite or sulfurous acid treatment has probably been the most frequently used and recommended procedure in preparation of apples to be frozen for 
bakers' use. Careful control is required for effective use of this procedure. One of two types of equipment is generally used for treatment; a tank with a "walking-beam" conveyor that continuously removes the slices from the solution, or wicker baskets that are filled with slices and dipped by hand. The former is preferable. The dipping solutions usually contain 3000-400o p.p.m. $\mathrm{SO}_{2}$, and the exposure time should be 3 or 4 minutes. Under these conditions, a holding period prior to freezing is not required.

After the apple slices have been well drained, they are packaged, usually in 30- or 5o-pound fiberboard cartons or enameled slip-cover cans. Sugar is not required for preservation, but during the sugar shortage, it was profitable for bakers to receive frozen fruit already sugared. Dry sugar is generally poured over the fruit in the packages before they are sealed and frozen.

Some processors prefer the blanching procedure. This is entirely satisfactory if blanching time is carefully controlled and excessive losses of soluble flavoring and nutrient constituents during cooling are prevented. When blanching is used, apples should be size graded to keep the slices uniform and insure complete heat penetration without overheating. Blanching is usually done on a wire mesh belt which conveys the sliced fruit through the steam chamber or blancher at a variable speed. For apples cut into twelfths, the blanching time is usually $11 / 2$ to 2 minutes in free-flowing steam $\left(200^{\circ}-212^{\circ} \mathrm{F}\right)$. Cooling should be done in a minimum quantity of ice water or with water sprays or air. Flumes should not be used to cool the blanched fruit. Fine mist or fog or rapid air-blast cooling are better because they result in smaller losses of soluble nutrients.

Several procedures using ascorbic acid have been suggested but are too new to have been tested on a large scale commercially (Luther and Cragwall, 1946; Bauernfeind and Siemers, 1946).

Powers and Esselen (1946) suggested the treatment of apples with Ca salts prior to freezing to keep them from becoming excessively mushy when baked in a pie. Concentrations from .03 to 1.5 per cent $\mathrm{Ca}$ in a treating solution were indicated. Hills et al. (1947) confirmed and extended these experiments and suggested vacuum impregnation to insure Ca penetration.

Applesauce.-Frozen applesauce is being packed in increasing quantities in consumer packages for retail distribution, either with or without added spices. For the most acceptable sauce, apples of suitable variety (both Gravenstein and Yellow Newtowns are used) are pared and cored, then sliced or chopped in a hammer mill, heated to boiling in a steam-jacketed or flashcoiled pan, and boiled until thoroughly softened. The heated apples are then pulped in a heavy-duty pulper using a fine mesh screen, and the pulp is received in blending tanks where it is sweetened by the addition of sugar, usually at $6: 1$. The proportion of sugar added varies with the tartness of the apples, but on the average is 10 pounds per bushel basket.

The mixture should then be cooled to a filling temperature of below $70^{\circ} \mathrm{F}$. 
Failure to cool the applesauce before packing has resulted in losses by fermentation. A simple method of cooling the applesauce is by storing it in vessels equipped with a rotating coil, such as is used in cooling milk products, through which refrigerated brine can be circulated, or by passing it through continuous tubular or plate freezers. An hermetically sealed container is preferred, although a paraffined paperboard carton with an inner bag of moisturevapor-proof plastic is satisfactory for shorter periods of storage.

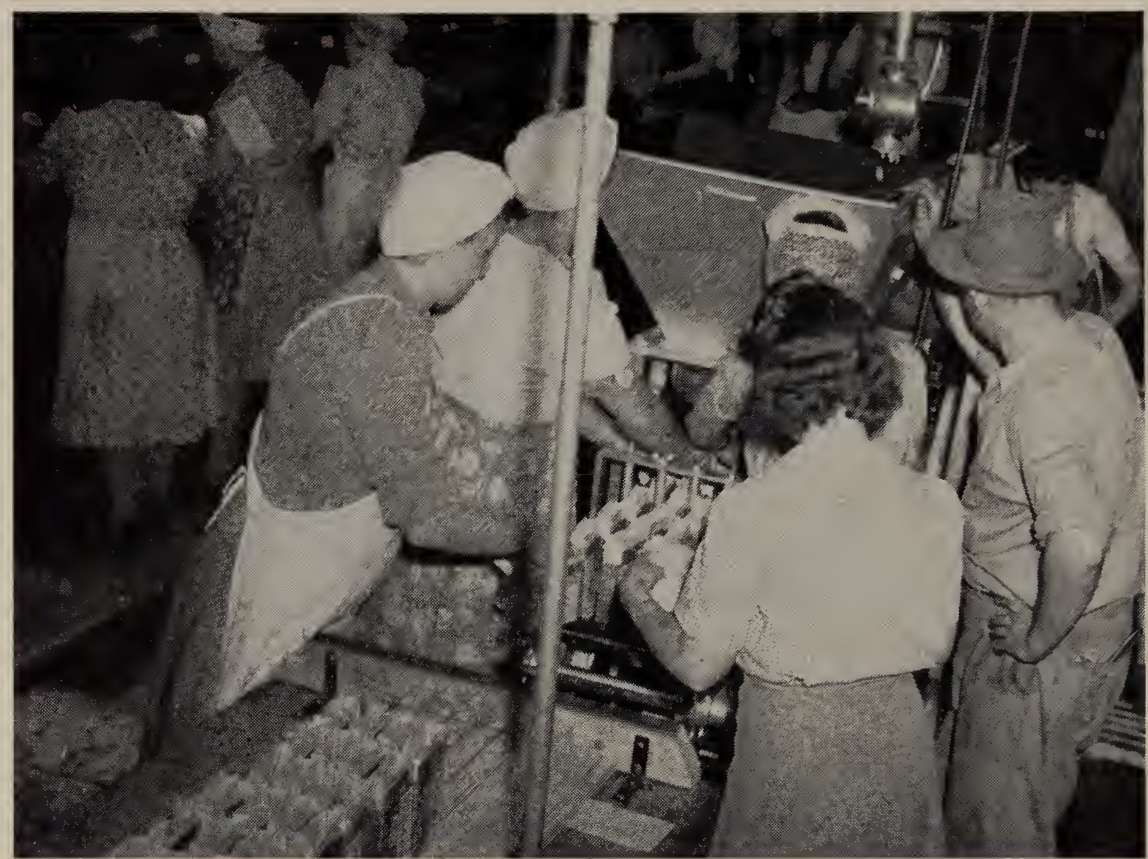

Fig. 13.-Cartons with inner bags, on the way to the filler. Product is applesauce. (Courtesy of Western Canner and Packer.)

Applesauce can also be made from the whole apples that have been sorted, washed, and trimmed. For this method, the apples are chopped by passage through a hammer mill or apple grater, then brought to boiling in a steamjacketed kettle, and passed hot through a heavy-duty pulper where most of the skin and seeds are removed. The resulting pulp which still contains small particles of skins and grit cells, is then passed through a finisher to screen these out, before being sweetened. It is desirable, however, to add the sugar after the first pulping, and bring it to a boil again before finishing. This treatment produces a smoother texture.

Apples should not be allowed to come into contact with copper or iron surfaces. Apple pulp absorbs copper rapidly and becomes green at even a low copper content. In order of preference, stainless steel, nickel, monel metal, or aluminum can be used.

In a recently completed, highly mechanized plant (Anon., 1946b), apples 
are delivered in lug boxes to girls working at a battery of 18 Boatell seed-cellers where the cores are rapidly removed. The cored apples are carried on a rubbercovered conveyor belt to a continuous steam peeler, from which they are transferred to a rotary, spindle-type spray washer where loosened skins are removed by sharp jets of water. The fruit then passes over a trimming table where adhering bits of skin, bruises, and blemishes are removed. The peeled and cored apples are then sliced into a cooking unit into which the proper quantities of sugar and water are regularly introduced. After precooking, the fruit drops into a stainless steel pulper from which it is pumped into a stainless steel agitated and heated holding tank. From this vessel, the sauce is dropped into a Girdler votator where it is cooled and from which it flows into the filling line. The sauce is filled into waxed paper bags, inserted into paperboard cartons, closed, and wrapped. The finished packages are trayed and trucked to the freezing department. They are precooled in an anteroom at $-5^{\circ} \mathrm{F}$, frozen in air-blast freezers at $-40^{\circ} \mathrm{F}$, and stored for shipment at $-10^{\circ} \mathrm{F}$.

The methods used for applesauce may also be used for frozen pearsauce and peachsauce. The pearsauce can be made from whole, washed pears; the peachsauce is made from halved, pitted, and peeled fruit (Cruess, 1931).

Baked Apples.-Frozen baked apples are another new development which might well be extended to pears and possibly other fruits. A discussion of frozen baked apples is given by Lee (1947).

\section{APRICOTS}

Since California produces over go per cent of the nation's total apricots, most of the reported investigations on their freezing have been made here. (For details see Cruess et al., 1920; Joslyn and Cruess, 1929; Joslyn, 1930b; Joslyn and Mrak, 1933; Joslyn, 1942; Hohl and Swanburg, 1946.)

Varieties.-Diehl and Warner (1945) have stated that desirable varietal characteristics for apricots are: "low browning tendency, even ripening, distinctive yellow or orange color, rich and characteristic flavor, fairly firm texture, easily separated seed, tender and smooth skin.'

Diehl, Wiegand, and Berry (1939) reported that the Tilton was the best variety for freezing in the Pacific Northwest. We have found Royal or Blenheim to be superior to Tilton. The Rualt, which has a very attractive deep color and good flavor, was also found to be excellent for freezing, but it is not grown commercially. Fully ripened, carefully handled Hemskirke from the Contra Costa County area made superior frozen halves, slices, and purée, which retained their original quality during eight years of storage at $0^{\circ} \mathrm{F}$.

Apricots for Bakers' or Processors' Use--Sulfur dioxide, blanching, and ascorbic acid have all been used to retain fresh color and flavor in fruit frozen for subsequent processing. Some processors prepare their firmer fruit by the 
blanching procedure and their softer, riper fruit by the sulfur dioxide, or ascorbic acid methods.

When $\mathrm{SO}_{2}$ is used, the ripe fruit is cut, pitted, spray washed and immersed in a sulfur dioxide bath for 3 minutes. The average concentration is 4000 parts $\mathrm{SO}_{2}$ per million, or 0.4 per cent. The dipping has frequently been done in Chinese wicker baskets. The $\mathrm{SO}_{2}$ treatments should be so controlled that not less than 75 p.p.m. nor over 100 p.p.m. of $\mathrm{SO}_{2}$ is present in the frozen product. As for apples, a suitably arranged conveyor system is preferable to the basket technique.

After draining, the fruit is ready for packaging, usually in bulk. Sugar is generally added, either in the crystalline form or as a heavy sirup. The ratio of fruit to sugar was formerly always 4 to 1 , but during the recent shortage, it has varied from this to $10: 1$, or occasionally none was added. When dry sugar is used, it may be poured over the fruit in the package, or it may be gently mixed in a special rotating mixer until the sugar dissolves, and then packaged. If sirup is used, it is always poured over the fruit.

For blanching, the firmer fruit is hand cut and pitted, sorted, spray washed, steam blanched (preferably in a single layer on a moving mesh belt for 3 to 4 minutes), and then cooled. Cooling may be done by immersion in large vats of iced water, by sprays of cold water, or by spraying, followed by short fluming or by air blast. The packaging and sugaring processes are similar to those for sulfited fruit. A few operators have also put up apricot packs in $15^{\circ}$ to $20^{\circ} \mathrm{Bal}$. or Brix sirup, using sirup blanching procedures as a means of retaining the advantages of heat treatment while minimizing the loss of soluble nutrients.

The sulfurous acid procedure is simple, and the fruit retains its fresh color and flavor (if not too much $\mathrm{SO}_{2}$ is used). The fruit thus prepared is suitable for use by bakers and preservers, but it cannot be used in products like canned fruit salad or baby food because the sulfur dioxide present will attack the tin plate and be reduced to objectionable hydrogen sulfide. This chemical property of $\mathrm{SO}_{2}$ has also been believed to cause some trouble to bakers by corrosion of the oven linings.

As pointed out by Joslyn (1942), although blanched apricots have better texture for pie baking, the sulfited fruit has better color and flavor. The latter, however, collapses on baking unless given a pretreatment (bringing to boil to expel air).

Apricots for Dessert Use.-Most frozen apricot halves in the past have been used for pie baking, jams, preserves, and baby food manufacture, but recently there has been a growing demand for the fruit packed in sirup in retail-sized packages for dessert use. For this purpose, ascorbic acid-pack is the best of the processing methods now being used. The procedure which has been used by most packers of apricot halves is essentially the following: The fruit is cut, pitted, washed, sorted, packaged, and covered with heary sugar sirup contain- 
ing about 0.04 to 0.05 per cent ascorbic acid in the final pack. This particular concentration had been recommended primarily for peaches, and since apricots darken more seriously than peaches, it was found inadequate. A combination of blanching for a very short time (usually about a minute), followed by packing with sirup containing ascorbic acid was used by a few processors, but just the "right combination" for satisfactory results was difficult to achieve.

Best results were achieved by packing $10 \mathrm{oz}$. of halved fruit to $6 \mathrm{oz}$. of a $4 \mathrm{o}^{\circ}$ Brix sirup containing at least 0.1 per cent ascorbic acid. Immersion in ascorbic acid solution or combinations of ascorbic acid with a short blanch which did not completely inactivate the enzymes, or mixtures of crystalline ascorbic acid and sugar were not satisfactory.

During the past year or two, the sales of frozen apricot halves for dessert have been dropping, and some believe that no more will be packed for this purpose. Toughness of the skins and poor sugar penetration have been the chief objections to frozen apricots. Both of these difficulties can be minimized by packing sliced apricots in sirup. This was originally suggested by Joslyn and Cruess (1929), and subsequent investigations confirmed its advantages. Another advantage of slices over halves is that less liquid is required to completely cover the fruit. A one-pound carton containing $11 \mathrm{oz}$. of sliced fruit with 5 oz. of $40^{\circ}$ Brix sirup containing o.1 per cent ascorbic acid makes an excellent product.

\section{BERRIES}

While the California production of berries is far below that of the Pacific Northwest, berry growing and processing are nevertheless of considerable economic importance. Strawberries, Boysen blackberries and Young blackberries are grown in three major districts. There are relatively few commercial plantings of raspberries, blackberries, and Logan blackberries and these are confined to the central coast area.

According to Butterfield (1942), the principal black-fruited bush berries (often called cane berries) now being grown in California are all varieties of blackberry. These include the Logan(commonly known as Loganberry), Boysen (Boysenberry), Nectar (Nectarberry), Phenomenal, and Young (Youngberry). The latter is a hybrid derivative of other members of the group. For strict accuracy, these varieties should be referred to as Logan blackberries.

Varieties.-Strawberry varieties grown in different regions react quite differently toward freezing preservation. In order to make a desirable frozen product, a strawberry variety should have a pleasing and pronounced flavor and acidity, which should be retained during freezing and thawing; it should be bright red with small core cavity and should retain its color during long storage. The fruit should be of uniformly good size and firm texture; white tips, prominent seeds, or hollow centers are undesirable. On thawing, the berries should not collapse badly or lose a large quantity of juice as leakage. 
Much study has been given to the relative suitability of strawberry varieties grown in several regions, including mainly the Pacific Northwest, the Middle Atlantic States, New York, New Jersey, Massachusetts, the Southern States, and California. An excellent review of these studies is given in Tressler and Evers' book. In California, the chief varieties frozen were Klondike in the southern area, and Banner (Marshall) in the other production regions. Banner has good color and flavor, is easily hulled in the field, and is a heavy bearer. Its defect for whole berry packs is its irregularity in size and shape. During the past few years, considerable interest has been centered in the five new diseaseresistant varieties (Tahoe, Sierra, Lassen, Shasta, and Donner), developed by Thomas and Goldsmith (1945). Preliminary laboratory experiments indicate that all of these varieties may be frozen satisfactorily. Further data are required before they can be ranked in order of preference or compared with the standard well-known varieties. Several commercial growers have their own new varieties and strains, some of which have had limited commercial freezing tests. A notable one of these is Driscoll's A 1 , which was outstanding in quality.

Barreling of Strawberries.-Since the beginning of the frozen-pack industry, the barreling of berries has been very important. Many other fruits have been

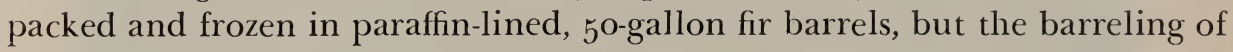
strawberries is the most important and illustrates the procedure used commercially.

The berries are generally. picked during the day and transferred the same evening to the barreling plants. They are usually hulled at the time of picking, principally because this practice adds to the grower's revenue, is somewhat cheaper than hulling at the plant, and tends to relieve congestion at the packing plants. In some sections of the country, the berries are not hulled in the field, but at the packing plants, either by hand or in a mechanical huller. In the field, the hulled berries are packed in wooden baskets, $5 \times 5 \times 2$ inches, holding one pound of berries. Twelve baskets are packed in a crate. In this way injury to the berries during transportation is minimized.

From the receiving platform the berries are trucked to the washer, and a crate at a time is dumped into an agitating hopper filled with cold water. From the hopper, the berries are carried up an incline by the force of sprays of water A tank of cold water may be substituted for the hopper and, from the tank, the berries may be carried slowly up an inclined belt conveyor, past water sprays, to the inspection belt. The berries are fairly well drained by the time they reach the inspection or sorting belt. In sorting, unhulled, green, mashed, molded, or wormy berries, and all foreign matter such as leaves, hulls, etc., are removed. The washing cleanses the berries and cools them to about $60^{\circ} \mathrm{F}$.

After the berries are washed and sorted, they are usually graded before being packed into barrels, although the former practice of packing without grading still survives. Discriminating buyers are willing to pay a premium for graded berries. 
Two types of graders are generally used. The older type is the common screen grader. The Allen grader, developed by Mr. W. G. Allen of Hunt Brothers Packing Corporation, has been installed in most modern plants. This grader

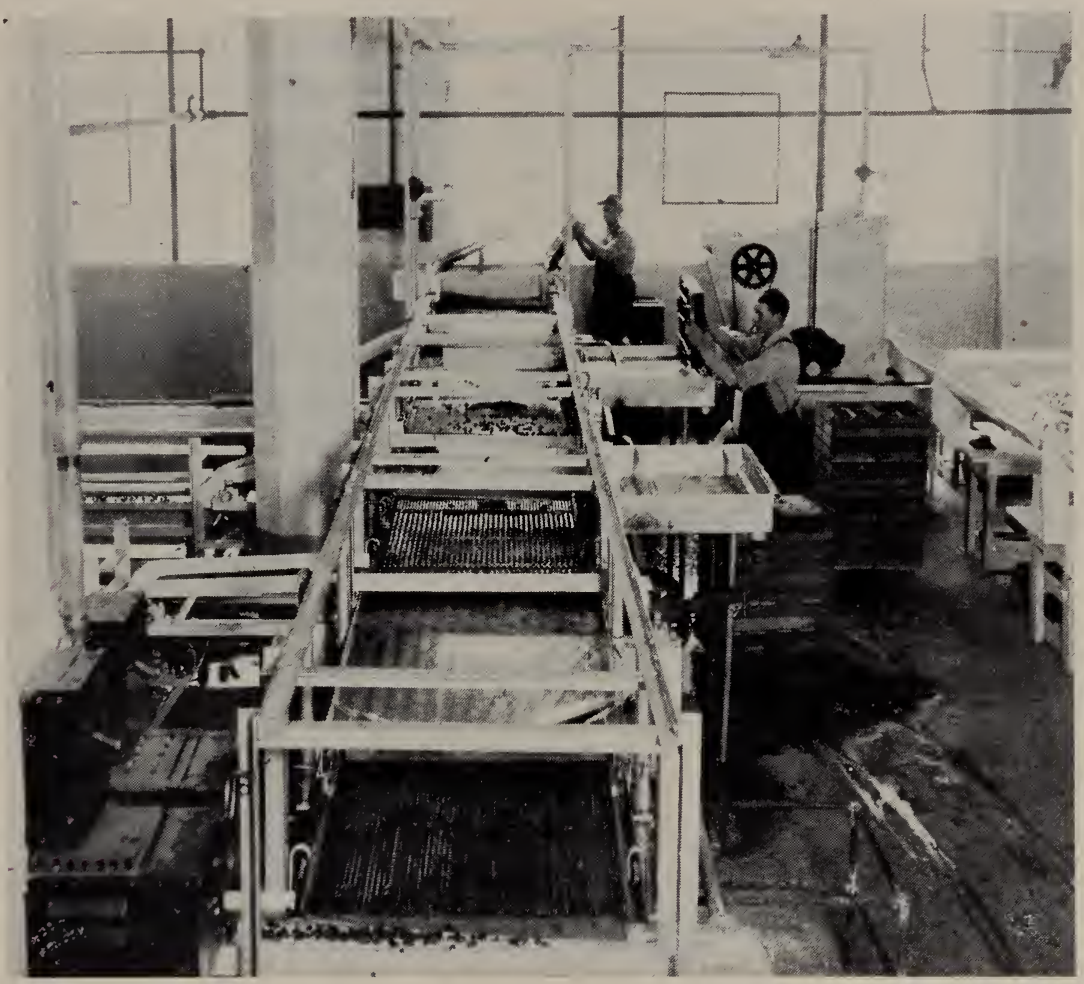

Fig. 14.- The Allen slat-type grader for small fruits. (From Cir. 320.)

consists of wooden-slat grading screens which cause minimum injury to the fruit. The Allen grader combines the best feature of the belt grader with several new features which increase its capacity. The following size grades are generally used:

\section{$1 / 2$ to $3 / 4$ inch in diameter. \\ $3 / 4$ to 1 inch in diameter. \\ 1 to $1 \frac{1}{4}$ inch in diameter. \\ $1 \frac{1}{4}$ to $13 / 8$ inches in diameter.}

Some packers grade to sizes different from those given. Field-run strawberries vary from $1 / 2$ to $11 / 2$ inches in diameter.

From the grader, the berries are conveyed to the barreling crew. One of the most common methods of barreling consists of adding berries and sugar to the barrel, which stands on a mechanical jolting platform beneath the end of the graded fruit delivery belt.

The sugar is added continuously or at frequent intervals during jolting so 
that a thorough mixing of the materials is insured. In the absence of a mechanical jolting platform, the barrels are jolted by rocking them back and forth by hand. Granulated cane or beet sugar (berry grade) is generally used; but some packers prefer to use confectioners' coarse grade sugar because the crystals adhere to the berries better and do not settle out so much.

In the better equipped plants, the sugar is added continuously from a hopper. First the barrel is filled about one third full of berries. Then the sugar

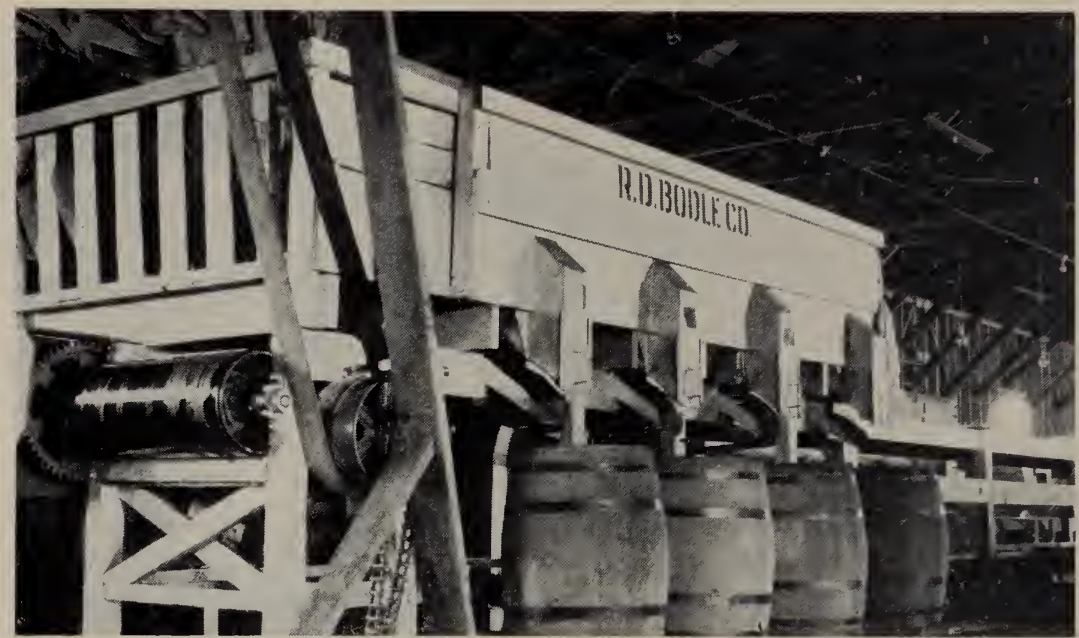

Fig. 15.-An example of the continuous sugar-admixturing hoppers which are coming into wide use. (From Cir. 320.)

is allowed to run slowly into the barrel and the remainder of the berries become coated by falling through the spray of sugar. As the sugar falls into the barrel it sifts through the unsweetened berries in the bottom and dissolves rapidly.

The barrels are brought to the desired weight, headed up, and are trucked to the cold storage. Occasionally, the barreling stations are not connected with freezing storage plants, although they are usually located near commercial cold storage warehouses where the berries are frozen as soon as possible.

The barrels are so filled as to allow about a 3 - or 4-inch headspace for expansion on freezing. There is additional air space in and around the packed berries. Where the berries are not packed very solidly this may amount to about $3 / 4$ fluid ounces of air space for each 12 ounces of berries.

The net weight of contents varies with the sugar added and the practice of different packers. It is generally as follows:

\begin{tabular}{|c|c|}
\hline TYPE OF PACK & $\begin{array}{l}\text { NET WEIGHT OF CONTENTS, } \\
\text { POUNDS }\end{array}$ \\
\hline Straight & $\ldots \ldots 375-390$ \\
\hline $2: 1$ & 450 \\
\hline $3: 1$ & $430-440$ \\
\hline $4: 1$ & $400-410$ \\
\hline
\end{tabular}


Ireland (1931) recommended that barreled sugared strawberries be rolled every two hours during the process of freezing ( 5 to 6 days at $5^{\circ} \mathrm{F}$ ) in order to cool the berries more evenly and keep the fruit well in contact with the sirup, to prevent oxidation, and to distribute the sirup evenly throughout the barrel. A "cold cure" over a period of 60 to go days at $13^{\circ}-14^{\circ} \mathrm{F}$, during which the barrels are reversed every 45 days, resulted in berries of a bright, natural color and firm texture, and in uniform distribution of sirup without crowding of the berries to the top of the barrel.

Sliced Strawberries.-Sliced strawberries have become very popular for dessert use. These are nearly always frozen in consumer-sized containers. The berries are emptied out of the picking crates, as previously described, and washed in a wide flume filled with violently agitated, rapidly running cold water. Powerful sprays agitate the water and berries, which flow into a shallow metal tank and down a cascade. Some of the berries strike a rapidly vibrating slat shaker and are moved down a short conveyor belt to the first sorting belt. The remainder fall into a second cascade of water, part of which falls on another slat shaker. The berries which strike this slat are moved to the second sorting belt. The remainder are carried similarly to the third and fourth sorting belts. Women sit on both sides of the 18 -inch, white rubber belts and eliminate all defective, underripe, overripe, and imperfectly capped berries. When the berries reach the far end of the sorting belts, they fall into the hopper of a gang disk slicing machine which cuts them into slices about $1 / 4$-inch thick. The sliced berries fall into large corrosion-resistant metal pans. When a pan is nearly full, it is adjusted to a prearranged weight, and another workman adds $1 / 5$, or any other desired proportion, of sugar. The contents of the pan are then dumped into a mixing machine which consists of a series of four hoppers, each turning the contents as it dumps them into the next hopper. The last hopper is that of a filling machine, from which the sugared, sliced berries are filled into waxed cups or tubs, cellophane- or parchment-lined cartons, or enameled tin cans. The packages are then sealed, stacked on trays, and frozen. After freezing, the small packages are packed into fiberboard shipping cases and stored at $0^{\circ} \mathrm{F}$.

Other Berries.-In general, most of the varieties of blackberries and raspberries are packed in much the same way as whole strawberries. In the Pacific Northwest the same washing and conveying equipment is used for all berries. If graders are used, they must be adjusted according to the kind of berry being processed. Cane berries are frequently barreled without sugar. Considerable quantitics are also frozen in 30- and 5o-pound, enamel-lined, slip-cover cans. These are most commonly packed with dry sugar in ratios varying from $2: 1$ to $5: 1$. During the last few scasons, sugar sirups of various concentrations have been used instead of dry sugar, especially for whole berries packed for the consumer trade. As yet, the data indicate that little, if any, advantage is obtained from freezing berries with added ascorbic acid. 
Loganberries, or other berries intended for wine, are often frozen by air blasts, in the baskets or crates in which they were picked. When frozen, the berries are broken apart, conveyed along inspection belts where defects and foreign matter are picked off, and then run into barrels, enamel-lined cans, or moisture-vapor-proof lined fiberboard boxes, usually holding 30 to $5^{\circ}$ pounds. The cleaned berries are then returned to cold storage usually maintained at about $o^{\circ} \mathrm{F}$. The product is free running, and sugar is never added.

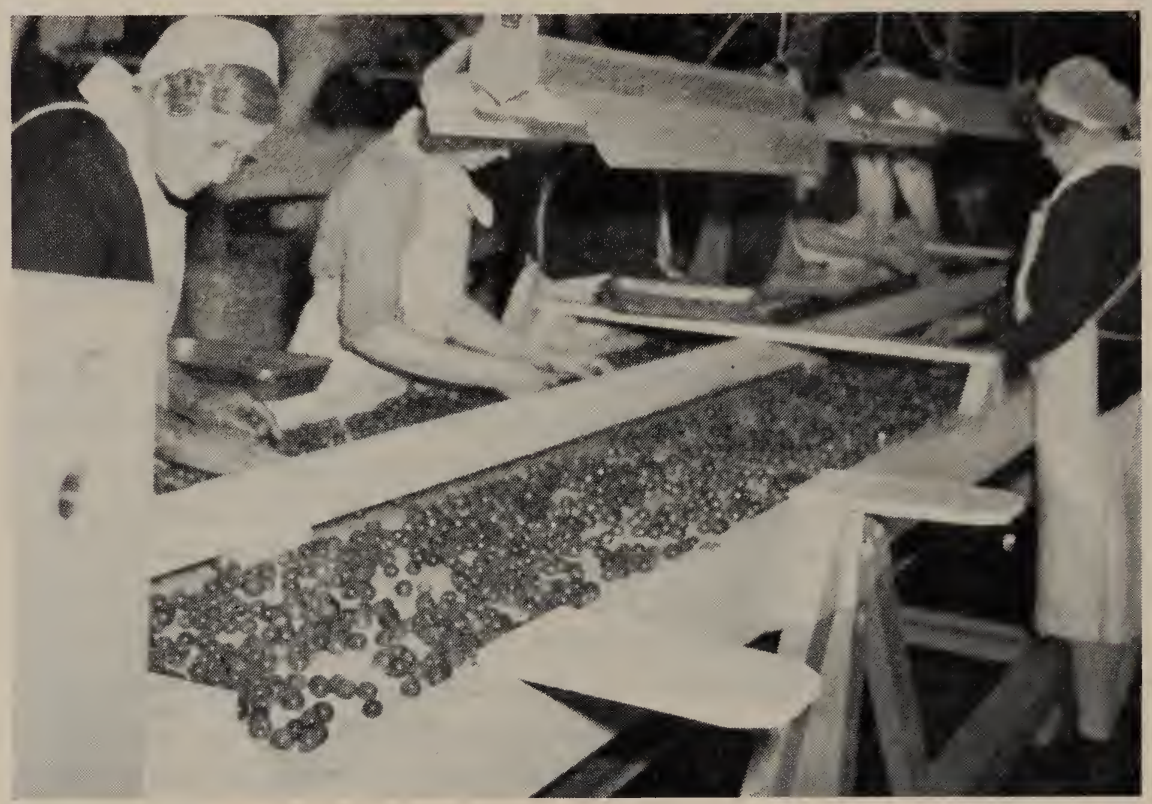

Fig. 16.-Inspecting cherries before filling containers.

(Courtesy of Western Canner and Packer.)

\section{CHERRIES}

General Discussion and Varieties.-Cherry freezing has been of commercial importance in the eastern and northwestern states about equally as long as berry freezing. The most popular product has been the pitted sour varieties in institutional packages or barrels, for use in pies or preserves. The three major sour varieties suitable for freezing are Montmorency, English Morello, and Early Richmond, in that order (Tressler and Du Bois, 1940). Among the subacid varieties, Royal Duke, May Duke, and Reine Hortense have been rated high by the same authors. There has been considerable difference of opinion as to the quality of frozen sweet cherries, the chief difficulty being prevention of oxidation, but commercial freezing of this fruit has recently attained importance in California. The following varieties have been found to produce acceptable frozen products in our laboratory: Napoleon (Royal Ann), Bing Lambert, Black Republican, and Black Tartarian. Pitted Black Tartarians, frozen in slip-cover tin cans with a $4: 1$ sugar ratio, made better pie stock than 
sirup- or water-blanched fruit of the same lot. Napoleon is the most commonly grown variety, but the quality of the red varieties is superior for freezing.

Cherries for Bakers' or Processors' Use-Since most frozen cherries are intended for the bakery trade, it is important to use a freezing procedure which will result in a maximum drained weight, or a minimum of juice. For this reason, dry sugar is generally preferable to sirup pack.

The following procedure is recommended for commercial use. The fruit must be harvested at its optimum fresh-eating maturity. When received at the plant in lug boxes, the fruit should be stemmed, washed, sorted, mechanically pitted, thoroughly mixed with dry sugar in a $4: 1$ or $5: 1$ ratio (preferably by means of a mechanical mixer). It should then be filled into $30-$ or 5 o-pound, enamel-lined, slip-cover tins, or cellophane- or parchment-lined fiberboard cartons, and frozen. $\mathrm{SO}_{2}$ treatment, controlled to give $75^{-1}$ oo p.p.m. in the final product, is recommended but not required.

Cherries for Dessert Use.-Cherries intended for dessert are best if frozen in sirup, but sugar penetration is practically impossible if the raw whole fruit is frozen. Our data show that steam blanching or lye dipping, both of which check the skins, allow sugar penetration, but pitting is the most acceptable way of assuring sugar penetration without destruction of desirable color and flavor characteristics. Ascorbic acid proved to be a useful inhibitor of oxidation in pitted Napoleon cherries when used in a concentration of .25 per cent, dissolved in $40^{\circ}$ Brix sirup, which covered the fruit. But for pitted Montmorency whole cherries of the sweet and sour varieties, there was no apparent advantage in using ascorbic acid with a sirup pack.

\section{CITRUS FRUITS}

By far the greatest volume of frozen citrus fruits has gone into juice. Recently, however, frozen grapefruit segments have become a popular item, although the idea is not new (Joslyn, 1929b; Chace and Poore, 1931).

Varietal Adaptability.-Marsh is the predominant grapefruit variety grown in Southern California. Heid (1941) reported that Marsh and Duncan grapefruit are suitable for frozen juice. These varieties, and pink and red-bred varieties, are also suitable for frozen sections or hearts. Valencia is generally agreed to be the best orange variety for frozen juice. Mandarin oranges are used almost exclusively for preparing sections. Juice of Eureka and Lisbon lemons has been commercially frozen. Limited tests of the Meyer lemon indicated that juice of this variety is not well adapted to freezing preservation. Stahl (1946) rated Florida grapefruit varieties in the following order with respect to suitability for freezing: Silver Cluster, Duncan, Excelsior, Florida Common, Marsh Seedless, and Thompson Pink. All of the seedy varieties were far superior to the scedless, the only disadvantage being the labor of removing the seeds. Of 
the Florida-grown orange varieties, Stahl found Mandarin, Pineapple, and Valencia superior to other commonly grown varieties.

Maturity, Harvesting, and Storage.-Citrus fruits for freezing are best if allowed to come to full maturity on the tree. If this is done, better flavor can be achieved in frozen fruit than in fresh market material which has been harvested early to facilitate storage and shipment. Preferably, fruit should be harvested by hand and placed in picking sacks. Some growers harvest by shaking the trees and allowing the fruit to drop to the ground. If this is done, a large canvas should be spread to catch the fruit, or the ground should be carefully cleared beforehand to avoid the danger of including spoiled fruit. When received at the plant, the fruit may be stored for short periods in large bins. Precooling to remove field heat is highly desirable. Before processing, a thorough washing with sprays, and a period of immersion in water containing 200 p.p.m. active chlorine, followed by further rinsing, is advisable.

Grapefruit Hearts.-Peeling is usually done by hand on cutting blocks raised two inches above the work table (Anon., 1946c). Cutting blocks and tables may be so arranged as to allow the peels to fall through a hole in the table as they are removed. This method is preferable to the lye or hot water treatment commonly used in grapefruit canneries, since heat, more than any other factor, accelerates oxidation. For sectioning the grapefruit, special wedge-shaped, double-bladed knives are used. The operator enters the knife along one edge of a carpellary membrane and turns it out against the next, thus freeing the segment. Inspection to eliminate imperfect sections, seeds, etc., follows. Stahl (1946) recommended that the fruit segments be evacuated immediately, released with $\mathrm{CO}_{2}$, or with sirup or juice, and packaged before coming to room temperature. For one-pound packages, $11 \mathrm{oz}$. of fruit: $5 \mathrm{oz}$. of $25^{\circ}$ to $30^{\circ} \mathrm{Brix}$ sirup (made in part at least with the juice lost from the fruit during and after sectioning) makes a suitable proportion. For larger institutional sizes, the packages can be made to hold relatively more fruit in proportion to the sirup required to cover it. In such a case, a higher sirup concentration of approximately $50^{\circ}$ Brix would be preferable.

Sliced or sectioned oranges may be packed in essentially the same manner. Stahl found that they were best when frozen in their own juice. They require less added sugar than grapefruit. Stahl also found that citrus fruits frozen with added ascorbic acid were of superior keeping quality, especially after thawing. To achieve the best results from addition of this antioxidant, the sirup used with the fruit in the proportion of $5 \mathrm{oz}$. sirup to $11 \mathrm{oz}$. fruit should be made to contain .05 per cent ascorbic acid. Packing the fruit in an atmosphere of nitrogen brought out the fruity flavors, accentuating the taste esters, while carbon dioxide covered up any off-flavors which might be present. If vacuum or gas pack is used, the fruit must be frozen in glass or metal containers. Otherwise, any of the other common types of container may be used. 


\section{FIGS}

Varieties and Maturity.-The fig varieties grown commercially in California are Kadota, Black Mission, Calimyrna (a modified Smyrna fig), and the white Adriatic.

Diehl and Warner (1945) summarized the desirable varietal characteristics of figs for freezing as follows: "Rich flavor and aroma, tender flesh and skin, dark color well retained, seeds not easily noticeable, and freedom from internal rots and tendency to sour."

Joslyn and Cruess (1929) found that whole Kadota figs frozen in $40^{\circ} \mathrm{Bal}$. sirup could be drained and rinsed after thawing and used in the same manner as fresh figs. Pentzer and Asbury (1931) found that Black Mission was the best, and Kadota the second best, variety for freezing in California. Diehl, et al. (1934) reported that California-grown Turkey Brown was unsatisfactory for freezing because of discoloration and inferior flavor. Cruess (1938) found Black Mission, Kadota, and Turkey Brown satisfactory for freezing. Among the varieties grown in Georgia, Woodroof and Bailey (1930) recommended Turkey Brown and Ischia White. Reed (1946) compared a series of varieties grown in Texas and found that Royal Vineyard, Dr. Hoggs Claire, and Reculver gave frozen packs of better quality than the Magnolia, which is the most common Texas variety.

Hohl (1946b) reported that Black Mission possesses most of the desirable characteristics; Calimyrna has good flavor, but the fruits have large seeds, tough skin, and many sour on the trees; Kadota is somewhat lacking in flavor, and tough skinned, but has very small, unfertilized seeds and good texture; Adriatic has a very tough skin and coarse internal structure. The three greenskinned varieties have a greater tendency toward development of oxidized offflavors upon storage of approximately a year than does Black Mission, and they contain the irritating proteolytic enzyme, ficin, which persists through freezing storage.

To develop the best eating qualities, figs must remain on the tree until fairly ripe, and by that time they are soft and will not stand the handling necessary for shipping. Figs for freezing should be harvested when fully ripe, but before shriveling starts.

Preparation for Freezing.-Figs to be prepared for freezing must be carefully washed and sorted, and all that show internal rots or souring must be eliminated. Slicing or halving permits both easy detection of internal rots or souring, and good penetration of sugar or sirup.

No satisfactory method of peeling has been developed. The ripe fruit is too delicate to stand the temperatures and handling of lye-peeling, and hand-peeling is too expensive, too slow, and difficult to do without tearing the tissue. The fruit may be frozen whole and then peeled with abrasive or friction vegetable peelers, but the partial defrosting which occurs during this process almost 
completely destroys the structure of the figs, and allows oxidation to be accelerated. The skin of the Black Mission, however, may be left on without impairing the quality of the frozen fruit.

Even though figs are less subject to oxidation than other fruits, they must be handled quickly during processing and freezing because of their high susceptibility to microbial spoilage.

Sliced figs covered with $35^{\circ}$ Brix sirup make the most attractive product for dessert use. Oxidation is so slow in the sirup pack that any benefit from the use of antioxidants is too small to justify the added expense involved. Blanching figs before freezing is effective in preventing oxidation, but imparts a cooked flavor and softens the tissues too much. Packaging and freezing are conducted in the same manner for this as for other fruits.

\section{GRAPES}

While most of the grapes grown in California have been used for raisins, wines, or fresh market, some have been canned and some frozen, chiefly for fruit cocktail.

A limited amount of work has been reported on the varietal suitability of grapes for freezing. Diehl and Warner (1945) state that desirable varietal characteristics are: "Vinifera types; even maturity, tender skin, sweet, delicate flavor, relative freedom from seediness, resistance to discoloration; native (Labrusca) types not usually suited to freezing except as juice." Woodroof (1930a) rated a series of Muscadine varieties in the following ordier with respect to suitability for freezing: Thomas, San Jacinto, Irene, Latama Hybrid, Scuppernong, Spalding, La Salle, Stuckey, Hunt, Flowers, Howard, and San Monta. He also reported that Concord, a Labrusca variety, was desirable.

Tressler and Evers stated that none of the New York grown varieties made satisfactory frozen products.

Pentzer et al. (1932) investigated Vinifera grape varieties for freezing in California and the Pacific Northwest and concluded that the Muscat of Alexandria retained its flavor and appearance best. The Thompson Seedless lacked flavor, except for sweetness. The other varieties were not suitable.

Woodroof (1945) described a process for freezing Muscadine grapes.

Harvesting of grapes for freezing may be the same as for fresh shipment. The fruit should have attained its optimum fresh table qualities when it is harvested. Our data indicate that Muscat, Thompson Seedless, and Ribier grapes, which make the most acceptable frozen products, are best if harvested at about $20^{\circ}$ Brix. At this maturity, they have their best fresh table qualities and the acidity is sufficient to prevent tartrate precipitation during freezing.

Grapes to be frozen for fruit cocktail processors are precooled and washed, stemmed and sorted, and packed into 30 -pound tins or plastic-lined, fiberboard cartons, using 18 pounds of grapes to 12 pounds of $35^{\circ}$ Brix sirup. If the grapes have been harvested at a maturity which is beyond the optimum, onehalf per cent citric acid added to the sirup will reduce tartrate crystallization. 


\section{MELONS}

While melons are sometimes classified as vegetables, they are similar to fruits in composition and in food uses.

Winter and Hustrulid (1944) list Beauty Osage, Bender's Surprise, Golden Gopher, Sugar Rock, and Sunrise varieties of muskmelons as suitable.

Harvey et al. (1936), and Diehl, Wiegand, and Berry (1939) were successful in getting a satisfactory frozen product from diced honeydew melons, watermelons, and muskmelons. Sugar Rock, Lane's Special, and Golden Osage were considered best by these authors. Cantaloupes suitable for freezing should have salmon- or orange-colored flesh which is deep enough to permit the cutting of balls.

Melons that are vine-ripened are of higher quality than those that are picked green. However, the melons should not be too soft since this usually results in watery, mushy flesh. In judging maturity, the characteristic odor of ripe cantaloupe, the condition of the stem attachment, and the appearance of the skin and netting are all factors to be taken into consideration.

Investigations in this laboratory indicate that Persian melons, honeydew, cantaloupe, and Crenshaw are best frozen as cubes or balls when covered with a sirup of $30^{\circ}-40^{\circ}$ Brix. Frozen watermelons became too flabby and took on a pumpkinlike flavor. All the varieties of melon were more prone to develop this off-flavor after storage when frozen without sugar or with dry sugar instead of sirup. Frozen melon, if consumed in the partially defrosted state while somc ice still remains in the tissues, is less flaccid and more pleasing in texture and flavor. A very attractive pack of mixed melon cubes or balls in sirup is easily prepared. Our experiments also indicated that there was no advantage to be gained by adding ascorbic acid to the sirup. A very light $\mathrm{SO}_{2}$ dip before freezing ( 2 minutes in 2000 p.p.m.) solution helped the fruit to retain its original flavor, but the taste of the sulfite itself was very easy to detect in melons. Blanching resulted in mushy fruit of an unnatural flavor.

Melons are prepared for freezing by halving, removing seeds, and paring before cubing or "sphering.". It is possible to do this mechanically with the smaller and firmer melons, such as cantaloupes, by paring them while they rotate on a large spindle which pierces the fruit, then slicing, stripping, and cubing in a large model dicer. The seeds and smaller pieces can be separated from the cubes by passing them over vibrating shaker screens.

Melon cubes or balls add color to fruit cocktail mixes, and are preferably frozen mixed with other fruits. This can be done with fresh fruits or by mixing frozen fruit after partial defrosting.

\section{NECTARINES}

This fruit is very similar to the peach, having originated as a sport, but it requires slightly different treatment in some respects to achieve the most satisfactory frozen product. The most commonly grown varieties are Stanwick, 
Rivers, Gower, and Quetta, all of which are white fleshed. Humboldt is the only yellow-fleshed variety grown on a commercial scale.

Varietal Adaptability.-Relatively little has been published concerning suitability of nectarine varieties for freezing. Desirable varietal characteristics as expressed by Diehl and Warner (1945) are "low browning tendency, character istic pronounced flavor, slightly blushed skin, and smooth firm texture free from fiber." Clark (1944) found that Golden State was superior to other varieties grown in New Jersey. Stanwick, Gower, and New Boy are generally listed as the California-grown varieties most suitable for freezing. Sorber $\left(194^{2}\right)$ recommended Stanwick and Tioga for purées.

We found that Tioga produces the most acceptable product, and has good acid sugar balance, texture, and general appearance. Unfortunately, there are practically no commercial plantings of this variety, and its cultural characteristics are such that it is not to be recommended for extensive planting. A series of yellow-fleshed seedlings, produced by Mr. Guy Philp of the University of California Pomology Division, made a frozen product of almost comparable quality. These are designated by the following nursery numbers: $27-11,27-12$, $27-13,24^{-13}, 25^{-13}$, and 26-13. They have not yet been introduced commercially. Humboldt freezes to make a fair product. Kim and Bim are yellow varieties grown only to a limited extent. Kim is a good variety for freezing; no data are available on Bim. Of the white-fleshed varieties so far tested, Gower has the best flavor and is good in texture. It has a large amount of anthocyanin pigment in both the skin and the pit cavity, which colors the sirup a bright red, but does not appreciably detract from the appearance. Stanwick may be rated as medium good to fair, with New Boy and a group of practically indistinguishable varieties (Ansenne, Goldmine, Diamond Jubilee, Surecrop) all known as "Australian Seedlings," closely following. This group of varieties is of pleasing flavor, but very soft texture. Quetta is unsatisfactory in flavor, texture, and appearance, besides being difficult to handle because of its cling stone. Thus, of the varieties at present available, Gower, Stanwick, and possibly New Boy, Humboldt, and Kim, are to be recommended.

Harvesting and Handling.-Since nectarines are essentially similar to peaches, the details of harvesting and handling are similar for these two fruits. Proper maturity is perhaps even more critical for nectarines than for peaches. They must yield to thumb pressure with some firmness and not be mushy. When slightly overripe, they take on a characteristic disagreeable flavor which is very noticeable. On the other hand, fruit harvested before it has reached full "eating ripeness" never attains its maximum flavor quality. The fruit ripens rapidly at the usual temperatures prevailing at harvest, and hence should be frozen immediately after picking. If necessary, it may be held a few days at $32^{\circ} \mathrm{F}$ with 85 per cent relative humidity. Discoloration at the seed and loss of flavor occur if such storage is prolonged. 
Packing Procedures.-Nectarines may be frozen either in halves or slices, peeled or unpeeled. Generally, unpeeled halves are preferred for commercial operations. The skins of most varieties are not so tough as those of apricots, and they generally are attractive in appearance. Peeled, frozen nectarines tend to be too mushy. Neither blanching nor sulfite treatment is satisfactory for natural flavor preservation in nectarines. Ascorbic acid in sirup to completely cover the fruits is the most satisfactory type of pack.

A recommended commercial procedure for nectarines would be: Sort and grade, wash, cut and pit, inspect and trim, package. (If 1-pound container is used, use 10 ounces of fruit: 6 ounces of $30^{\circ}-40^{\circ}$ Brix sirup, containing 0.1 per cent ascorbic acid or 0.03 per cent ascorbic acid plus 0.5 per cent citric acid.) Seal, close, overwrap, tray and freeze, case and store at $0^{\circ} \mathrm{F}$. Of the large containers available, the enameled slip-cover tin can or the cellophane- or parchment-lined, fiberboard carton are most suitable for nectarine halves. For these containers, the ratio of fruit to sirup may be somewhat higher. Ascorbic acid, if added to the sirup, should be calculated to give $15^{\circ}$ to $200 \mathrm{mg}$. per pound of finished pack. Thus, a 30-pound package should contain 4.5 to 6 grams of ascorbic acid.

\section{OLIVES}

The freezing of cured, ripe olives has been successfully done experimentally (Cruess and Marsh, 1933; Diehl and Berry, 1933; Hoey, 1941; Joslyn, unpublished; Hohl, 1943), but so far, it has not been undertaken commercially. Mission is the best variety for freezing. Other varieties, particularly Sevillano, lose too much in texture unless they are heated before freezing, but this again results in flavor which is similar to the canned, instead of the desirable characteristic flavor of freshly cured olives. Curing of the fruit would be executed in the usual manner, and quick-freezing, which is important for texture retention, may be accomplished by any of the usual methods, including brine immersion or brine-spray freezing.

\section{PEACHES}

Varietal Adaptability.-Peach varieties have been more extensively studied than any other fruit with respect to their adaptability to freezing. There is also, however, more disagreement with regard to results of the investigations than there is concerning any other fruit. This is probably explained by the fact that the character of a peach variety, in particular, is greatly affected by its growing conditions (climate, soil, weàther, fertilizer, etc.). In general, clingstone varieties have been considered unsuitable for frozen dessert packs, and have only been frozen for special purposes such as reprocessing for fruit cocktails, baby foods, or pies, or during emergency periods, such as the recent war when the importance of quality was temporarily forgotten. There has also been rather widespread agreement that the white-fleshed peach varieties generally gave less satisfactory frozen products than the yellow fleshed. This fact is 
caused mainly by their usually soft texture and great susceptibility to oxidative browning.

The desirable varietal characteristics of the yellow-fleshed freestones include pronounced flavor which is not appreciably changed by freezing preservation, firm but tender texture, and relatively low tendency to darken oxidatively. The trees should yield well every year, the fruit should ripen uniformly, be easily peeled, and be able to withstand relatively rough handling without bruising badly.

During the past three fruit seasons, a comparison was made of the varietal suitability of a number of commercial and seedling peaches grown at the University of California Division of Pomology's experimental orchards near Winters. It was found that the best frozen sliced peaches can be prepared from J. H. Hale, Rio Oso Gem, and Elberta. The relative ranks of these three varieties are a matter of personal preference. Rio Oso Gem is perhaps best of the group for texture, and it usually is slightly less subject to browning, but its disadvantages are a relative lack of characteristic peach flavor, and the diffculty sometimes experienced in peeling it. J. H. Hale usually has the best appearance, with its red flesh around the cavity and lack of ragged edges. Its flavor is generally pleasing. Its texture is slightly softer than Rio Oso Gem, but the pieces look firm. Some, but not all, tasters prefer the Elberta's flavor. Its texture is generally softer than that of the other two varieties, and its titrable acidity is significantly lower. Its greater availability is a point in its favor.

Early Elberta and Fay Elberta are nearly as good as the three varieties discussed above, but they are generally rated lower because of a slight deficiency in flavor. The Sunbeam is a New Jersey variety which has not yet been extensively planted in this state, but it is of interest because it does not brown upon exposure to oxygen. When preserved by freezing, it retains excellent fresh color and does not take on any oxidized flavor, but its flavor is slightly flat. Its texture is rather flabby, but it is generally rated as good, particularly by those judges who object seriously to "brown," "oxidized," or "dried peach" flavor. The remaining Winters-grown varieties were considered only fair or poor in these tests.

Kirkman Gem, a patented sport of Rio Oso Gem, has had limited commercial trial, but has yielded an excellent product. However, there is probably only one commercial planting of it in the state.

In general, the earliest ripening varieties, while they are less subject to darkening than the others, lack characteristic flavor and are rather fibrous and mushy in texture. The best varieties all fall into the group which ripens in August during the main peach season. The late varieties are less suitable, mainly because of their great susceptibility to oxidation. Of the six or eight white-fleshed varieties tested, White Hale is the only one which yielded an acceptable frozen product.

Some comparison of cling peach varieties was made, but there are such small differences in flavor among these when frozen that no conclusions can be 

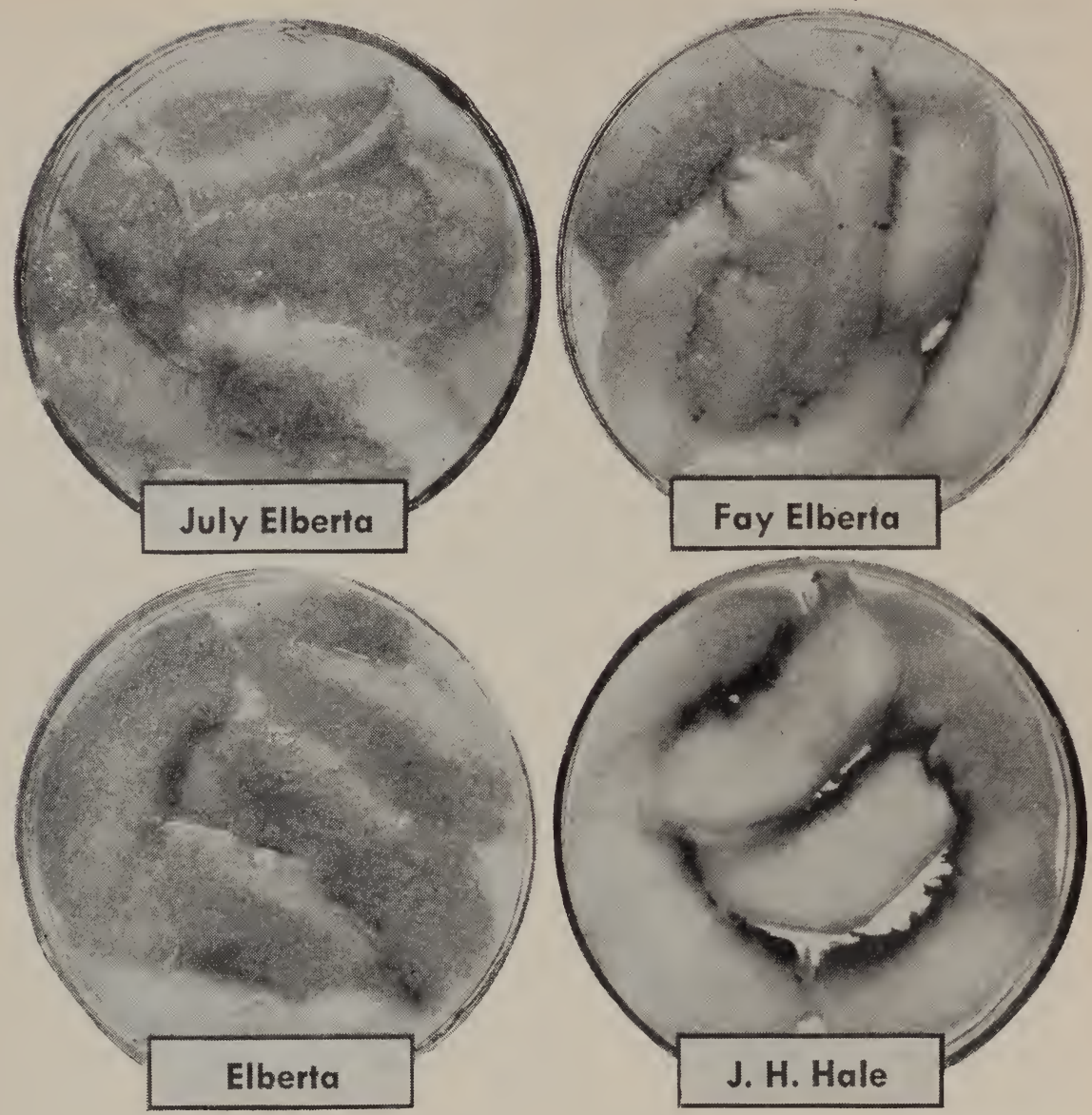

Fig. 17.-Above, and opposite page,

drawn. None made satisfactory frozen dessert products, unless preheated to tenderize the tissue, but even with such treatment, the product is inferior to canned cling peaches. Varietal differences in texture of frozen cling peaches were noticeable.

Maturity, Harvesting, and Storage.-More skill and care are required in handling and harvesting peaches to be used for freezing than is required for those to be shipped fresh or used for canning. For the latter purposes, the fruit is picked while firm, and allowed to ripen on its way to market. If fruit intended for canning is bruised, the subsequent cooking, destroys any discoloration which may occur. However, it is imperative that peaches for freezing be soft ripe, and it is preferable that they reach this stage while still on the tree. Only experienced and trained pickers can understand the delicate task of handling soft ripe fruit to get it from the trees to the packing plant in optimum condition. If a variety is chosen which ripens unevenly, it may be necessary to dis- 

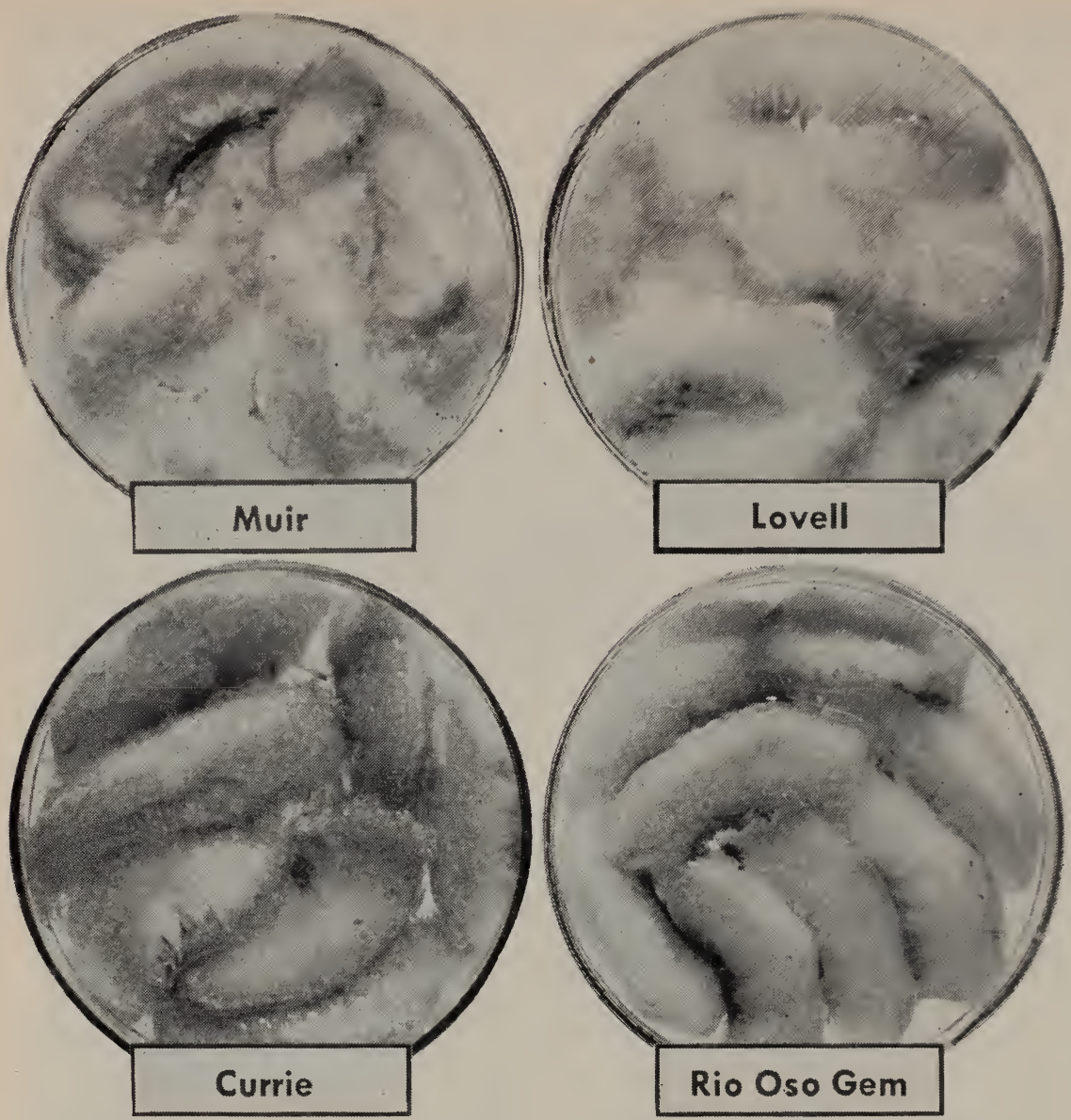

appearance of different varieties of frozen peaches.

card the underripe portions. If it is found impractical to allow the fruit to become soft ripe on the tree, it may be harvested a day earlier in the firm ripe stage, when it may be handled a little more roughly. This procedure has the added disadvantage of requiring more containers and storage space in either the plant or a field shed. If it is necessary to hold ripe peaches because of holidays or other temporary shutdowns, or when the volume coming in is greater than plant capacity, the fruit may be stored safely at $36^{\circ} \mathrm{F}$. Woodroof $(1930 \mathrm{~b})$ reported that peaches may be stored for as long as three weeks in favorable seasons. It has sometimes been observed that a short period of cold storage before processing is useful in preparing the tissues for steam peeling. This is particularly true of the Rio Oso Gem.

Preparation for Freezing.-The peeling of freestone peaches has always been a problem in the freezing industry. Hand-peeling is slow, expensive, and less sanitary than other methods. Lye-peeling, which is generally applied to peaches 
for canning, offers several objectionable features, chief of which is the undesirable effect of the heat upon the flesh just beneath the peel. A lye-peeled peach for canning is satisfactory because the subsequent processing completes the heating which extended only part way through the peach during the peeling operation, but this effect is, of course, lacking in freezing. Lye-peeling, as ordinarily applied (at almost the temperature of boiling water), leaves a cooked layer immediately below the peel and a partially cooked layer just beneath

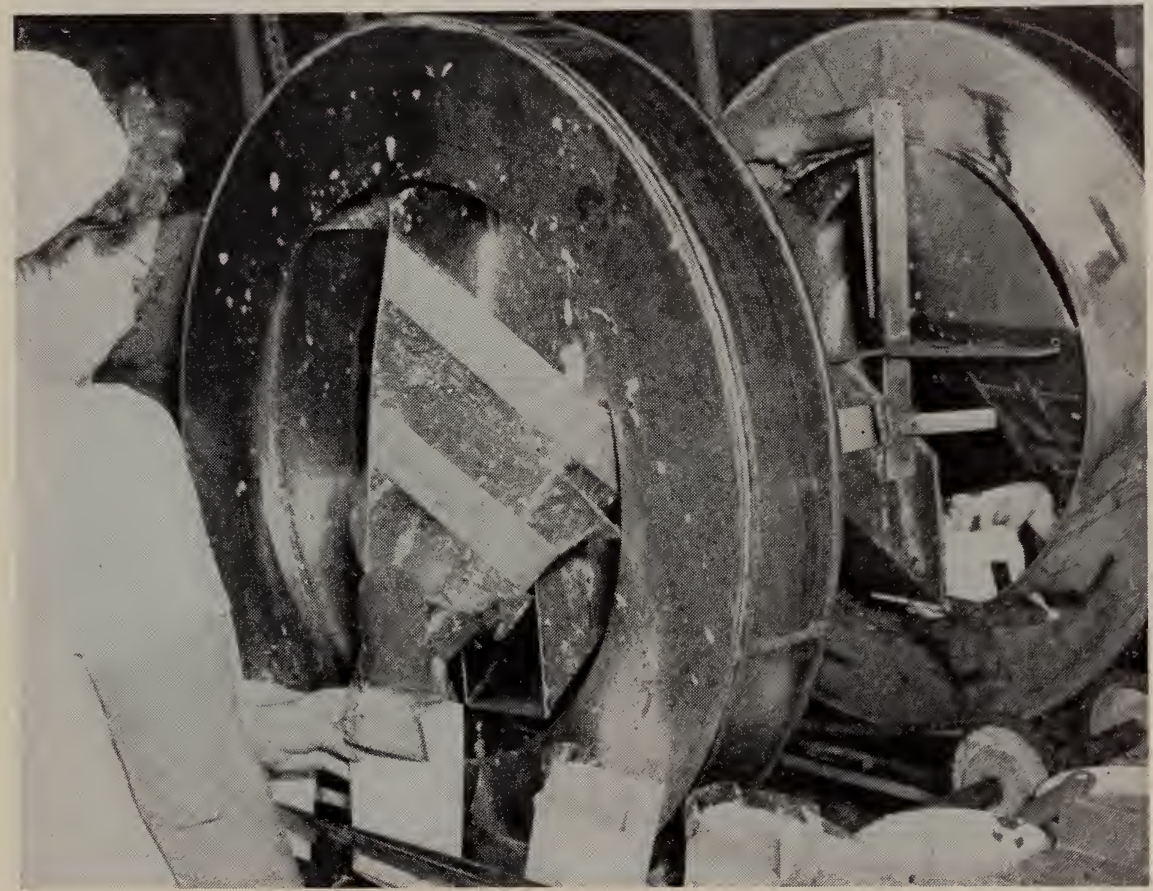

Fig 18.-Filling wheels placing peaches in 1-pound containers prior to freezing. (Courtesy of Western Canner and Packer.)

that which is extremely subject to browning. Woodroof (1931a) and others have demonstrated that peach tissue heated to $140^{\circ}$ to $15^{\circ} \mathrm{F}\left(60^{\circ}-70^{\circ} \mathrm{C}\right)$ darkens more rapidly than that subjected to temperatures above and below this range. Therefore, he recommended that peaches be peeled at $140^{\circ} \mathrm{F}$ in a 10 per cent lye bath where they remain for two minutes, after which the skins are removed by women wearing rubber gloves. Following peeling, the peaches are washed in clear running water and finally rinsed in 2 per cent citric acid to neutralize the excess alkali and retard browning.

Pitting of freestone peaches is ordinarily done by hand by girdling the peach with a knife and lifting the pit out with the point of the knife. From 8 to 12 per cent of the weight of peaches is lost during lye-peeling if they are peeled before pitting. (The pit constitutes about 6 to 10 per cent of the weight of the peach.) Some processors prefer to halve and pit before lye-peeling be- 
cause of the difficulty experienced by the workers in handling the slippery, lyepeeled fruit. However, if this procedure is followed, the peeling losses rise to 10 to 15 per cent of the weight, the attractive red anthocyanin pigments in the pit cavity turn brown to black and the flesh is badly disintegrated.

Peaches may also be peeled satisfactorily by scalding in steam. The length of time required to loosen the skins varies with the fruit's variety and maturity. For soft ripe fruit, 1 minute suffices, but for firm fruit, $1 \frac{1 / 2}{2}$ to 2 minutes may be required. Immediately after scalding, the fruit should be cooled by spraying, to loosen the skins and to keep the fruit from becoming softened by the heat. A modification of this procedure is to cut and pit the fruit, place the cut side down on a moving belt which passes through a steam chamber in approximately 75 seconds, and follow with a spray cooling. The halves are then removed from the belt and the skins are slipped off.

The method of peeling to be selected depends upon variety of fruit, availability of equipment, and use for which the fruit is intended.

The peaches are generally sliced mechanically by means of radially spaced rotary disks or fixed knife blades. Each half should be cut into 5 to 8 longitudinal slices.

Peaches for dessert are usually packed with sirup containing added ascorbic acid. Generally, for a 1-pound container, 11 ounces of fruit with 5 ounces of $40^{\circ}$ Brix sirup, containing 0.1 per cent ascorbic acid is satisfactory. Slight modifications of this procedure may be necessary to suit individual conditions such as size and shape of containers, type of liners, variety and size of fruit, etc.

Special Products and Treatments.-Clingstone peaches are generally much more satisfactory as a canned, rather than a frozen, product. However, if so desired, they may be frozen for later use in pies, preserves, baby foods, or fruit cocktails. In any case, lye-peeling by the usual procedure employed for canned peaches, followed by thorough rinsing, preferably with some acid included, is the best procedure. Peaches intended for reprocessing into preserves or purées may be frozen in halves. Those intended for pies are best sliced, while those intended for fruit cocktail may be diced. Steam-blanching is the best method of preventing discoloration in cling peaches. The time required will depend upon the size of the pieces and other factors, and must be determined by the operator. Overblanching is not so serious with cling peaches as with freestone and, in fact, is desirable as it helps to tenderize the tissues. Most commonly, cling peaches would be frozen in large, institution-sized containers, and sugar need not, but may, be added if the buyer so desires. Freestone peaches, frozen for pie use, or for use in the home for jam making, are best when treated with sulfite solution as for apricots-immersed in a 0.4 per cent solution for $3 \mathrm{~min}$ utes for halved fruit-but may be scalded as well.

During the war, Sorber (1943) investigated the freezing of whole unprocessed peaches and other fruits to prolong the preserving or processing season. $\mathrm{He}$ found this procedure feasible for preserves or home canning as long as the 
fruit was defrosted and heated to a temperature sufficient to inactivate the enzymes immediately after removal from freezing storage. In our experience, freezing of halved, peeled clingstone peaches for subsequent processing has been found more advantageous.

\section{PEARS}

Pears, chiefly Bartletts, are one of California's most important fruits. The pear is a notable exception to the rule that fruit for freezing should be harvested at eating maturity. Pears must be picked while they are still green and allowed to ripen at room temperature, preferably after cold storage for a week or longer. In general, pears are not recommended for freezing, except as purées, because of losses of flavor and texture, but Tressler and Evers (1947) state that the Kieffer and Bartlett varieties are somewhat superior to others for freezing as halves or quarters. Our data indicate that the Bartlett is superior to Beurre Hardy. Pears which have been frozen commercially to a limited extent have been used mainly for reprocessing. To prepare for freezing, peel as for canning, core, cut into halves, fill into large containers, cover with $40^{\circ}-50^{\circ}$ Brix sirup, and freeze. For retail use, they could be sliced in a cling peach slicer. Pears are extremely subject to browning, and should therefore be handled quickly after peeling. Addition of 75 to 100 p.p.m. $\mathrm{SO}_{2}$ to the fruit before freezing would prevent discoloration, but is detrimental to flavor.

\section{PERSIMMONS}

The Hachiya is the persimmon variety most frequently planted. It was recommended for freezing as pulp or purée by Cruess and Joslyn (1929). Freezing of the whole fruit has been done experimentally in this and other laboratories. Woodroof (1931 b and 1932) stated that frozen Japanese persimmon; lose practically all of their characteristic aroma. Our experiments have shown that whole frozen persimmons darken and deteriorate in flavor very rapidly upon thawing. They also are very soft in texture, but not noticeably more so than a very ripe fresh persimmon. Dorsett (1928) reports that in northeastern China, persimmons are piled on the ground under straw and allowed to freeze there. When needed, the fruit is simply put into a vessel of cold water to thaw slowly, and is reported to be as good as when freshly picked. This indicates that frozen whole persimmons might readily be produced in this country, too. If the fruits are exposed too much to air during thawing, they turn brown.

For recommended commercial procedure, see section on purées. For persimmons, it is of even more than usual importance that the proper stage of maturity be selected for freezing, since underripe persimmons are very astringent.

\section{PLUMS AND PRUNES}

Plums and prunes are excellent when frozen for use in pies. The suitability of our commercial varieties for freezing has been reported for purées by Sorber (1942), who concluded that the French, Imperial, and Stewart prunes 
and the Gaviota, Methley, and Wickson plums were satisfactory. Our data indicate that good pie or jam stock can be prepared from Methley, Gaviota, Beauty, Apex, Santa Rosa, Tragedy, Acer, Diamond, and Duarte plums, and French, Imperial, and Italian prunes. Plums and prunes do not make a very satisfactory frozen dessert pack because of their tough skins, high acidity, and lack of sugar penetration into the tissues.

The procedure recommended for the freezing of plums is to harvest them at fresh eating maturity, sort, wash, cut into halves or quarters, and pit. Add sugar or sirup; freeze in large or small containers. Tressler (1935) reported that the flavor is better, but the skins are tougher, if dry sugar is used. If dry sugar is used, a $3: 1$ ratio is recommended, and this should be mixed in until enough juice is drawn out to cover the slices. If sirup is used, the quantity should be just sufficient to cover the sliced fruit, and it should be at least $60^{\circ}$ Brix. Storage at the lowest available temperature is also recommended. We have observed that many varieties of plums, especially Kelsey, Wickson, Burbank, and several others, are very likely to take on a haylike oxidized flavor, particularly in the skins, during prolonged storage ( 6 months or longer) at $o^{\circ} \mathrm{F}$. About 100 p.p.m. $\mathrm{SO}_{2}$ or 0.1 per cent ascorbic acid will help to prevent this.

\section{RHUBARB}

Like melons, rhubarb is usually termed a vegetable, but in composition and uses, is a "fruit."

California has two commercially important production areas for rhubarb, Alameda County, where Strawberry and Cherry are the principal varieties, and Los Angeles County where Giant Cherry and Crimson Winter are most popular. All varieties yield a product of good flavor, but those. with deep red color make a more attractive pack. The texture is much changed by freezing.

The stalks should be harvested while they are succulent. Rhubarb may be frozen either with or without previous blanching, but the blanched product keeps better during storage. If this is done, the common commercial procedure is to trim off the leaves and butt ends, slice the stalks into 1-inch lengths, inspect and eliminate defective pieces, spray wash, steam blanch (usually $11 / 2$ to 2 minutes), cool with fog sprays or air blast, package, and freeze. Rhubarb for pie is usually frozen in institution-sized paper or metal containers, or barrels. If unblanched, the stalks are sometimes merely cut into lengths to fit the packages selected. Further information can be found in the references cited (Harvey, 1933; Rabak, 1938).

\section{TROPICAL AND SUBTROPICAL FRUITS}

\section{AVOCADOS}

Southern California produces a significant crop of avocados, and there is frequently a surplus, particularly of culls from the packing houses. Investigations of Cruess and Harrold (1927) and subsequent laboratory studies 
(Joslyn, 1930c; Woodroof, $1931 b$ and 1932) show that this fruit loses flavor and texture if frozen whole, or sliced, but that the purée keeps $w e l l$ at $o^{\circ} \mathrm{F}$ storage, especially when sweetened and deaerated before freezing. Such frozen pulp is excellent for making ice cream. Unsweetened purée is suitable for salad dressings, cocktail spreads, etc. Adriano et al. (1933) reported that all the Philippine fruits kept better when stored at $0^{\circ} \mathrm{F}$ or $-40^{\circ} \mathrm{F}$, than at $18^{\circ} \mathrm{F}$.

\section{COCONUTS}

The wartime shortage of dried coconut stimulated interest in a frozen-pack product, which had been reported successful by Adriano et al. (1933). The rigid structure of coconut tissue makes it one product whose texture is unaffected by freezing and thawing. Our experiments here have shown that excellent fresh flavor may be retained for storage periods of at least two years at $\mathrm{o}^{\circ} \mathrm{F}$, by merely freezing the shredded flesh in its own milk plus the water taken from the center of the fruit. Sugar may be added, but is not required. In fact, that frozen without added sugar is preferable since it has a better pure white color. Sugar, probably because of its plasmolysing effect which draws most of the water from the cells and leaves mainly the oily material in the vacuoles, gives the shredded coconut a translucent appearance which is unattractive. Several commercial processors have frozen shredded coconut without sugar during the past few seasons, and this has been marketed both at retail and to confectioners and bakers. The additional moisture present makes it necessary to readjust formulas designed for dried coconut.

\section{DATES}

Southern California produces a valuable crop of dates, particularly of the Deglet Noor variety. Most of these are dried, but recently there has been some interest in freezing them to preserve the fresh characteristics. Commercial laboratory tests have given promising results on frozen fresh, whole dates, particularly of the Barhi variety (Winter, F., unpublished data). Sorber (1942) found that date purée could be satisfactorily frozen without added sugar, and that it could be utilized for making ice cream, puddings, etc.

\section{GUAVAS}

Guavas have not yet been produced on a commercial scale in California, but Webber (1942) showed that many varieties could be grown successfully in southern California. Reports on successful experimental freezing of guava have been written by Adriano et al. (1933) and Cruess et al. (1945). The most successful frozen guava product was blanched or unblanched purée, with or without added sugar. Frozen slices or halves, in sirup or dry sugar, become rather flabby and the prominent stone cells are more noticeable by contrast. Pie made from the slices and ice cream made from the purée were very acceptable products. 


\section{MANGO, PAPAYA, PASSION FRUIT}

Mango may be frozen most satisfactorily as a purée, but success has also been reported in freezing the sliced fruit of both mango and papaya in sugar or sirup (Adriano et al., 1933; Anon., 1945). Poore (1935) found that frozen passion fruit juice and purée were excellent products.

\section{PINEAPPLE}

Pineapple enjoys universal popularity, and while it has not yet been commercially grown in California, proximity to Hawaiian and Mexican centers of production explains local interest in the freezing of pineapple products. As pointed out by Eckart and Cruess (1931), the pineapple has a great advantage for freezing because of its failure to darken oxidatively. It also has the added advantage of losing little or none of its original texture. Other investigators who have reported successful freezing of pineapples or juice include Adriano (1933), Anon. (1945), Joslyn (unpublished), Chace and Poore (1932), Plagge and Lowe (1942), and Hohl (1945). Best flavor can be achieved only if the pineapple is allowed to reach full maturity on the plant. Therefore, pineapple freezing should be done in the centers of production rather than at distant processing plants. The fully ripe fruit should be pared, cores and other woody portions should be removed, and the fruit sliced in any desired style, or crushed. It may be packed either with dry sugar in a $4: 1$ ratio, or covered with $30^{\circ}-40^{\circ}$ Brix sirup or with its own juice. The size of the container is determined by the use for which the product is intended. In frozen pineapple, a very disagreeable fishy off-odor and flavor have sometimes been observed to develop during storage, particularly in underripe fruit. Tressler and Evers report that these off-flavors are more likely to occur in the Red Spanish than in other varieties, and that they may be caused by the action of proteolytic enzymes. Our own observations have indicated that these off-flavors are much more noticeable in pineapple frozen with added sugar than in similar fruit which was frozen with nothing added. Neither ascorbic acid nor sulfur dioxide was effective in preventing the development of these flavors. The occurrence of these off-flavors is by no means universal in samples which have been stored for long periods, and samples may also vary in their response to antioxidants. Several lots which we have held for from one to several years never developed it, while some others had a marked off-flavor within less than six months. 


\section{CRUSHED, SIEVED, OR PURÉED FRUITS}

Certain fruits can best be frozen in the crushed or pulped condition, either because they lose texture when frozen whole or sliced, or because they may best be distributed in crushed form. Where the fruit is used for ice cream, ice, jam, and general soda fountain use, it is preferred in this form.

Flavor and color are better preserved in sieved or pulped fruits, as oxidative deterioration can be minimized, particularly if the resulting pulp is deaerated. The full value of antioxidants, such as ascorbic acid, is obtained with fruit

Table 16

VARIETIES OF FRUIT AND PROPORTIONS OF SIRUP FOR DESSERT PURÉE USE*

\begin{tabular}{c|c|c}
\hline \hline Kind or variety of fruit & $\begin{array}{c}\text { Concentration } \\
\text { of sirup }\end{array}$ & $\begin{array}{c}\text { Parts of pulp to 1 } \\
\text { part sirup } \\
\text { by volume }\end{array}$ \\
\hline Cranberry, passion fruit...................... & $\begin{array}{c}\text { Degrees Brix } \\
67\end{array}$ & 1 \\
Montmorency cherry, feijoa, Logan blackberry, Santa & & \\
Rosa and Claret plums, Boysen blackberry, straw- & 67 & 2 \\
berry, and Young blackberry ................. & 67 \\
Blackberry, Bing cherry, crabapple, Calimyrna fig, & 67 & 3 \\
Hachiya persimmon......................... & 67 & 4 \\
Apricot, Humboldt nectarine, and Ranaree raspberry..... & 50 & 1 \\
\hline
\end{tabular}

* Source of data:

(1942).

Sorber, D. G. Frozen, sliced, crushed, and puréed fruits. Canner $94(7): 16-7,36 ;(8): 18,20,22,32$.

pulps, and sugars also exert their full protective effect since both these agents can be uniformly incorporated throughout the entire fruit mass.

Only fully ripe, well-colored, and strongly flavored fruit should be selected for pulping. Such fruit as apricot, pear, peach, plum, cherries, berries, Persian melon, cantaloupe, persimmon, papaya, mango, and guava can be well preserved in this form. Avocados, because of their extreme sensitivity to enzyme oxidation, have not been successfully frozen as pulp in the usual manner, but when properly deaerated and vacuum-packed, are satisfactory if used immediately after defrosting.

The stone fruits should be peeled, halved, and pitted before pulping in the usual nonaerating juicer used as a sieving device. This is particularly true of avocados and persimmons. Apricots and peaches need only be pitted if a twostage siever is used, or if the fruit is passed through a grinder of the meatchopper type before sieving. Soft fruits, such as berries, can be sieved directly. In sieving the fruit, particular care should be taken to avoid exposure to air, or aeration during pulping and subsequent treatment. 
The fruit purées are best preserved after sweetening with sugar or heavy sirup. Flavor and color retention is better in a $4: 1$ pack, although the $5: 1$ or $6: 1$ pack is preferred by ice cream manufacturers. Usually, the addition of citric acid improves the palatability and keeping quality of the fruit; 0.5 per cent citric acid may be used with the $4: 1$ pack of most fruit pulps. In addition, ascorbic acid added at the rate of about $0.02-0.03$ per cent by weight will improve color and flavor retention in most fruits.

Fruit pulps can be well preserved only in hermetically sealed containers. Surface oxidation can be avoided by closure under vacuum, by covering the surface with a small volume of sugar solution containing added antioxidant, or by placing a parchment paper disk, wetted with an antioxidant solution, over the surface.

In our experience, avocado pulp is best when it is deaerated and then packed in a vacuum-closed can. If the fruit is rapidly handled during peeling, pitting, sieving, sweetening, and packing, fair success may be had by filling tin cans so that they are completely filled after expansion by freezing has occurred. The frozen avocado pulp should be thawed under refrigeration and used in milk shakes, ice creams, etc., right after partial defrosting.

A combination of crushed, sieved fruit and sliced fruit is finding favor for ice cream use.

Frozen purée desserts of high quality can be prepared by a method recommended by Sorber (1932). Fruit purées are diluted with $67^{\circ}$ Brix or Bal. sirup in proportions which depend upon the sweetness of the particular fruit (for example, for cranberry, equal volumes of pulp and sirup are recommended, while for persimmon, four volumes of pulp are used to one of the sirup), and are quick frozen. The smoothness of the product depends upon the rate of heat exchange during freezing, the percentage of water and soluble solids in the purée, the proportion, particle size, and distribution of the insoluble solids, and the nature of the protective colloids present. These purées must be eaten at just the right temperature so that they are neither too hard nor too runny. The proper serving temperature is difficult to achieve under practical conditions. The varieties of fruit, and the proportions of sirup recommended by Sorber are shown in table 16 .

\section{VELVA FRUIT}

The Western Regional Research Laboratory (Anon., 1946d) has developed a frozen fruit purée dessert using gelatin ( 0.5 per cent) as a stabilizer. The mixture is prepared by dissolving sugar (and approximately 0.2 per cent citric acid for less tart fruits) in the ratio of one part for each 2.4 parts of fruit or enough to make a soluble solids content of $37-38$ per cent in the purée. The gelatin is mixed with ten times its weight of water, heated to $180^{\circ} \mathrm{F}$ to dissolve and sterilize it, and carefully mixed with the sweetened purée, stirred to prevent lumps of gelatin. The mixture is then frozen in an ice cream freezer to get smooth texture and about oo per cent overrun. Velva Fruit can be prepared 
from raspberries, strawberries, Loganberries, Boysenberries, Youngberries, apricots, plums, cantaloupes, nectarines, and peaches. Typical formulas for Velva Fruit are shown in table 17. The ingredients given are sufficient for 100 gallons of mix and will yield 200 gallons of Velva Fruit.

Tressler (1942) developed a similar product using pectin as the stabilizer. Its main purpose was for use in ripple or marble ice creams. In order for the

\section{Table 17}

TYPICAL FORMULAS FOR VELVA FRUIT*

\begin{tabular}{|c|c|c|c|}
\hline Ingredient & Formula A $\dagger$ & Formula B $\dagger$ & Formula $\mathbf{C} \dagger$ \\
\hline 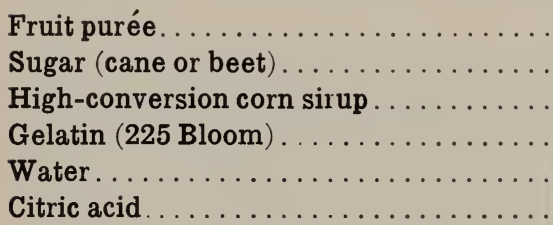 & $\begin{array}{l}617 \mathrm{lbs} . \\
258 \mathrm{lbs} . \\
4 \mathrm{lbs} .13 \mathrm{oz} . \\
96 \mathrm{lbs} \text {. }\end{array}$ & $\begin{array}{l}591 \mathrm{lbs} . \\
165 \mathrm{lbs} . \\
123 \mathrm{lbs} . \\
4 \mathrm{lbs} .13 \mathrm{oz} . \\
96 \mathrm{lbs} . \\
\ldots \ldots\end{array}$ & $\begin{array}{l}649 \mathrm{lbs} . \\
216 \mathrm{lbs} . \\
4 \ldots \\
4 \text { lbs. } 13 \text { oz. } \\
95 \mathrm{lbs} . \\
1 \mathrm{lb} .14 \mathrm{oz} .\end{array}$ \\
\hline
\end{tabular}

* Source of data: Anonymous. Velva-fruit, a new frozen fruit dessert. Western Regional Research Laboratory, Albany, California. (U. S. Dept. Agr., Bur. Agr. Indus. Chem.) Mimeo. Cir. A1C-40 Rev. No. 1, 6 pp. March, 1946.

$\dagger$ Formulas $A$ and $B$ for fruits with a high acid content, such as raspberries, Boysenberries, strawberries, Santa Rosa plums, or Montmorency (sour) cherries; in formula B, high-conversion corn sirup, such as the $43^{\circ}$ Bé enzyme-converted sirup, is used to replace one third of the sugar; formula $\mathrm{C}$, for fruit with relatively low acid content such as apricots, cherries, and pears.

product to have about 10 per cent higher total solids content than the ice cream mix, and still not be too sweet, Tressler has incorporated quantities of enzyme-converted corn sirup in his formulas, details of which are also given in his textbook.

Paul (1946) has suggested many excellent uses for frozen fruit purées in a variety of desserts.

\section{JAM AND JELLY BASES}

Frozen jam and jelly bases are good for home use because they permit the housewife to make jam or jelly at any season, without the trouble of preparing the raw fruit. Fruits or fruit mixtures for these products must be properly balanced in acid and pectin content.

The preparation of canned and bottled fruit jelly juices for household preparation of jelly was developed a number of years ago at this Station (Cruess and Marsh, 1932 and 1941). These products, if frozen, can be preserved with a better degree of color and flavor retention. The recommended process is: Cook crushed or sliced fresh fruits of suitable variety with water to cover, until soft; press, filter and concentrate the juice, preferably in a vacuum, until it will give a good jelly if it is boiled to the jellying point with an equal volume of cane sugar. Jam bases were prepared by steaming sliced, crushed, or coarsely ground fruit, and packing without sugar. The sieved or puréed fruit described on page 86 can be used for jam making. In using these products, the housewife 
simply adds sugar in equal amounts and boils to the jellying point, $220^{\circ} \mathrm{F}$. She is saved the trouble and labor of preparing the raw fruit, and may make jelly at any time of the year.

The successful preparation of these bases, particularly the jelly base, lies in selecting fruits or mixtures of fruits properly balanced with regard to acid and pectin content, and in extracting the desired quantities of pectins of suitable quality. These difficulties, of course, can be minimized by the common use of liquid pectin preparations in the home. A better plan is that of adding to the fruit pulp or fruit juice before freezing just the right amount of pectin and acid. Cox (1945) has developed such a product in which the quantity of pectin and acid added is sufficient to enable jam or jelly to be made by thawing, heating to boiling, adding a specified amount of sugar, and boiling one minute. The following formulas illustrate typical batches of jam and jelly base as prepared by Cox:

\section{JAM BASE PACKAGE}

Youngberry purée (9.5 per cent soluble solids) . . 752 grams

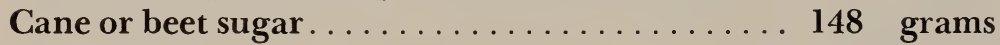

Citric acid .

Pectin (150 grade slow set)

Total

3.5 grams

4.0 grams

907.5 grams
2-POUND

PACKAGE

JELLY BASE

Youngberry juice (9.0 per cent soluble solids) . 748 grams

Cane or beet sugar . . . . . . . . . . . . 150 grams

Citric acid ..................... 4.5 grams

Pectin (150 grade slow set) ............ 5.3 grams

Total
100-POUND ВАTCH

83 pounds

16 pounds 6 ounces 7 ounces

100 pounds

100-POUND

BATCH

82.5 pounds

16.5 pounds

8 ounces

9 ounces

100 pounds

The pectin, with some of the sugar (1 part pectin to 6 of sugar), may be added to the purée or juice, placed in a tank equipped with agitator, and mixed by stirring. Finely powdered citric acid is then added and dissolved and, finally, the remaining sugar. The standardized bases are then packaged in two-pound containers. In using, the housewife places the frozen fruit pulp or juice in a 6-quart kettle, breaks it up, thaws it thoroughly, and heats to boiling. Four level measuring cups of granulated sugar, previously measured out in a pan, are added, stirred to dissolve, and the mixture again heated to boiling and boiled for one minute. It is then removed from the fire, skimmed, poured into glasses, and sealed. The slow-setting pectin was used to allow bubbles of air to escape from the jelly or jam. The proportions of liquid and sugar and the boiling time were planned to give a jam or jelly of 64 to 68 per cent soluble solids. The short boil was used for better flavor and color retention, but it is 
long enough to insure sterility and to invert sufficient sugar to prevent crystallization during storage of jam or jelly.

A frozen marmalade base containing sweetened orange juice, pectin, citric acid, and softened peel strips can be prepared as described above.

Frozen fruit has long been used by the preserve industry in the production of jams and preserves. This method provides year-round operation, and results in preserves of fresh flavor and color. Thompson et al. (1946) not only confirmed the value of freezing fruit products for preserve making, but also reported that preserves freshly made from frozen stock have better color and flavor than those made from fresh stock and stored at room temperature.

\section{FRESH FRUIT SPREADS}

A method of preparing jellied cranberry sauce, without extensive heating, and preserving it by freezing was developed by Boggs and Johnson (1947). The method is based on the cold process of preparing jellies described by Baker and Goodwin (1941), and has advantages not only for cranberry gel, but also for gels made from a wide variety of fruits. Color and flavor are superior to those in products prepared by conventional methods involving boiling, and are better retained during storage. Syneresis (weeping) can be held to any level desired, and the process is well adapted to continuous production.

To prepare cranberry gel, steam the berries on trays for 2 minutes, cool to at least $120^{\circ} \mathrm{F}$, and purée in a conical screw expeller-type press, using a 0.033 in. screen. Add 118 pounds of water to each 100 pounds of puréed berries. The purée may also be prepared by boiling equal weights of berries and water in a steam-jacketed kettle, partially cooling, puréeing, and then cooling to approximately $80^{\circ} \mathrm{F}$. To 100 pounds of purée containing the added water, add $0.4^{2}$ to $0.5^{8}$ pounds of rapid-set, $15^{0}$-grade citrus pectin (the quantity depends upon the quantity and quality of pectin present in the cranberries) with 13 pounds of sugar. Stir the pectin-sugar mixture with the purée at room temperature for 15 minutes to dissolve the pectin. Then add 53.7 pounds of sugar to the purée-pectin-sugar mixture and stir until all the sugar is dissolved. As soon as the sugar is dissolved, package the liquid mix in heavily-waxed paper cups and allow to stand at $70^{\circ}-80^{\circ} \mathrm{F}$ for approximately 24 hours. During this time, the gel structure forms and strengthens. Freeze the gel and store it at $\mathrm{O}^{\circ} \mathrm{F}$ or below. Defrost just before serving.

A similar process may be used for other fruits (Johnson and Boggs, 1947). In some cases, a small amount of fruit acid must be added to the juice or purée during preparation. The soluble solids content-approximately 57 per centis somewhat lower than that of ordinary jellies and jams, but this is desirable to avoid masking the fresh fruit flavor and to make preparation easier. The procedure suggested for raspberry gel is illustrated in the following flow sheet. 
DIAGRAM ILLUSTRATING PREPARATION OF RASPBERRY GELLED FRUIT

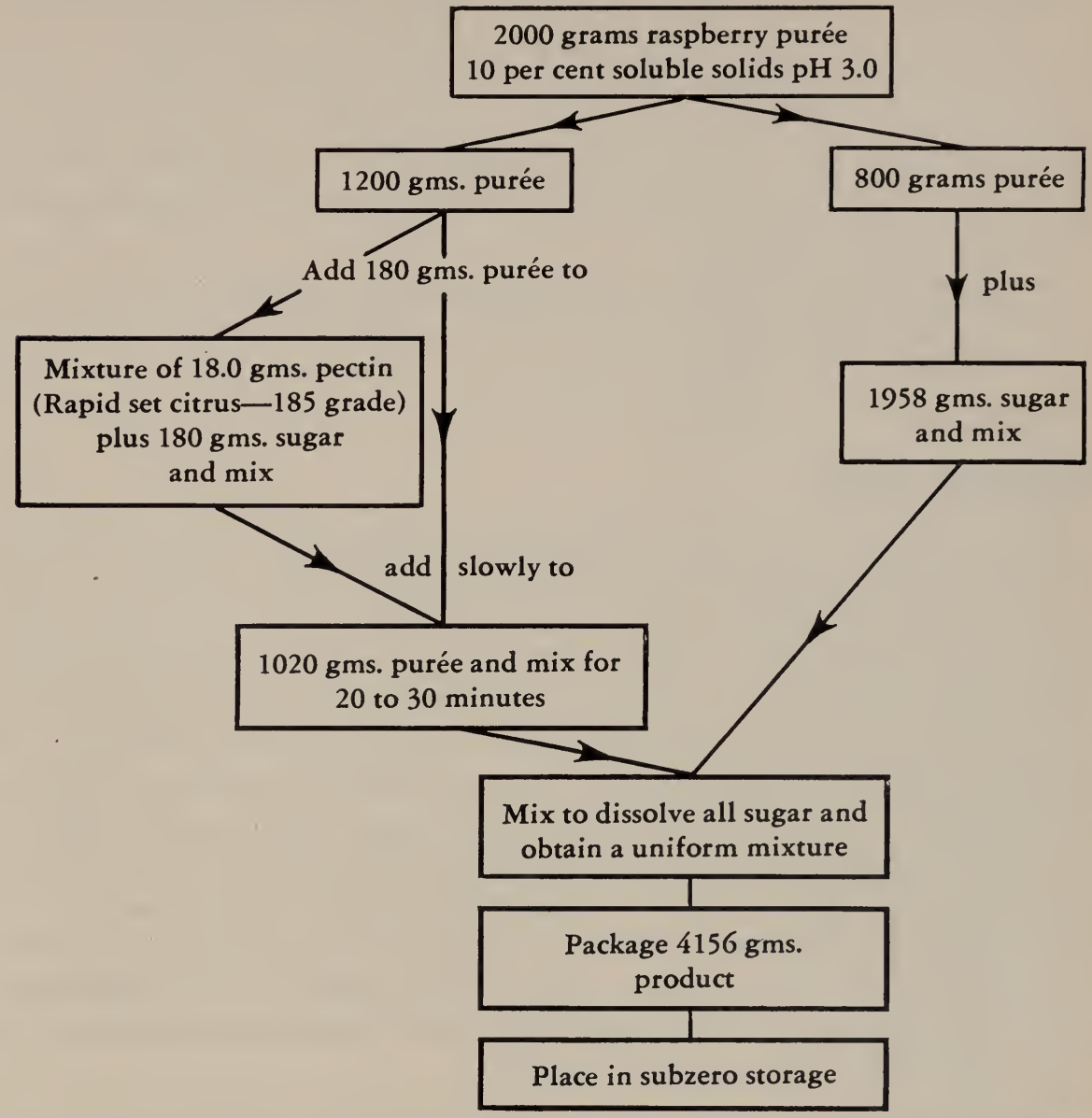

Source of data: Johnson, G., and M. M. Boggs. New fresh fruit spreads preserved by freezing. Food. Indus. 19(11):80-83, 201-202.

\section{FREEZING FRUIT JUICES}

The quantity and types of fruit juices frozen can be greatly increased when the current practices of selecting fruit for juice production, of extraction, and of freezing are improved.

Large quantities of orange juice, smaller quantities of grapefruit and lemon juices, and limited quantities of other fruit juices are frozen commercially. Failure to use freshly harvested, sound fruit of high quality, and to extract the juice under conditions that would avoid contamination (by metals, undesirable portions of the tissues surrounding the juice sacs, and air), and improper freezing and storage have resulted in the distribution of products of poor quality (Cruess, 1946; Cruess et al., 1946). The most serious defect 
occurring in many of the frozen juices is the marked separation and clotting of the pulp particles, which occurs upon thawing, particularly in citrus juices. In severe cases, the juice, after standing, consists of a clear liquid floating above a sediment of badly curdled and clotted particles. In addition, undesirable changes in flavor occur. These are due partly to oxidative changes, which produce stale or terpeney flavors, and partly to nonoxidative changes such as hydrolysis of the precursors of the bitter principles (naringin in grapefruit, and limonin in orange).

The principles and practices of fruit juice production have been discussed elsewhere (Joslyn and Marsh, 1937; Tressler, Joslyn, and Marsh, 1939), and only the general directions are given in this section, together with a brief description of current practices.

\section{ORANGE JUICE}

Difficulty has been experienced during the last four or five years in obtaining fruit of the proper quality in California. Only fully ripe, freshly harvested, Valencia oranges should be used. In investigations carried out during 19311932 , it was found that juice extracted within two weeks of storage at $70^{\circ} \mathrm{F}$, or four weeks of storage at $32^{\circ} \mathrm{F}$ was better in initial flavor and keeping quality than that extracted later (Joslyn and Marsh, 1934). The fruit should be at its optimum maturity as determined by color, flavor, and growing conditions. Juice extracted from immature fruit (Balling degree below 12 and acidity of over 1) will become better in flavor, and that from overmature fruit will lack orange flavor and be stale. In the Los Angeles and Riverside areas, the fruit is at its best for one month, while that from the coast counties, particularly Orange County, is better in general and is more acceptable over a longer portion of its growing season. Packing-house culls, if these are damaged or diseased, are not so suitable as orchard-run fruit.

The fruit should be stored, as received, in shallow, ventilated bins, and each lot should be analyzed. Fruits should be blended as taken from the bins - unless the scale of operation will warrant blending of the various lots of juices to obtain a product as standardized as possible in flavor and color. (Most consumers prefer a Balling-acid ratio of about 14 to 1.) The fruit from the bins is passed over a sorting belt to remove moldy or otherwise damaged fruit. The sound fruit is then washed and cleaned by passing it through a soaker bath (preferably one containing a detergent and sterilizing agent [quaternary ammonium salts or hypochlorite]). From the bath, the fruit passes under cold water sprays and over revolving brushes which scrub the surfaces as they are sprayed. The washed fruit is then thoroughly rinsed with clean water and dried by passage over revolving parallel brushes so that the surface is reasonably dry and free from excessive numbers of microörganisms (bacteria, yeast, and mold spores).

The clean, dry fruit is then fed by conveyor to a size grader if automatic citrus-juice extractors are used. The latter have displaced semiautomatic 
hand-fed reamers. At present, the Brown citrus-juice extractor is used although other types of automatic extractors are being developed. Among these is the Pipkin, or "F.M.C.," extractor that extracts juice and oil separately. In the extraction, particular care should be taken to prevent contact with iron or copper surfaces and to minimize contamination with rag juice (the albedo carpellary membranes and seeds contain enzymes, bitter glucosides, and other objectionable constituents). Exposure to air should also be prevented as should contamination with peel oil (present in the outer flavedo layer). The extracted juice should be strained in nonaerating, stainless-steel strainers (usually of the helical screw type) operating in an enclosed, perforated screen housing. The perforations should not be over o.o3o inch in diameter.

The strained juice should be deaerated by pumping, with a nonaerating pump, into vacuumized vessels where, by a combination of impact spraying and film (holding vacuumization at $29^{\prime \prime}$ vacuum or over), the occluded and dissolved oxygen and other gases are removed. The residual oxygen content of the deaerated juice should be as low as possible for best flavor retention. The deaerated juice can then be subjected to several pretreatments. If it is to be packed under vacuum in hermetically sealed cans, the juice is pumped out of the deaerator into a heat exchanger where it is precooled to $40^{\circ} \mathrm{F}$ or below. It is then filled cold into citrus enamel-lined cans, with a nonaerating bottom filler, and then closed by a vacuum-closing machine. If it is to be packed in a moisture-vapor-proof bag in a paperboard carton, the juice should be flash pasteurized to inactivate pectic enzymes and obtain maximum solution of pectic substances. This is done by passing the juice through a tubular heat exchanger in which it can be brought quickly to $200^{\circ} \mathrm{F}$, held at that temperature for 15 seconds, and then quickly cooled to below $70^{\circ} \mathrm{F}$ (or flash pasteurized at $190^{\circ} \mathrm{F}$ for $1 / 2$ minute) before being precooled to a filling temperature of not over $40^{\circ} \mathrm{F}$. Even in vacuum-closed containers, short-time, high-temperature pretreatment is desirable for retention of maximum flavor and appearance. Even after deaeration, the vacuum may be relieved with air without serious impairment of quality. It is preferable to use an inert gas such as water-pump nitrogen, or a mixture of 4 parts nitrogen to 1 of carbon dioxide. The nitrogen carbon dioxide-treated juice, particularly if slightly charged with nitrogen, is of fresher flavor and less subject to oxidative deterioration.

It is essential that the juice be frozen as quickly and as completely as possible to prevent separation and accumulation of unfrozen liquid of high solids content. Canned juice is frozen commercially by passing it through freezing tubes in which refrigerated alcohol at $-40^{\circ} \mathrm{F}$ (Finnegan, 1941) is passed in turbulent stream over the surfaces of the cylindrical cans as they rotate slowly. Or the cases may be put into an agitating freezer in which they are rolled over in a moving stream of refrigerated alcohol in a revolving inner drum. This drum rotates in a larger, concentric, hollow steel drum. By rapid rotation during freezing, citrus juices have been successfully frozen in glass (Finnegan, 1944). Air-blast freezing in cellophane bags or in other types of paraffined 
paperboard containers has not been satisfactory with precooled orange juice. If the orange juice is previously frozen into a thick slush in nonaerating continuous freezers (such as the continuous tubular ice cream freezer or the plate freezers), or in batch vertical-flooded ammonia freezers, and packed as a heavy orange ice into paperboard containers, it may be frozen in air-blast freezers.

The container should be filled so as to allow space for expansion-usually to 90 per cent of its capacity. The inner walls should be inert to the juice, and the container should be capable of being hermetically sealed. At present, only the citrus enamel-lined can and the glass jar fulfill these requirements.

The largest sized container that can be frozen sufficiently rapidly when filled with liquid juice is the gallon can. If orange juice is to be frozen in larger containers for subsequent processing, it should first be prefrozen to the consistency of a thick ice.

To retain flavor and avoid separation, the frozen juice should be thawed rapidly, preferably with agitation during defrosting, and kept below $50^{\circ} \mathrm{F}$. Small containers are best defrosted by storage over night in a household refrigerator at $45^{\circ} \mathrm{F}$.

\section{LEMON JUICE}

Eureka or Lisbon varieties of lemons are both satisfactory for freezing, but particular care should be taken to prevent contamination by peel oil and to reduce exposure to air during extraction and processing. Lemon juice is less stable than orange juice, but suffers less separation.

\section{GRAPEFRUIT JUICE}

The Marsh seedless grapefruit is the only available variety in California. Since it contains appreciable quantities of naringin, an intensely bitter glucoside, in the early stages, and is flat in flavor when overmature, particular care should be taken to use only the fully ripened fruit, and to avoid cold-stored fruit which yields juice of poor keeping quality. Otherwise, the process is similar to that for orange juice.

\section{OTHER FRUIT JUICES}

The juices of apples, berries, cherries, passion fruit, and pineapple can be well preserved by freezing and, from time to time, limited quantities of these juices have been introduced commercially with some degree of consumer acceptance. Apple juice has proved most acceptable, as evidenced by the continual freezing of small quantities in the Sebastopol region. Passion fruit juice has such a pronounced flavor, and is so acid, that it is usually not acceptable unless sweetened or blended with other juices. Quick-frozen canned Hawaiian pineapple juice, when first introduced commercially over ten years ago, proved popular, but was too high in price to sell readily. It is being produced again. Each type of juice presents special problems, but they all have in common the tendency for fruit pulp separation if slow-frozen or stored above $o^{\circ} \mathrm{F}$, and 
a tendency to oxidative deterioration. This is less likely to occur in frozen berry and cherry juices and most likely to be found in pineapple juice. Apple juice reacts somewhere between the two extremes.

Apple juice is best when it is extracted from blends of several varieties of apples which are balanced with regard to acid, tannin, and sugar content. When prepared from a single variety, Gravenstein was found to be best, Winesap second, Jonathan third, and Yellow Newtown last in recent tests carried out by Cruess and Glazewski (1945). Mountain apples from Watsonville or Santa Cruz districts were better than those grown in the coastal valleys, in our experience. The apple juice extracted by the conventional process (crushing the whole fruit in a hammer mill, and then pressing the juice out in cheeses in a rack-and-frame hydraulic filter press) is brown in color, oxidized in flavor, and may have an objectionable press-cloth taste. This juice, when strained to remove coarse particles and quickly frozen, is of acceptable flavor to some consumers, and its flavor may be further improved by deaeration before freezing. The cloudy juice has more apple flavor than the clear juice, but the latter is more attractive in appearance and, when clarified with pectic enzymes, does not have a tendency to separate or form jelly when frozen. The juice extracted by continuous mechanical disintegrators is apt to be too pulpy, although it shows better color and vitamin retention, particularly when deaerated and flash-pasteurized immediately following extraction. Improved disintegrators are in process of development and, when available, may produce juice of more satisfactory quality for freezing.

With berries, the main problem is that of color extraction. This can be obtained by heat extraction of the anthocyanin pigments before pressing, or by freezing. Juice extracted from berries such as Boysenberries, Youngberries, or Loganberries, frozen in barrels (even without sugar), and then thawed, is of excellent color and flavor.

With grapes, there are two problems: color extraction in red grapes, and detartration. The former is accomplished by heating after crushing and before pressing, and the latter by freezing in bulk, defrosting, and separating by decantation and filtration. Grape juice and other juices may be frozen in large containers for subsequent repacking and out-of-season distribution.

In the preparation of pineapple juice, particular care should be taken to use fruit tissues from ripe pineapples, and to avoid excessive exposure to air during processing. The juice is best when it is deaerated prior to freezing.

Tomato juice can be preserved by freezing, but its original flavor is so well retained that frozen tomato juice has little acceptance by consumers accustomed to the characteristic flavor of the canned juice. For freezing, select sound, uniformly ripe tomatoes of good color and flavor. These should be washed, chopped, and rapidly brought to $200^{\circ} \mathrm{F}$ in a flash-coil tank or continuous preheater. This inactivates pectin-esterase and ascorbic acid oxidase. The tomatoes are then cooled, deaerated, and rapidly frozen in hermetically sealed vacuum-closed containers. 
The fruit juices lend themselves to the production of blended products. A mixture of grapefruit and orange in equal proportions is quite popular at present. At one time, a blend of grapefruit, orange, and lemon, was marketed. Pineapple blends well.with orange juice, and apple juice may be used for blending with more acid juices.

Suitably enameled tin cans or glass containers are more satisfactory for freezing these juices than are paperboard containers, unless the paperboard is inert, moisture-vapor-proof, has a liquid-tight coating or liner, and can be hermetically sealed. As an added precaution against oxidation, containers for juice should be closed under vacuum.

\section{FREEZING SWEETENED JUICES, SIRUPS, NECTARS, PUNCHES, AND CONCENTRATES}

\section{These products are easy to prepare for serving, have excellent color and flavor, and are growing in popularity with consumers.}

The addition of sugar markedly improves the keeping quality of fruit juices, and the resulting sirups are attractive for use in beverages. The citrus juices, berry juices (Loganberry, Youngberry, and Boysenberry), and passion-fruit juice produce acceptable sirups for use as beverages because their high acidity and pronounced flavor carry through into the finished beverage. The sweetened products can be prepared readily by the addition of 7 pounds of sugar per gallon of juice. The mixture is stirred, with a minimum of aeration, until the sugar is dissolved. It is then deaerated, packaged, and frozen. For best flavor retention, the citrus juices should first be deareated and flash-pasteurized. The sweetened fruit juices will not only keep well in storage, but may also be readily served by preparing the beverage without previous defrosting of the juice. One volume of this frozen fruit juice sirup is added directly to three volumes of water, and stored. The water melts the ice in the sirup and is, in turn, cooled by it. The ease with which these sirups can be prepared for serving, and the excellent color and flavor of the resulting beverage led to its introduction by Joslyn $(1930 \mathrm{o})$. At that time, sales tests indicated that the consumer acceptance for these sirups was better than for the fruit juices.

The fruit juice sirups may be fortified with added color and flavor, but are even better when prepared as mixtures of individual sirups and frozen with small pieces of fruit. Pineapple and orange, grapefruit and orange, and grapefruit, orange, and lemon blends are very attractive; many others will suggest themselves.

In 1930, a punch sirup was prepared which met with some sales success, and now the market is even more receptive to such products.

The punch sirup was prepared by mixing equal parts of the following:

1. Orange sirup, prepared by adding 7 pounds of sugar to one gallon of extracted orange juice. 
2. Lemon sirup, prepared by adding 7 pounds of sugar to one gallon of burred lemon juice.

3. Red grape concentrate, prepared by concentrating unsulfured Alicante Bouschet, Carignane, or Petit Sirah grape juice to $\mathbf{7 0}^{\circ}$ Bal., in glass-lined vacuum pans. This concentrate, which is used as a color base should not have any objectionable flavors and should be a rich red, not brown, color. Grape concentrate, produced by concentrating grape juice by freezing storage, yields a product of excellent quality.

Cruess and Glazewski (1946) recently reported that pulpy fruit juices or nectars can be well preserved by freezing individually or as blends. Apricot nectar was prepared by steam-blanching halved, pitted, ripe Blenheim apricots for $31 / 2$ to 4 minutes to inactivate enzymes concerned in oxidative discoloration. The fruit was then puréed by sieving in a conical-screw, conical-screen continuous extractor, mixed with an equal volume of $15^{\circ} \mathrm{Bal}$. sugar solution, and frozen in hermetically sealed containers. This frozen nectar is very attractive in color, aroma, and flavor, and can be used not only as a beverage, but also as a base for fruit ice, or in milk shakes, whips, gelatin desserts, etc. The addition of fresh lemon juice ( 6 per cent by volume) markedly improved the flavor of the apricot nectar, as did also the addition of 0.2 per cent citric acid. Several blends of apricot with other fruit juices were prepared. Of these, the following were most acceptable: 2 parts apricot nectar and 1 part of apple juice, or 1 part apricot purée with 2 parts apple juice; 2 parts Valencia orange juice and 1 part apricot nectar; pineapple and apricot, after acidification.

Pulpy fruit juice beverages can be prepared from other fruits but, as a rule, require acidification to be palatable. A blend of puréed peach from highly flavored, yellow freestone peaches, such as the J. H. Hale, Elberta, or Rio Oso Gem, with an equal volume of $15^{\circ} \mathrm{Bal}$. sugar solution and 0.3 per cent added citric acid, is excellent in flavor. The ripe peaches were lye-peeled in 2 per cent boiling lye solution, washed thoroughly in cold water, dipped into a dilute citric acid solution (o.5 per cent), halved, pitted, steam-blanched 8 to 10 minutes, and puréed in a nonaerating, screw-expeller press. Bartlett pears, ripened to optimum canning conditions, peeled, halved, cored, steam-blanched until cooked through, and sieved as above, produced a satisfactory beverage when mixed with an equal volume of $15^{\circ}$ Bal. sugar solution and acidified with 0.3 per cent citric acid. Equal volumes of the pear purée and filtered Gravenstein apple juice were found superior in flavor to a blend of the pear nectar with the juice. Blends of apricot and pear, pear and peach, pear and Santa Rosa plum, and pear and pineapple nectars were found to be satisfactory. Plum beverages were made in various ways from red-colored, strongly flavored varieties, such as Duarte, Santa Rosa, and Satsuma. Usually, two volumes of $15^{\circ}$ sugar solution to one of purée were found best, as addition of only one volume of sugar solution made the resulting beverage too sour and somewhat too thick. 
The tropical fruits, such as mangoes, guavas, and papayas can be used individually in the preparation of frozen pulpy beverages or blended with acid fruit juices, such as citrus, pineapple, or passion fruit. Unheated, pulped mangoes were used in early beverage studies, and later observations were made on papaya beverages. Cruess and Glazewski (1946) prepared guava nectar by cutting guavas in half, steaming till soft, and blending with two to three volumes of $15^{\circ} \mathrm{Bal}$. sugar solution. The nectars from varieties of naturally high acidity required no additional acid; those of medium to low acidity required 0.2 to 0.4 grams of citric acid per $100 \mathrm{cc}$ for proper balance in flavor. Blends of guava purée (1 part) with Valencia orange juice (3 parts) or grapefruit juice (3 parts) were found to be attractive.

\section{FROZEN CITRUS JUICE CONCENTRATES}

\section{The two new processes discussed in this section are suitable for all fruit juices, and further improvement in the quality of such products is expected.}

While it has long been recognized that fruit juices concentrated by evaporation in vacuum have but short storage life at room temperature and above, and that heat injury and flavor loss are most severe in later stages of concentration, effective means to overcome these conditions were not available until recently. Fruit juices, particularly citrus juices, concentrated sufficiently to prevent microbial spoilage (about $70^{\circ} \mathrm{Bal}$. or $7: 1$ concentrates) were subject not only to flavor changes during concentration in the best of the available vacuum pans, but also underwent chemical deterioration (both oxidative and nonoxidative in nature) in color and flavor at room temperature. Storage of concentrates under refrigeration, at $30^{\circ} \mathrm{F}$ or below, in sealed containers, will prevent changes in color and flavor (Irish, 1925). To avoid changes in flavor that occur when juice in concentrated form is heated, Joslyn and Marsh (1937) recommended that the extent of concentration be reduced (to $4: 1$ from $7: 1$ ), and the resulting light concentrate be preserved by freezing storage.

One of the first successful attempts to obtain better flavor retention during concentration was made by Johnson (1938) and Meinzer (1940a and 1940b), who found that by separating the chromatophores from the steamed juice by centrifuging before concentration, flavor losses in concentration would be prevented. The clear citrus juice was concentrated to about $72^{\circ} \mathrm{F}$ and stored in large tin containers or barrels, at about $32^{\circ} \mathrm{F}$, and the chromatophores were preserved by quick-freezing and storage at $0^{\circ} \mathrm{F}$. Just prior to distribution, the frozen chromatophores were defrosted and blended with the concentrated serum. The pre-separation of chromatophores also facilitated concentration by freezing.

Recently two methods have been developed for the production of partly concentrated citrus juices of good flavor. In the first (Stahl and Jordan, 1946), concentrated citrus juices were prepared by a modification of the Gore process 
of concentration by freezing. Juice was extracted, by reaming, with minimum contamination by peel oil, strained on shaker screens to separate rag and remove most of the chromatophores, deaerated, precooled, and frozen, either in cans or in continuous freezers. The solidly frozen juice was put through an ice shaver or crusher, then fed into a high-speed basket centrifuge in which the partially concentrated juice was separated. The larger the ice crystals, the better was the separation. The freezing and centrifuging cycle was repeated until the desired degree of concentration was obtained; each freezing cycle was reported to triple the concentration. The concentrate was then deaerated and brought to the desired degree of concentration by blending with freshly extracted juice or overconcentrated juice, and incorporated with juice sacs saved from the second screen of the shaker-strainer. The concentrate was frozen at $44^{\circ} \mathrm{Bal} .(4: 1)$ at which it was ideal for preservation freezing at $0^{\circ} \mathrm{F}$. At $-5^{\circ}$ $\mathrm{F}$, the concentrate was solid, at $+5^{\circ} \mathrm{F}$, soft solid, and at $15^{\circ} \mathrm{F}$, liquid. Its vitamin $\mathrm{C}$ content was best retained at $-5^{\circ} \mathrm{F}$, but flavor retention was satisfactory in the range of $-5^{\circ}$ to $+15^{\circ}$. This concentrate was readily reconstituted from $0^{\circ} \mathrm{F}$ by addition of water, or could be readily dispensed at soda fountains as a beverage base at $15^{\circ} \mathrm{F}$. The loss in solids on freezing-centrifuging was 2 per cent in can freezing, and 5 to 10 per cent in flake ice machine or continuous freezing.

In the second method the extracted and strained citrus juice was concentrated by evaporation in vacuum to $4: 1$, and then mixed with an equal volume of freshly extracted juice. The latter improved the flavor of the concentrate and diluted it so that a 3:1 concentrate was obtained. This was preserved by freezing, and prepared for use by addition of 2 volumes of water to 1 of concentrate. Both concentrates are of good flavor and, in time, will displace the frozen single-strength juices.

These processes are applicable to all fruit juices. Further improvements in the quality of the juices concentrated in vacuum will be made by the use of recent improvements in fractional condensation of the esters and other volatile constituents evolved during concentration, and then returned to the concentrate. 


\section{LITERATURE CITED}

Adriano, F. T., A. Valenzuela, and L. G. Miranda.

1933. Studies on the quick freezing of Philippine fruits and utilization of the frozen pack products. Philippine Jour. Agr. 4(1): 41-59.

AikeEN, W. H.

1946. New plastic films-their packaging qualities. Modern Packaging 19 (9): 141-44, 172.

ANONYMOUS.

1934. Frozen foods. West. Canner and Packer 10(5):7-19.

1945a. Commercial preparation and freezing preservation of sliced apples. Western Regional Research Lab. U. S. Dept. Agr. Information Sheet A1C-57.

Also: Food Indus. 16:805-6, 862-63; and The Canner 100(19):20, 22, 24, 36. (1945).

$1945 b$. Experiments in freezing tropical fruits. Quick Frozen Foods 7(12):52-53.

1946a. Dimensions of frozen food packages. Quick Frozen Foods 8(10):84.

$1946 \mathrm{~b}$. Well organized line speeds applesauce freezing at Merced. West. Canner and Packer. 38(13):75-77.

1946c. New Arizona plant freezes dessert grapefruit segments. West. Canner and Packer 38(7):51-53.

1946d. Velva-fruit-a new frozen fruit dessert. Western Regional Research Laboratory, Albany, California. (U. S. Dept. Agr., Bur. Agr. Indus. Chem.) Mimeo. Cir. AlC-40. Rev. No. 1. (Also published in Ice Cream Field 43(3):43-44, 52-54, 56; Ice and Refrig. 106(5):263-66.)

1947. Frozen fruits and vegetables face major problems in '46. West. Canner and Packer. Statistical Review and Yearbook Number, April 25, 1947. 265-301.

BAKER, G. L., and W. M. GOoD.

1941. Pectic decomposition vs. sugar inversion in jelly. Food Indus. 13(8):45-46, 91.

Baulrnfeind, J. C., F. W. Jahns, E. G. Smith, and G. F. Siemers.

1946. Vitamin C stability in frozen fruit processed with crystalline 1-ascorbic acid. Fruit Prod. Jour. 25(11):324-30, 347.

Bauernfeind, J. C., and G. F. Siemers.

1946. Methods of freezing sliced apples with 1-ascorbic acid. Fruit Prod. Jour. 26:4-7, 27.

BERRY, J. A.

1933. Destruction and survival of microörganisms in frozen pack foods. Jour. Bact. 26: 459-70.

Berry, J. A., and C. A. Magoon.

1934. Growth of microörganisms at and below $0^{\circ} \mathrm{C}$. Phytopathology 24:780-96.

Boggs, M. M., and G. Johnson.

1947. How jelled cranberry sauce is preserved by freezing. Food Indus. 19(8):97-99, 204, 206.

Buck, R. E., G. L. BAKer, and H. H. Mottern.

1944. Pectinates improve frozen fruit. Food Indus. 16(2):100-2, 134.

Butterfield, H. M.

1947. Bush berry culture in California. California Agr. Exp. Sta. Cir. 80: 1-56.

Caldwell, J. S., J. M. Lutz, and H. H. Moon.

1932. How to get better quality in frozen peaches. Food Indus. 4(12): 402-5.

Chace, E. M. and H. D. Poore.

1931. Quick freezing citrus fruit juices and other fruit products. Indus. and Engin. Chem 23:1109-12.

1932. Quick frozen pineapple juice. Cold Storage 35(417):274.

Cllark, J. H.

1944. Tentative rating of fruit varieties for quick freezing. New Jersey Agr. Exp. Sta. Mimeo. Cir. (unnumbered). Dec. 14, 1944.

Ci.AYTON, W. G.

1932. Colloid aspects of food chemistry and technology viii, 571 pp. P. Blakiston's and Son, Inc. Philadelphia.

Committee on Food Research, Quartermaster Food and Container Institute for the Armed Forces.

1946. Food acceptance research. Quartermaster Corps Manual QMC 17-9. Office of the Quartermaster General, War Dept., Washington 25, D.C. 1-121. 
Cox, R. E.

1945. Something new in frozen foods. A frozen fruit product for household jelly and jam making. Fruit Prod. Jour. 24:169, 187.

Cruess, W. V.

1931. Utilization of surplus peaches and pears. Canning Age 12:457-61, 512-15.

1938. Commercial fig products. Fruit Prod. Jour. 17:337-39, 343, 368-69, 373, 379; and 18: $39-42$.

1946. Studies of frozen food samples bought in open market. Food Freezing $\mathbf{1}(\overline{7}): 243-45$, 268, 306-7, 322-23.

Cruess, W. V., and I. G. A. Glazewski.

1945. A note on frozen apple juice. Fruit Prod. Jour. 25:5, 27.

1946. Progress Report-frozen pack fruit nectars. Frosted Food Field 3(1):1, 12-13.

Cruess, W. V., I. G. A. Glazewski, and H. Sfagrave-Smith.

1946. Experiments on frozen citrus juices and syrups. Fruit Prod. Jour. 26:8-10, 25.

Cruess, W. V., and E. Harrold.

1927. Investigations on the utilization of cull avocados. Fruit Prod. Jour. 7(2):12-14.

Cruess, W. V., L. A. Hohl, M. A. Jimenez, S. Nichols-Roy, R. Torres, and M. Zorilia.

1945. Experiments with guavas. The Canner 100(21):22, 24, 38, 40. Also: Fruit Prod. Jour. 24:263-66, 283, 285.

Cruess, W. V., and M. A. Joslyn.

1929. The utilization of surplus persimmons. Calif. Cult. 72(10):285, 301.

Cruess, W. V., and G. L. Marsh.

1932. Fruit jelly juices. Fruit Prod. Jour. 11:325-27.

1933. Frozen pack ripe olives. Fruit Prod. Jour. 12:176.

1941. Utilization of California fruits. Calif. Agr. Exp. Sta. Cir. 349:1-53.

Cruess, W. V., E. L. Overholser, and S. A. Bjarnason.

1920. Storage of perishable fruits at freezing temperatures. Calif. Agr. Exp. Sta. Bul. 324: $1-43$.

Daughters, Milo R., and Dawrence S. Glenn.

1946. The role of water in freezing foods. Refrig. Engin. 52(2):137-40.

DENNY, F.

1942. Inactivation of the browning system in frozen-stored fruit tissues. Contrib. Boyce Thompson Inst. 12:309-20.

Diehl, H. C.

1945. Need of technical supervision in the selection, preparation and freezing of fruits and vegetables. Frozen Food Indus. 1(2):16-17, 43-46.

1946. What's to be done about quality control. Food Freezing 2(2):74, 76-77, 78.

DieHL; H. C., and J. A. BERRY.

1933. Some observations on the behavior of cured ripe Mission olives, preserved at low temperatures. Amer. Soc. Hort. Sci. Proc. 30:233-37.

DienL, H. C., and C. R. Havighorst.

1945. Frozen foods-the past-the potential. Food Indus. 17(3):83-100.

Diehl, H. C., J. R. Magness, C. R. Gross, and V. B. Bonney.

1930. The frozen pack method of preserving berries in the Pacific Northwest. U. S. Dept. Agr. Tech. Bul. 148:1-37.

Diehi, H. C., W. T. Pentzer, J. A. Berry, and C. E. Asbury.

1934. Suggestions for freezing foods are outlined. West. Canner and Packer 26(5):31-33: $(6): 39-41 ;(7): 33-35 ;(8): 43-44$.

DIEHL, H. C., and K. F. WARNER.

1945. Freezing to preserve home-grown foods. U. S. Dept. Agr. Cir. 709:1-62.

Dieill, H. C., E. H. Wiegand, and J. A. Berry.

1939. Preservation of fruits and vegetables by freezing in the Pacific Northwest. U. S. Dept. Agr. Mimeo. Cir. 53:1-58.

DORSETT, P. H.

1928. Culture and outdoor winter storage of persimmons in the vicinity of Peking, China. U. S. Dept. Agro Cir. 49:1-12.

Dove, W. F.

1946. Developing food acceptance research. Science 103:187-90. 
DuBois, C. W., and D. L. Colvin.

1945. Loss of added vitamin $\mathrm{C}$ in the storage of frozen peaches. Fruit Prod. Jour. 25:101-3.

Eckart, Thomas G., and W. V. Cruess.

1931. Freezing storage of pineapple products. Fruit Prod. Jour. 10:364-66.

Evers, Clifford F., and Barbara L. Hutchings.

1947. Quality control in the packaged frozen fruit industry. Fruit Prod. Jour. 26(5): 136-43.

Fabian, Joseph R.

1946. What size container. Frozen Food Indus. and Locker Plant Jour. 2(11):20-21, 38, 43.

Fellers, C. R., and M. J. MACK.

1929. Utilization of cold packed fruit in frozen dairy products. I. Strawberries and raspberries. Fruit Prod. Jour. 9:8-11, 46-47, 106-9.

Finnegan, W. J.

1935. Preserving citrus juices by freezing. Ice and Refrig. 88:51-54.

1938. Food freezing-engineered for quality and economy. Ice and Refrig. 95:355-61.

1941. Freezing juices in cans. Fruit Prod. Jour. 20:141-43, 146.

1944. Freezing citrus juice in glass. Food Packer 25(7):28-29, 56.

HaRvey, R. B.

1933. Conditions for successful storage of frozen fruits and vegetables. Fruit Prod. Jour. 12: 143, 151

Harvey, R. B., W. B. Combs, R. H. Landon, and Alice M. Child.

1936. Extending the use of melons by frozen storage. Fruit Prod. Jour. 15: 146-48.

Havighorst, C. R., and H. C. Diehl.

1947. Frozen food report No. 2. Transportation, warehousing and marketing. Food Indus. 19(1):3-28, (2):73-86.

HEID, J. L.

1941. The freezing preservation of citrus fruits and juices. Fruit Prod. Jour. 20:375-77, 384, 389.

Hills, C. H., C. S. Nevin, and M. E. Heller.

1947. Firming apple slices. Fruit Prod. Jour. 26:356-62.

HOEY, J. J.

1941. Fast frozen olives. Pacific Rural Press and Calif. Farmer 142:130-31.

HoHL, LEONORA A.

1943. More experiments with frozen pack ripe olives. The Canner 97(11): 10 .

1945. Untreated natural pineapple freezes best. Quick Frozen Foods 8(4):93, 95.

1946a. Preparation and pretreatment of fruits for freezing. Food Freezing 1:287-90, 312-14.

1946b. The freezing preservation of California fruits. Figs. Food Packer 27(11):66, 68, 70.

Hohl, Leonora A., and Joyce SWAnburg.

1946. Freezing of California fruits. Apricots. Food Packer 27(4):37-38, 68, 70, 72

Hustrulid, A., and J. D. Winter.

1943. The effect of fluctuating storage temperatures on frozen fruits and vegetables. Agr. Engin. 24:416.

IRELAND, R.

1931. Cold packed barreled fruit in 1930. Food Indus. 3:214.

1941. Freezing and shipping of cold pack strawberries sugared in barrels. Ice and Refrig. 100:239-40.

IRISH, JOHN, $\mathbf{H}$.

1925. Fruit juice concentrates. Calif. Agr. Exp. Sta. Bul. 392:1-20.

JoHnson, DAvid L.

1938. Concentrates from vegetables, fruits, or berries. U. S. Patent No. 2,115,815. May 3, 1938. (Through Chem. Abstr. 32:4686.)

Johnson, G., and M. M. Boggs.

1947. New fresh fruit spreads preserved by freezing. Food Indus. 19(11):80-83, 201-02.

JoHNSON, H. D.

1943 (Sept.). Precooling and refrigeration tests on frozen fruits and vegetables from Hillsboro, Oregon, and Kent, Wash., to Jersey City, N.J., July 11 to July 26, 1943, inclusive. War Food Administration. U. S. Food Distribution Administration. Transportation and Warehousing Branch. Unnumbered mimeo. 6 pp. 7 tables. Sept., 1943. 
JosLYN, M. A.

1929a. Freezing fruit in small containers. Fruit Prod. Jour. 9:41-43, 57.

1929b. Freezing storage of citrus products. Fruit Prod. Jour. 9(1):13-15.

$1930 a$. The possibilities of preserving California strawberries by the frozen pack method. California Cult. 75(8):173, 185.

$1930 b$. Why freeze fruit in sirup? Food Indus. 2:350-52.

1930c. Preservation of fruits and vegetables by freezing storage. Calif. Agr. Exp. Sta. Cir. 320:1-35.

1934. The present status of methods of improving the quality of frozen fruit and fruit products. Fruit Prod. Jour. 13:142-45, 153, 155.

1938. Certain technological aspects of preservation freezing. Quick Frozen Foods 1(2):1013,53 .

1941. Color retention in fruit products. Indus. and Engin. Chem. Indus. Ed. 33:308-14.

1942. Frozen apricots. Preservation freezing of apricots for subsequent processing by bakers, baby food firms and others. West. Canner and Packer 34(8):45-47, 49-50.

1946a. Industry needs field servicemen and technologists. Quick Frozen Foods 8(8):71-72, 126.

1946b. Enzyme activity-index of quality in frozen vegetables. Food Indus. 18:1204-10.

Joslyn, M. A., and W. V. Cruess.

1929. Freezing storage of fruits and vegetables for retail distribution in paraffined paper containers. Fruit Prod. Jour. 8(7):9-12; (8) 9-12.

JosLYN, M. A., and G. L. MARSH.

1930. Heat transfer in foods during freezing and subsequent thawing. I. Temperature changes in sugar solutions, sweetened fruit juices, and other liquids. Indus. and Engin. Chem. 22(11):1192-97.

1932a. Observations on the effect of rate of freezing on texture of certain fruits and vegetables. Fruit Prod. Jour. 11:327-31.

1932b. Heat transfer in foods. Temperature changes in fruit, vegetable, meat and fish products during freezing and thawing. Refrig. Engin. 24:81-88.

1932c. Temperature changes in small food containers in fiberboard cases. Refrig. Engin. 24:214-24, 234, 236, 239.

1933. Changes occurring during freezing, storage, and thawing of fruits and vegetables. Calif. Agr. Exp. Sta. Bul. 551:1-40.

1934. The keeping quality of frozen orange juice. Indus. and Engin. Chem 26:295-99.

1937. Utilization of fruit in commercial production of fruit juices. Calif. Agr. Exp. Sta. Cir. 344:1-63.

Joslyn, M. A., and E. M. Mrak.

1930. Prepared fresh apples for bakers' use. Fruit Prod. Jour. 9:309-11.

1933. Investigations on the use of sulfurous acid and sulfites in the preparation of fresh and frozen fruit for bakers' use. Fruit Prod. Jour. 12:135-40.

JosLyn, M. A., and M. SHERrill.

1933. Inversion of sucrose by invertase at low temperatures. Indus. and Engin. Chem. Indus. Ed. 25:416-17.

KERTESZ, Z. I.

1933. The oxidase system of a non-browning yellow peach. New York Agr. Exp. Sta. Tech. Bul. 219:1-14.

1942. Invertase activity in identical mixtures in the liquid and frozen state. Amer. Chem. Soc. Jour. 64:2577-78.

LEE, F. A.

1947. The preservation of baked apples by freezing. Fruit Prod. Jour. 26:366-67.

LOEFFLER, H. J.

1944. Velva-fruit-a new frozen fruit dessert. Ice and Refrig. 106:(5):263-66.

Lutz, J. M., J. S. Caldwell, and H. H. Moon.

1932. Frozen pack: Studies on fruits frozen in small containers. Ice and Refrig. 83:111-13.

Luther, H. G., and G. O. Cragwall.

1946. Ascorbic-citric acids prevent browning of cut fruit. Food Indus. 18:690-92, 794, $796,798,800$. 
McCoy, D. C., S. V. Cook, and G. A. Hayner.

1946. An evaluation of frozen food wrapping materials. Food Freezing 2(2):69-72, 93, 101.

Meek, George W., and Van Rensselaer Greene, Jr.

1947. Food freezers evaluated. Food Indus. 19(9):1213-17.

Meinzer, Gotthold, $\mathbf{H}$.

1940. Concentrating citrus fruit juices. U. S. Patent No. 2, 187.572, Jan. 16, 1940. (Through Chem. Abstr. 34:3394) and U. S. Patent No. 2,190,991, Fel). 20, 1940. (Through Chem. Abstr. 34:4177.)

Mondain-Monval, P.

1925. Sur la solubilité du saccharose. Compt. rend. 181:37-44. (See also International Critical Tables, McGraw-Hill Book Co., Inc. 1927. Vol. II, p. 345.)

Munilita, A., and F. Vogrelsinger.

1937. Accion protectora de los azucares sobre la oxidacion de la vitamina C. Arch. de la Soc. de Biologia. Montevideo. 7:281-88.

Paul, Pauline.

1946. Fruit purées. Mich. Agr. Exp. Sta. Cir. Bul. 200:1-19.

Pentzer, W. T., and C. E. Asbury.

1931. Observations on the freezing storage of figs. Fruit Prod. Jour. 10:218.

Pentzer, W. T., C. E. Asbury, and H. C. Diehl.

1932. Progress report on figs and grapes. (Read at Univ. of Calif. Frozen Food Conf., May 27.)

Perry, R. L.

1938. Air velocity, diameter of product and freezing rates. Refrig. Engin. 36(1):16-19.

Pickett, T. A.

1932. Comparative study of juices from frozen fruits. Indus. and Engin. Chem. 24:35.3-54.

Pl.agge, H. H., and B. Lowe.

1942. Frozen fruit and vegetable research indicates desirable new products for lockers. Ice and Refrig. 102(6):357-61.

Ponting, J. D.

1944a. The enzymic oxidation of ascorbic acid. Ph.D. thesis in Agr. Chem., U. of Cali. fornia, 1-65.

1944b. Catechol test for frozen fruits. Quick Frozen Foods 7(5):31, 46.

PoORE, H. D.

1935. Passion fruit products. Fruit Prod. Jour. 14:261-68.

Powers, J. J., and W. B. Esselen, Jr.

1946. The use of Ca salts in freezing McIntosh apples. Fruit Prod. Jour. 25:200.

RABAK, W.

1938. Freezing preservation of hot house or forced rhubarb. West. Canner and l'acker 30(3):25-27, 29.

Rabak, William, and H. C. Diehl.

1944. "Fondant-like" formation on fruits caused by crystallization of sucrose. West. Canner and Packer 36(4):55.

RAвAK, W., and J. B. Stork.

1946. What is the protective value of the double overwrap. Food Indus. I8(11):82-83, 220.

REED, H. M.

1946. Investigations on the freezing storage of figs. Quick Frozen Foods 8(7):84-85.

Richardson, Jessie E., and Helen H. Mayfield.

1944. Influence of sugars, fruit acids and pectin on the oxidation of ascorbic acid. Mont. SAMISCH, R. Agr. Exp. Sta. Tech. Bul. 423:1-20.

1935. The measurement of phenolase activity. Jour. Biol. Chem. II0:643-54.

Sater, Lenore E., Mary E. Kirkpatrick, Kay E. Stein, Hazel B. Murray, and Dorothy G. SKINNER.

1947. The effect of various pretreatments of frozen peaches on quality. Food Freezing 2(3):128-31, 144, 162.

Silamrai, E. F.

1941. The mechanism of stabilization of ascorbic acid by cane sugar. Voprosy Pitanya 10 (3-4):42-48. (Through Chem. Abs. 40:371, 1946.) 
SHORT, B. E.

1944. The specific heat of foodstuffs. I, An experimental determination. Univ. Texas Publication No. 4432:1-26.

ShrAdEr, J. H., and A. H. Johnson.

1934. Freezing orange juice. Indus. and Engin. Chem. 26:869-74.

Sorbtir, D. G.

1932. A new quick frozen fruit product. Fruit Prod. Jour. 11:229-30, 249, 255.

1942. Frozen, sliced, crushed, and puréed fruits. Canner 94(7):16-17, 36; (8):18, 20, $22,32$.

1943. Freezing storage prolongs peach packing season. Quick Frozen Foods 5(9):16, 28.

STAHL, A. L.

1946. Tests prove best methods of citrus heart freezing. Quick Frozen Foods 8(6):59; (7):91.

STAHL, A. L., and M. B. Jordan.

1946. The concentration of citrus fruit juices. Food Freezing 1:375-77.

Thomas, H. E., and E. V. Goldsmith.

1945. The Shasta, Sierra, Lassen, Tahoe, and Donner strawberries. Calif. Agr. Exp. Sta. Bul. 690:1-20.

Thompson, Helen H., S. R. Cecil, and J. G. Woodroof.

1946. Stored frozen stock produces better preserves. Food Ind. 18(9):1311-43, 1510.

Tressler, D. K.

1935. Methods of freezing fruits and fruit juices. Ice and Refrig. 88(4):275-77. (Also N. Y. State Hort. Soc. Proc. 80:149-56.)

1942. Using fruit purées to get new flavors in ribbon ice cream. Food Indus. 14:49-51, 99.

Tressler, D. K., and C. W. DuBois.

1940. Freezing and storage of foods in freezing cabinets and locker plants. N. Y. Agr. Exp. Sta. Bul. 690:1-60.

Tressler, D. K., and C. F. Evers.

1947. The freezing preservation of foods. 2d Edition. xviii +932 pp. Ari Publishing Co. Inc., New York, N.Y.

Tressler, Donald K., Maynard A. Joslyn, and Gforge L. Marsh.

1939. Fruit and vegetable juices. xii + 544 pp. Avi Publishing Co., Inc., New York, N.Y.

WEBBER, H. J.

1942. Extending guava production to California. Amer. Soc. Hort. Sci. Proc. 41:228-33.

Weiser, R. S., and C. M. Osternd.

1945. Studies on the death of bacteria at low temperatures. Jour. Bact. 50:413-39.

Welis, Earl P.

1946. Food freezing by immersion in alcohol. Food Freezing 2(2):83, 100.

WIEGAND, E. H.

1931. The "frozen pack" method of preserving berries. Ore. Agr. Exp. Sta. Bul. 278:1-12.

1941. The effect of delayed freezing on fruits. Proc. Third Annual Meeting. Northern California Section. Inst. Food Technologists. Mimeo. 1-59 (see particularly pp. 33-40).

Winter, J. D., and A. Hustrulid.

1944. Freezing foods for home use. Minn. Agr. Exp. Sta. Ext. Bul. 244:1-24.

Woodroof, J. G.

1930a. Fruit freezing conference. Ga. Agr. Exp. Sta. Cir. 89:1-15.

$1930 b$. Preserving fruits by freezing. I. Peaches. Ga. Agr. Exp. Sta. Bul. 163: 1-46.

1931a. Preservation freezing. Some effects on quality of fruits and vegetables. Ga. Agr. Exp. Sta. Bul. 168:1-23.

1931b. Fruit freezing tests. Ga. Agr. Exp. Sta. Annual Report 36-37.

1932. Preservation of fruits and vegetables by freezing as an industry. Fruit Prod. Jour 11:138-43.

1939. Freezing by immersion methods and media. Refrig. Engin. 37:381-87.

1915. Freezing muscadine grapes. Food Packer 26(12):18.

Woodroof, J. G., and J. E. BAILEY.

1930. Preserving fruits by freezing. II. Figs. Ga. Agr. Exp. Sta. Bul. 164:1-11.

Woodroof, J. G., and Ethyl Shelor.

1947. Effect of freezing storage on strawberries, blackberries, raspberries, and peaches.

Food Freezing 2(4):206-9, 223.

WOOLRICH, W. R.

1933. The latent heat of foodstuffs. Univ. Tenn. Engin. Exp. Sta. Bul. 11:1-18. 


\section{GENERAL REFERENCE SOURCES}

\section{BIBLIOGRAPHIES}

U. S. Department of Agriculture.

Bureau of Agr. and Industrial Chemistry. 800 Buchanan St., Albany, Calif. Selected bibliography on freezing preservation of fruits and vegetables, 1920-1944. Mimeographed Circular AlC-46 Rev. No. 1, April, 1945. 16 pp. Western Regional Research Laboratory. ERdman, Frederick Seward.

A bibliography of literature on frozen food. Refrigerating Engineering. 48(5):374-80, 414, 416, 418, 420, 422, 426, 428, 430. Nov., 1944.

MCINTOSH, JENNIE.

Freezing projects in progress 1946 in United States and Canadian laboratories. Irozen Food Foundation, Syracuse, N.Y. Mimeo. 1-23, 1946.

Weil, B. H., and Frances Sterne.

Literature search on the preservation of food by freezing. State Engineering Experiment Station, Georgia School of Technology. Special Report No. 23, vii + 409 pp. June, 1946.

\section{PRESERVATION FREEZING}

American Society of Refrigerating Engineers.

The refrigerating data book, fourth edition, vol. II. Refrigeration applications. 413 pp. +148 pp. advertising. The American Society of Refrigerating Engineers, 37 West 39th St., New York. 1940. (See particularly part I. Freezing Processes, 3-59.)

Carlton, Harry.

The frozen food industry. 186 pp. University of Tennessee Press, Knoxville, Tennessee. 1941. Cruess, W. V.

Commercial fruit and vegetable products. Second edition, $\mathrm{x}+798 \mathrm{pp}$. McGraw-Hill Book

Company, Inc., New York. 1938.' (See particularly Chap. XXXI, pp. 688-715.)

FinNEGAN, W. J.

Finnegan fast freezers. Reprints of food freezing and engineering findings. W. J. Finnegan Co., 7402 Santa Monica Blvd., Los Angeles 46, Calif. 1946. (Bound set of reprints.)

JACOBS, MORRIS B., Editor.

The chemistry and technology of food and food products, vol. I, xv +952 pp.; vol. II, xx 890 pp. Interscience Publishers, Inc., New York. 1944. (See vol. II, chap. X, Donald K.

Tressler. Food preservation by temperature control, 312-35.)

VON LOESECKE, HARRY W.

Outlines of food technology. 505 pp. Reinhold Publishing Corp., 330 West 42d St., New York. 1942. (See particularly chap. 15, pp. 459-83.)

Prescott, Samuel C., and Bernard E. Proctor.

Food technology. ix +630 pp., McGraw-Hill Book Company, Inc., New York. 1937. (See particularly chap. XV, pp. 443-87.)

Tressler, Donald K., and Clifford F. Evers.

The freezing preservation of foods. Second edition. xviii + 932 pp. Avi Publishing Company, Inc., 31 Union Square, New York. 1947.

ZAROTSCHENZEFF, M. T.

Between two oceans. Rapid Chilling and Freezing Systems for Fish and Meat. 157 pp. Cold Storage and Produce Review, Empire House. St. Martin's-le-Grand, London ECl, England. 1930.

\section{REFRIGERATION}

American Society of Refrigerating Engineers.

The refrigerating data book. Refrigeration application volume. Second edition. 683 pp.+ 190 pp. adv. A.S.R.E. 40 West 40th St., New York. 1946.

MACINTIRE, HORACE J.

The principles of mechanical refrigeration. Second edition. ix +317 pp. McGraw-Hill Book Co., Inc., New York. 1928.

Refrigerating engineering. v +415 pp. J. Wiley \& Sons, Inc., New York. 1937. 
Motz, William $\mathbf{H}$.

Principles of refrigeration. Third edition. $x i+1019$ pp. Nickerson and Collins Co., Chicago, Ill. 1932.

RABER, B. F. and F. W. Hutchison.

Refrigeration and air conditioning engineering. vii +291 pp. J. Wiley \& Sons, Inc., New York. 1945.

SPARKS, NORMAN R.

Theory of mechanical refrigeration. ix +225 pp. McGraw-Hill Book Co., Inc., New York. 1938.

WOOLRICH, W. R.

Handbook of refrigerating engineering. 331 pp. D. Van Nostrand Co., Inc., New York. 1929.

\section{FRUIT PRODUCTION}

Auchter, Eugene C., and H. B. Knapp.

Orchard and small fruit culture. Third edition. xxi 627 pp. New York, J. Wiley \& Sons, Inc. 1937.

Chandler, William $\mathrm{H}$.

Fruit growing. v 777 pp. Houghton Mifflin Co., New York. 1925.

North American orchards. xvi +516 pp. Lea and Febiger, Philadelphia. 1942.

Deciduous orchards. 438 pp. Lea and Febiger, Philadelphia. 1942.

Gardner, Victor R., Frederick C. Bradford, and H. D. Hooker.

The fundamentals of fruit production. xvi +686 pp. McGraw-Hill Book Co., Inc., New York. 1922.

Gourley, J. H., and F. S. Howlett.

Modern fruit production. vii +579 pp. Macmillan Co., New York, 1941.

SHOEMAKER, JAMES S.

Small fruit culture. ix +434 pp. The Blakiston Co., Philadelphia. 1934.

United States Department of Agriculture.

Yearbook of Agriculture, 1933, pp. 319-68. Fruits and vegetables. (Consists of a number of short articles by various authors.)

\section{CALIFORNIA EXPERIMENT STATION PUBLICATIONS ON FRUIT PRODUCTION}

Allen, F. W.

1929. Plum growing in California. Calif. Agr. Ext. Cir. 34: 1-65. (Out of print.)

1932. The harvesting and handling of fall and winter pears. Calif. Agr. Exp. Sta. Bul. 533: $1-46$.

1937. Apple growing in California. Calif. Agr. Exp. Sta. Bul. 425: 1-95.

Allen, F. W., J. R. Magness, and M. H. Haller.

1927. The relation of maturity of California plums to shipping and dessert quality. Calif. Agr. Exp. Sta. Bul. 428:1-41.

ButTERFIELD, H. M.

1947. Bush berry culture in California. Calif. Agr. Exp. Sta. Cir. 80:1-56.

CARYL, R. E. (revision by J. C. Johnston).

1946. Citrus culture in California. Calif. Agr. Ext. Cir. 114:1-46.

Condit, IRA J.

1941. Fig culture in California. Calif. Agr. Ext. Cir. 77:1-67.

Davis, Glen N., and Thomas W. Whitaker.

1942. Growing and handling cantaloupes and other melons. Calif. Agr. Exp. Sta. Cir. 352: $1-40$.

Davis, Luther D.

1941. Pear growing in California. Calif. Agr. Ext. Cir. 122:1-87.

HENDRICKSON, A. H.

1937. Apricot growing in California. Calif. Agr. Ext. Cir. 51:1-60. (Out of print.)

1940. Prune culture in California. Calif. Agr. Ext. Cir. 41:1-39.

ЈАСов, H. E.

1947. Grape growing in California. Calif. Agr. Ext. Cir. 116:1-85. 
PhilP, Guy L.

1947. Cherry culture in California. Calif. Agr. Ext. Cir. 46:1-51.

Philp, Guy L., and Luther D. Davis.

1946. Peach and nectarine growing in California. Calif. Agr. Ext. Cir. 98: 1-64.

Thomas, Harold E.

1939. The production of strawberries in California. Calif. Agr. Ext. Cir. 113:1-92. (Out of print.)

Food Freezing.

\section{JOURNALS}

Published monthly by John T. Ogden, 95 Liberty St., New York 6, N.Y. \$4.00 per year.

Food Industries.

Published monthly by McGraw-Hill Publishing Co., Inc., 330 West 42d St., New York, N.Y. Articles of general interest stressing unit operations and technology; frequently articles on frozen food technology. $\$ 3.00$ per year.

Food PACKer.

Published monthly by Vance Publishing Corp., 139 North Clark St., Chicago 2, Illinois. National manufacturing journal for food packers. Articles of general and occasionally of particular interest. $\$ 2.00$ per year.

Frosted Food Field.

Published monthly by Frosted Food Field, 19 West 44th St., New York 18, N.Y. The newspaper of the industry. $\$ 3.00$ per year.

Frozen Food EquipMent.

The purchase guide for the frozen food industry. Published by Service Publications, 12 t West Fourth St., Los Angeles 13, California.

Frozen Food Industry and Locker Plant Journal.

Published monthly by Food Publications, Inc., 304 East 45 th St., New York 17, N.Y. $\$ 3.00$ per year.

The Fruit Products Journal and American Food Manufacturer.

Published monthly by Avi Publishing Co., Inc., 31 Union Square, New York. Articles of general interest and also on technology of frozen fruit and vegetable products. $\$ 2.50$ per year.

ICE AND REFRIGERATION.

Nickerson and Collins Co., Chicago, Ill. Section on frozen food.

LOCKER OPERATOR.

Published monthly by Locker Publications Co., 1421 Walnut St., Des Moines, Iowa. Official organ of National Frozen Food Locker Association and Frozen Food Locker Manufacturers and Suppliers Association. $\$ 1.50$ per year.

Quick Frozen Foods and the Locker Plant.

Published monthly by E. W. Williams Publications, Inc., 82 Wall St., New York 5, N.Y. The national publication of the quick freezing industry. $\$ 3.50$ per year.

REFRigerating ENGINEERING.

Official publication of The American Society of Refrigerating Engineers. 40 West 40th St., New York 18, N.Y. Deals with economic application of refrigeration and air conditioning; articles of general interest and frequently of direct interest to frozen food packers.

ReFrigeration Abstracts.

Published quarterly by American Society of Refrigerating Engineers, 40 West 40 th st, New York 18, N.Y. $\$ 7.00$ per year.

Western Canner and Packer.

Published monthly with two issues in April (one an annual statistical issue) by Western Trade Journals, Inc., 121 Second St., San Francisco 5, California. Has special frozen foods section. $\$ 3.00$ per year.

IWESTERn Frozen Food.

Published by Sidney Beede, 303 Maritime Bldg., Seattle, Washington. $\$ 2.00$ per year. 



\section{AGRICULTURE}

.. Contains brief, easy-to-read progress reports of agricultural research, and is published monthly by the University of California College of Agriculture, Agricultural Experiment Station.

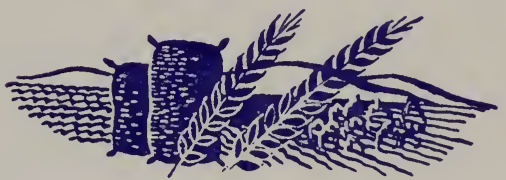

FIELD CROPS

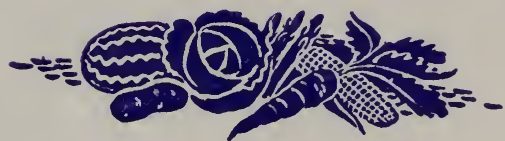

TRUCK CROPS

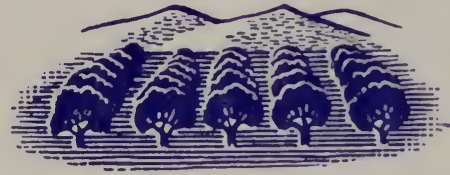

ORCHARDS

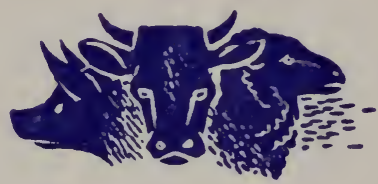

LIVESTOCK

CALIFORNIA AGRICULTURE offers information useful to the farmer and food processor, fogether with announcements of other publications dealing with farm subjects as they are issued by the College of Agriculture.

Upon your request, your name will be added to the mailing list to receive CALIFORNIA AGRICULTURE without cost. Send your name and address to:

California Agriculfure, Publications Office, College of Agriculfure, University of California, Berkeley 4, California 